\title{
From home towards the nursing home in dementia: Informal caregivers' perspectives on why admission happens and what they need
}

Citation for published version (APA):

Afram, B. (2015). From home towards the nursing home in dementia : Informal caregivers' perspectives on why admission happens and what they need. [Doctoral Thesis, Maastricht University]. Maastricht University. https://doi.org/10.26481/dis.20150501ba

Document status and date:

Published: 01/01/2015

DOI:

10.26481/dis.20150501ba

Document Version:

Publisher's PDF, also known as Version of record

\section{Please check the document version of this publication:}

- A submitted manuscript is the version of the article upon submission and before peer-review. There can be important differences between the submitted version and the official published version of record. People interested in the research are advised to contact the author for the final version of the publication, or visit the DOI to the publisher's website.

- The final author version and the galley proof are versions of the publication after peer review.

- The final published version features the final layout of the paper including the volume, issue and page numbers.

Link to publication

\footnotetext{
General rights rights.

- You may freely distribute the URL identifying the publication in the public portal. please follow below link for the End User Agreement:

www.umlib.nl/taverne-license

Take down policy

If you believe that this document breaches copyright please contact us at:

repository@maastrichtuniversity.nl

providing details and we will investigate your claim.
}

Copyright and moral rights for the publications made accessible in the public portal are retained by the authors and/or other copyright owners and it is a condition of accessing publications that users recognise and abide by the legal requirements associated with these

- Users may download and print one copy of any publication from the public portal for the purpose of private study or research.

- You may not further distribute the material or use it for any profit-making activity or commercial gain

If the publication is distributed under the terms of Article $25 \mathrm{fa}$ of the Dutch Copyright Act, indicated by the "Taverne" license above, 


\section{FROM HOME TOWARDS THE NURSING HOME IN DEMENTIA}

Informal caregivers' perspectives on why admission happens and what they need

Basema Afram 


\section{FROM HOME TOWARDS THE NURSING HOME IN DEMENTIA}

Informal caregivers' perspectives on

why admission happens and what they need

The research presented in this dissertation was conducted at the School for Public Health and Primary Care (CAPHRI), department of Health Services Research, Maastricht University. CAPHRI is part of the Netherlands School of Primary Care Research (CaRe), which has been acknowledged by the Royal Netherlands Academy of Science (KNAW)

The research described in this dissertation related to the RightTimePlaceCare project were funded under a grant from the European Commission within the seventh framework programme (project 242153). Printing of this dissertation was financially supported by CAPHRI-research program 'Innovations in the care of the elderly', ABN-AMRO and Alzheimer Nederland.

ISBN

978-94-6259-6269

Cover

M. Bosveld

Lay-out

Promotie In Zicht, Arnhem

Print

Ipskamp Drukkers, Enschede

Copyright (C) Basema Afram, Arnhem 2015

All rights reserved. No part of this dissertation may be reproduced or transmitted in any form or by any means, electronic or mechanical, including pholocopying, recording or any information storage or retrieva system without permission from the author, or when appropriate, from the publisher of the publications

Basema Afram

Ter verkrijging van de graad van doctor aan de Universiteit Maastricht op gezag van de Rector Magnificus, Prof. Dr. L.L.G. Soete, volgens besluit van het College van Decanen,

in het openbaar te verdedigen,

op vrijdag 1 mei 2015 om 14:00 uur 
Promotor

Prof. dr. J.P.H. Hamers

\section{Copromotoren}

Dr. H. Verbeek

Dr. M.H.C. Bleijlevens

\section{Beoordelingscommissie}

Prof. dr. J.M.G.A. Schols (voorzitter)

Prof. dr. A.L. Francke (VUmc)

Dr. M.E. de Vug

Prof. dr. T. van der Weijden

Prof.dr. G.A.M. Widdershoven (VUmc)

\section{Contents}

Chapter 1 General Introduction

Chapter 2 Reasons for Institutionalisation of People with Dementia: Informal Caregiver Reports from Eight European Countries

Chapter 3 Older Persons with Dementia at Risk for Institutionalisation in Eight European Countries: A Cross-Sectional Study on the Perceptions of Informal Caregivers and Healthcare Professionals

Chapter 4 Predicting Institutional Long-Term Care Admission in Dementia: A Mixed-Methods Study of Informal Caregivers' Reports

Chapter 5 Needs of Informal Caregivers During Transition from Home Towards Institutional Care in Dementia: A Systematic Review of Qualitative Studies

Chapter 6 Informal Caregivers' Needs During Care Transition to Institutional Long-Term Care in Dementia: A Focus Group Study

Chapter 7 General Discussion

Summary

Nederlandse samenvatting

Valorisation addendum

Dankwoord

About the author

\section{Publications}




\section{1}

General Introduction

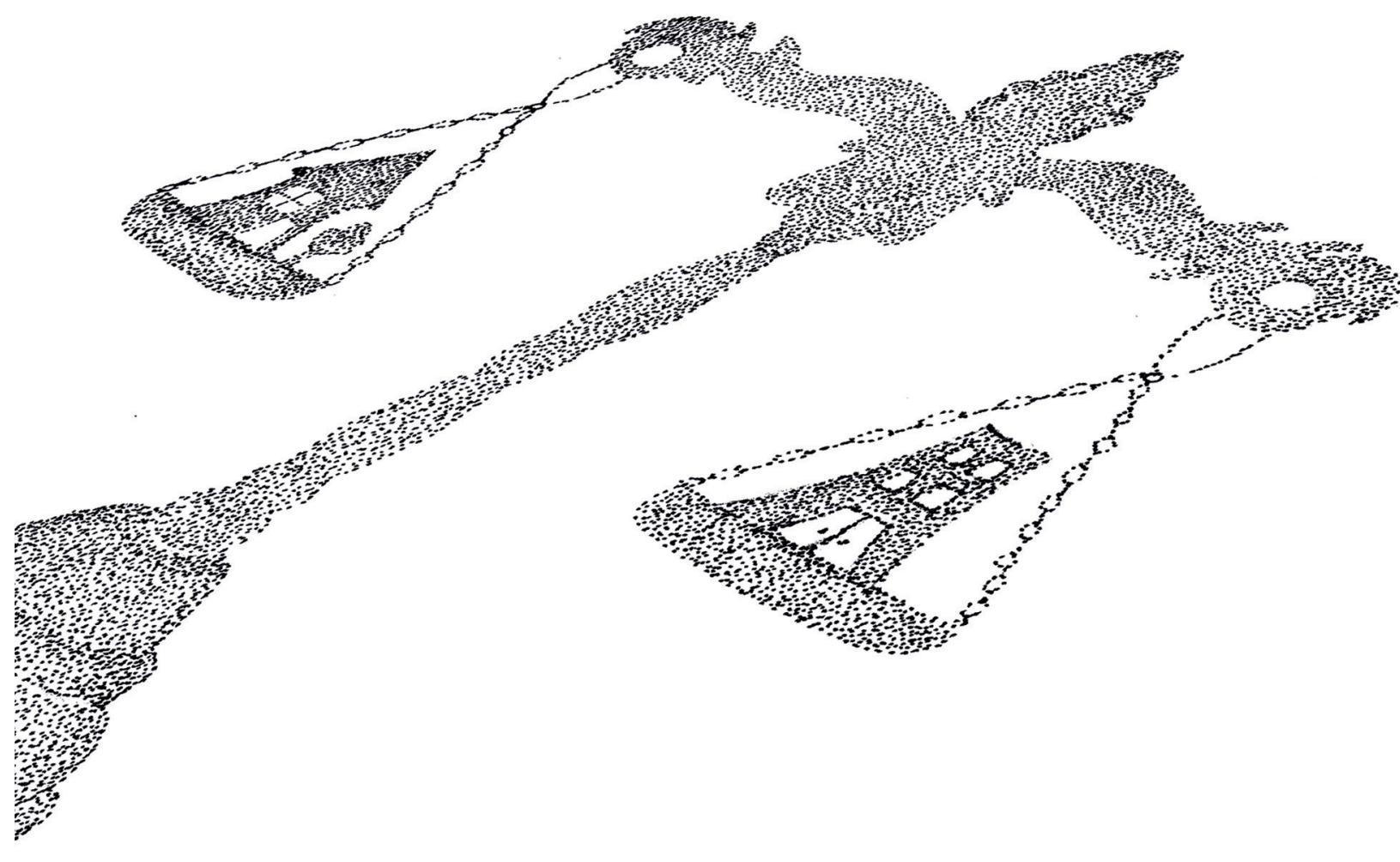




\section{Introduction}

Worldwide a trend is evident of an ever growing elderly population requiring care., Currently, governmental policy in most countries is to provide this care in the home situation and appeal to the social networks of the care receivers. ${ }^{3}$ Both the aging population, as well as the before mentioned policies result in an increasing reliance on informal caregivers.

Despite political efforts to provide care in the home situation, and therewith postpone admission to institutional long-term care (ILTC), the needs of enpron with dementia will at a certain point surpass the possibilities of homemaking ILTC admission necessary. This dissertation focuses on the perspective of informal caregivers regarding the permanent care transition of elderly people with dementia from home-based care towards ILTC.

Within this first chapter some background is provided regarding dementia and informal caregivers of people with dementia (PwD). Furthermore, care transition is explained. Subsequently the RightTimePlaceCare project is introduced, which is the large European project underlying this dissertation. Finally the aims of this dissertation and its outline are specified.

\section{Dementia}

Dementia is an overarching term for a range of, up to now, incurable syndromes which mainly affect the elderly population. ${ }^{4}{ }^{5}$ Dementia describes symptoms that people with various brain disorders or brain damage can have and is characterised by: an overall cognitive decline, a reduced ability to perform day-to-day activities, and an increase in so called non-cognitive symptoms such as aggression, agitation, wandering behaviour and depression. ${ }^{5}$ As the dementia progresses and the symptoms increase, a person with dementia will require more and more support and care in order to get through the day.

With an ever growing elderly population, the total number of PwD will increase as well, considering that the risk for developing one of the underlying causes of dementia increases with age. 1, 2, 6 For the year 2010 there was a worldwide estimate of 35.6 million PwD, a number that is thought to expand to 115.4 million in 2050.6,7 European estimates show that the number will almost double in 40 years towards 18.65 million PwD in 2050.6, 7 In order to continue to care for this vulnerable sub-group of the population, there is an increasing reliance on informal caregivers., 2 Though staying at home and receiving home based care is preferred by most older people, ${ }^{8-10}$ this is not always possible due to increasing care demands, as is the case with dementia. This situation heralds the need for care transition towards ILTC. 


\section{Informal caregivers in dementia}

Informal caregivers are considered the cornerstone of dementia care, ${ }^{1,2}$ with much of the care at home being delivered by family and friends. ${ }^{11,12}$ The definition of informal caregivers used in the RightTimePlaceCare project and, therefore, in this dissertation is as follows: "Someone who, on a voluntary basis, provides care for an older person with dementia or who has or takes the responsibility for this care. Most often this is a relative, friend, or neighbour and usually he or she will not be paid." All main caregivers providing informal care are eligible. Caregivers who provide care on a voluntary basis through an organization or those who provide care as a career are not defined as an informal caregiver. Informal caregivers can, and often do, provide day-to-day hands on care, such as core activities of daily living (ADL) and instrumental activities of daily living (IADL) which can be provided by healthcare professionals (HCPs). Additionally, informal caregivers also have an important role in advocating for the person with dementia and organizing their care.13

is calculated by the Alzheimer's association that in the US 15.4 million people provide 17.5 billion hours of unpaid informal care at home for PwD annually. ${ }^{14}$ For Europe figures are known of an average of approximately 175 hours spent on ADL and IADL per month by the main informal caregiver. ${ }^{15}$

Though the day-to-day care of PwD residing in ILTC is predominantly performed by HCPs, the caregiving role of informal caregivers does not end, with caregivers stil expressing a need to be involved in the care. ${ }^{16,17}$ The type of care and obligations do change however. For example, day-to-day care may decline after admission, but frequent visits to the facility where the person with dementia resides and tasks such as collaboration with HCPs and administrative tasks become more prominent. ${ }^{12,} 18$ The importance of informal caregivers in dementia care is, therefore, very evident. Informal caregiving is sometimes referred to as a career, ${ }^{19,} 20$ implying it to be an intense and intensive task to fulfi.

nformal caregivers of PwD are known to be affected by their caregiving on multiple levels. Some studies show how caring results in positive aspects such as satisfaction and enjoyment of caring, feeling rewarded, useful, and appreciated. ${ }^{21-23}$ However, besides these positive effects, many negative effects of caring are known. Studies show that informal caregivers of PwD show higher levels of depression, burden and health problems compared to non-caregivers but also compared to caregivers of people with other conditions. ${ }^{24-28}$ These effects of caring indicate that, besides providing care themselves, informal caregivers often develop needs for help as well.

Particularly during the care transition from home-based care towards ILTC informal caregivers experience adverse effects. Informal caregivers report struggles with making the decision regarding a permanent care transition towards ILTC. They state feelings of guilt, doubt, sadness, failure, and betrayal (of marital commitment) due to the decision. ${ }^{20,29-34}$ The care transition process and accompanying decisions are made harder by the fact that this process cannot be shared with the person with dementia due to his or her cognitive state. Consequently, informal caregivers face making a hard decision for someone without being able to consult that person. The decision for care transition towards ILTC is considered one of the hardest phases encountered by informal caregivers, ${ }^{20,29}$ and caregivers often delay this decision to the very end resulting in unplanned and untimely care transition. Considering the adverse effects and difficulties experienced by informal caregivers, focusing on the perspective of the informal caregiver regarding the care transition towards ILTC in this dissertation is valuable.

\section{Care transition and the gaps in knowledge}

During the course of dementia there are multiple points of transitions in care, starting with living at home without formal services towards living at home with forma services. Another care transition can be the temporary transition towards hospital care or rehabilitation care. The focus of this dissertation is solely on the permanent care transition from home-based care towards ILTC. Within this dissertation the term care transition' is used for the permanent admission to ILTC. The term 'care transition period' is considered any amount of time starting prior to admission when care transition is contemplated up to an adjustment period after the actual admission.

Care transition in dementia occurs when the person with dementia comes to a stage where his or her care needs surpass the possibilities of home-based care. Current research regarding the care transition of PwD mainly focuses on what might predict admission, or on changes in predictors prior and post admission. Furthermore studies regarding the care transition commonly either look at the period up to admission ${ }^{35-37}$ or start from the moment of admission. ${ }^{38,} 39$ Studies covering the entire span of the care transition period, as described previously, are rare..$^{40}$ Moreover research from the perspective of the informal caregiver on care transition is sparse. Those studies in existence relate mainly to informal caregivers' experiences regarding the decision they had to make concerning the care transition. ${ }^{32,41-46}$

Looking at existing literature, two gaps still seem to exist in the current knowledge regarding the care transition of PwD: 1) Why does care transition occur according to informal caregivers? 2) What do informal caregivers actually need, in terms of care, services, and support, during the care transition period? These two lines are explored in this dissertation.

Why does care transition occur: Predictors for care transition

There is a wealth of studies that have looked at predictors for care transition. Regression analyses show certain characteristics of PwD which seem to predict care 
transition, being: a higher age; living condition prior to admission; ethnicity; health status; functional impairment; cognitive impairment; medication use; marital status presence of BPSD; and duration of the dementia., 47, 48 Informal caregiver factors predicting care transition are: age; marital status; caregiver depression; psychological distress; employment status; social network and support; caregiving hours; caregiver health; and the desire to institutionalise. ${ }^{2,47}$ However, almost none of these studies highlighted the perspective of the informal caregivers or looked at the predictors on an individual case level.

Furthermore, knowing which characteristics of PwD who make the care transition differ from the characteristics of PwD who do not is important information, but does not suffice since this only provides general statements in a very diverse population. The care transition is preceded by the decision for admission. Informal caregivers have an important voice in the care transition process, including the actual decision for care transition from home-based care towards ILTC. ${ }^{20,49-51}$ Informal caregivers most likely are the ones who have the best overview of the particular and individua situation of the person with dementia. This would mean they should be able to indicate what (combination of) reasons will lead to care transition in their particular situation. This information may provide better insights into the particular care needs of the person with dementia and his or her situation. Providing appropriate suppor during the care transition period, may increase the likelihood of suitable and timely institutionalisation, ${ }^{52}$ and consequently the best possible care in the most suitable setting is provided. Because informal caregivers have an important voice in the process of admitting their relative with dementia to ILTC, ${ }^{20,} 49$ they are a valuable source of information regarding reasons for institutionalisation. More insight regarding the perspective of the informal caregiver is of value to understand their experiences and anticipate institutionalisation to complement our current knowledge.

Though it may be the case that informal caregivers can offer specific information regarding the reasons for care transition, this information has not been given that much attention in research. Neither what informal caregivers expect might cause care transition, nor what, in their opinion, were the actual reasons for care transition have been studied rigorously. This leaves a potentially valuable source of information in the research on care transition of PwD untapped.

\section{What do informal caregivers need: (Care) needs during} the care transition period

When studying existing models on care needs, such as Andersen's 'model of healthservices utilisation', ${ }^{3}$ van Bilsen's theoretical model on the relationship between elderly people's needs, resources and demand for care; ${ }^{54}$ and Luppa's dementia specific theoretical framework on the need for care transition, 47 informal caregivers are considered a resource for the needs of the care receiver. However, besides being resources, informal caregivers often develop needs of their own as well. Studies show that informal caregivers have diverse needs, such as: advice on how to handle certain situations, information, and emotional support.40, 55, 56 Though research on needs is not novel, research on the needs of informal caregivers specifically during the care transition period is lacking.

The question remains of why it is important to meet the needs of informa caregivers during the care transition of PwD. Research states that unmet needs of caregivers may impede their ability to care for, and support, the persons with dementia An impeded ability to care can be caused by the emotional and physical effects of caregiving. ${ }^{57,58}$ In turn, diminished care abilities may result in unmet needs of the person with dementia as well, resulting in earlier care transition or even the demise of the person with dementia. ${ }^{59}$ Furthermore, unmet needs of informal caregivers wil change their role in the care transition period from a resource of care for PwD, to having care demands of their own.

\section{Objectives}

The two questions leading this dissertation are as follows:

1) What are the reasons for ILTC admission according to informal caregivers?

This question concerns not only the reasons for ILTC admission from informa caregivers' perspectives stated in their own terms, but also whether informa caregivers can indicate these reasons before care transition has actually occurred. Additionally it is interesting to know whether the views of informa caregivers and HCPs are comparable regarding possible reasons for admission prior to care transition.

2) What needs do informal caregivers experience during the entire care transition period from home-based care towards ILTC?

\section{RightTimePlaceCare}

All of the original studies included in this dissertation were performed as part of a European project aimed at improving dementia care for European citizens called RightTimePlaceCare (RTPC). The RTPC study is supported by a grant from the European Commission within the seventh framework programme (project 242153). The exact aim was to improve health services for European citizens with Dementia by developing best practice strategies with a specific focus on the transition from forma home care to ILTC. The following eight countries were involved in RTPC: England, Estonia, Finland, France, Germany, the Netherlands, Spain, and Sweden. Due to the broad aim of the project, multiple facets of dementia care were highlighted, each with its own work package (WP). For the studies in this dissertation, data collected in the 
second and third work packages (WP2 and WP3) has been used. WP2 encompassed focus groups held with informal caregivers exploring their views on several care related topics. WP3 consisted of the collection of clinical data using semi-structured interviews and aimed, in part, to assess factors influencing care transition of PwD.

\section{Dissertation outline}

This dissertation aims to provide scientific foundation on the perspective of informa caregivers regarding the care transition of PwD towards ILTC. In order to do so, certain facets of the care transition were studied, forming the chapters of this dissertation.

Chapter two inventories the actual reasons for admission according to informa caregivers. Informal caregivers of PwD who recently made the care transition towards ILTC were asked to state what, according to them, was the main reason for admitting their relative with dementia to ILTC. After providing an overall inventory, countryspecific overviews are provided in order to distinguish between the reasons for admission in the eight participating countries. The questions answered in this chapter are: 1) What are the reasons for the institutionalisation of people with dementia according to informal caregivers; 2) To what extent do these reasons vary among informal caregivers from eight European countries?

Chapter three presents a study exploring expected reasons for admission to ILTC according to both informal caregivers as well as HCPs across eight European countries. This chapter further explores the conformity of the expected reasons for LTC admission between an informal caregiver and a HCP at the individual case level. This is done by answering the following questions: 1) What are the potential reasons for the institutionalisation of older persons with dementia according to informa caregivers and according to HCPs in eight European countries?; 2) To what extent do the views of informal caregivers and HCPs vary?

Chapter four describes a mixed methods study aiming to establish whether informal caregivers are capable of indicating beforehand, that is while the person with dementia still lives at home, what will be the actual reasons for admission. This is studied by comparing qualitatively gathered data on the actual reasons for admission, collected after care transition, with both qualitative and quantitative data that was gathered prior to care transition. The questions answered are: 1) What is the correspondence between expected reasons for admission to ILTC and actual reasons for admission, both as stated by informal caregivers?; 2) Are scores on measurement instruments prior to admission in accordance with actual reasons for admission as stated by informal caregivers?

Chapter five provides the findings of a qualitative systematic review aiming to uncover needs and problems encountered by informal caregivers during the care transition period using publications on the experiences of informal caregivers regarding the decision for institutionalisation. The question leading this chapter is: What are the problems and needs as experienced by informal caregivers of PwD during the care transition period from home-based care to ILTC?

Chapter six presents a qualitative study among informal caregivers of PwD providing in-depth views on the needs and related problems encountered by Dutch informal caregivers specific to the care transition period. The question for this chapter is: What are the needs expressed by informal caregivers of PwD during the care transition period from home-based care towards ILTC? 


\section{References}

OECD. Health at a Glance 2013: OECD Indicators. 2013.

Prince M, Prina M, Guerchet M. World Alzheimer Report 2013: Journey of Caring: An Analysis of Long-Term Care for Dementia. London: Alzheimer's Disease International 2013.

Moïse P, Schwarzinger M, Um M-Y. Dementia Care in 9 OECD Countries: A comparative analysis OECD Publishing; 2004

4. hitp://www.who.int/mediacentre/factsheets/fs362/en/. Accessed on july 28, 2014

5. Alzheimer's Association. 2014 Alzheimer's Disease Facts and Figures. 2014.

6. Alzheimer 's Disease International. World Alzheimer Report 2009. London: Alzheimer 's Disease International: 2009.

7. Prince M. Bryce R, Albanese E, Wimo A, Ribeiro W. Ferri CP. The global prevalence of dementia: A systematic review and metaanalysis. Alzheimer's and dementia : the journal of the Alzheimer's Association. 2013:9:63-75 e2.

8. Van Tits M, Lambeck S, Muffels R. 55-plussers in beeld. Een onderzoek naar de vraag van ouderen in West-Brabant op het gebied van zorg, wonen en welzijn. , Tilburg: IVA Tilburg/TISSER, 2000.

9. Van Bilsen P, Hamers J, Groot W, Spreeuwenberg C. Welke zorg vragen ouderen? Een inventarisatie Tijdschrift voor Gezondheidswetenschappen. 2004;82:221-8.

10. Rosenberg M, Everitt J. Planning for aging populations: inside or outside the walls. Progress in Planning 2001; $56: 119-68$.

11. Alzheimer's Association. 2012 Alzheimer's disease facts and figures. Alzheimer's and Dementia

12. Schulz R, Belle SH, Czaja SJ, McGinnis KA, Stevens A, Zhang S. Long-term care placement of dementia patients and caregiver health and well-being. Journal of the American Medical Association. 2004:202:961-7.

3. Alzheimer's Disease International. World Alzheimer Report 2013 Journey of Caring An analysis long-term care for dementia. London: Alzheimer's Disease International; 2013.

14. Alzheimer's Association. 2012 Alzheimer's disease facts and figures. 2012.

Zwakhalen SMG, Verbeek H, Bleilevens MHC, Arram B, Beerens HC, Ruwaard D, et al. RightTimePlaceCare: Statistical Report: Survey on long term care in Europe. 2012.

16. Bramble M, Moyle W, McAllister M. Seeking connection: family care experiences following long-term dementia care placement. Journal of Clinical Nursing. 2009;18:3118-25.

17. Givens JL, Lopez RP, Mazor KM, Mitchell SL. Sources of Stress for Family Members of Nursing Hom Residents With Advanced Dementia. Alzheimer Disease and Associated Disorders. 2012;26:254-9.

18. Strang VR, Koop PM, Dupuis-Blanchard S, Nordstrom M, Thompson B. Family caregivers and transition to long-term care. Clinical Nursing Research. 2006;15:27-45.

19. Gaugler JE, Pearlin LI, Leitsch SA, Davey A. Relinquishing in-home dementia care: difficulties and perceived helpfulness during the nursing home transition. American Journal of Alzheimer's Disease and Other Dementias. 2001;16:32-42.

20. Caron CD, Ducharme F, Griffith J. Deciding on institutionalization for a relative with dementia: The mos difficult decision for caregivers. Canadian Journal on Aging-Revue Canadienne Du Vieillissement. 2006;25:193-205

21. Tarlow BJ, Wisniewski SR, Belle SH, Rubert M, Ory MG, Gallagher-Thompson D. Positive aspects of caregiving - Contributions of the REACH project to the development of new measures for Alzheimer's caregiving. Research on Aging. 2004;26:429-53

22. Pruchno RA, Michaels JE, Potashnik SL. Predictors of Institutionalization among Alzheimer-Disease Victims with Caregiving Spouses. Journals of Gerontology. 1990;45:S259-S66.

23. Kramer BJ. Expanding the Conceptualization of Caregiver Coping - the Importance of Relationship-Focused Coping Strategies. Family Relations. 1993;42:383-91.

24. Haley WE, West CAC, Wadley VG, Ford GR, White FA, Barrett JJ, et al. Psychological, social, and health impact of caregiving: A comparison of black and white dementia family caregivers and noncaregivers. Psychology and Aging. 1995;10:540-52.
25. Pinquart M, Sorensen S. Differences between caregivers and noncaregivers in psychological health and physical health: A meta-analysis. Psychology and Aging. 2003;18:250-67.

26. Mioshi E, Foxe D, Leslie F, Savage S, Hsieh S, Miller L, et al. The Impact of Dementia Severity on Caregiver Burden in Frontotemporal Dementia and Alzheimer Disease. Alzheimer Disease and Associated Disorders. 2013;27:68-73.

27. Ory MG, Hoffman RR, Yee JL, Tennstedt S, Schulz R. Prevalence and impact of caregiving: A detailed comparison between dementia and nondementia caregivers. Gerontologist. 1999;39:177-85.

28. Bertrand RM. Fredman L, Saczynski J. Are All Caregivers Created Equal? Stress in Caregivers to Adults With and Without Dementia Journal of Ading and Health 2006.18.534-51.

29. Gaugler JE Pearlin $\downarrow$ L Leitsch SA, Davey A. Relinquishing in-home dementia care: difficulties and

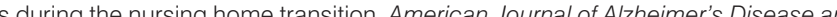
Other Dementias. 2001;16:32-42.

30. Livingston G. Leavey G. Manela M. Livingston D, Rait G. Sampson E, et al. Making decisions for people with dementia who lack capacity: qualitative study of family carers in UK. British Medical Journal

31. Wendler D, Rid A. Systematic Review: The Effect on Surrogates of Making Treatment Decisions for Others. Annals of Internal Medicine. 2011;154:336-U208.

32. Tilse C. Meaning as outcome: Understanding the complexity of decision-making around residential placement in aged care. Australian Social Work. 2000;53:15-9.

33. Dellasega C. Nolan M. Admission to care: facilitating role transition amongst family carers. Journal of Clinical Nursing. 1997;6:443-51

34. Nolan M, Dellasega C. 'I really feel I've let him down': supporting family carers during long-term care placement for elders. Journal of Advanced Nursing. 2000:31:759-67.

35. Hileman JW, Lackey NR, Hassanein RS. Identifying the needs of home caregivers of patients with cancer. Oncology Nursing Forum. 1992;19:771-7.

36. Shankar $J$ Muthuswamy SS. Support needs of family caregivers of people who experience mental illness and the role of mental health services. Families in Society. 2007;88:302-10.

37. Ventura AD, Burney S, Brooker J, Fletcher J, Ricciardelli L. Home-based palliative care: A systematic literature review of the self-reported unmet needs of patients and carers. Palliative Medicine. 2014:28: 391-402.

38. Henriksson A, Benzein E, Ternestedt BM, Andershed B. Meeting needs of family members of person with life-threatening illness: A support group program during ongoing palliative care. Palliative and

39. Verhaeghe S, Defloor T, Van Zuuren F, Duijnstee M, Grypdonck M. The needs and experiences of family members of adult patients in an intensive care unit: a review of the literature. Journal of Clinical Nursing. 2005; $14: 501-9$

40. Peeters JM, Van Beek AP, Meerveld JH, Spreeuwenberg PM, Francke AL. Informal caregivers of persons with dementia, their use of and needs for specific professional support: a survey of the National Dementia Programme. BMC Nursing. 2010;9:9.

41. Park M, Butcher HK, Maas ML. A thematic analysis of Korean family Caregivers' experiences in making the decision to place a family member with dementia in a long-term care facility. Research in Nursing and Health. 2004;27:345-56.

42. Kwon SH, Tae YS. Nursing Home Placement: The Process of Decision Making and Adaptation among Adult Children Caregivers of Demented Parents in Korea. Asian Nursing Research. 2012,6.143-51.

43. Chang Y-P, Kraenzle Schneider J, Sessanna L. Decisional conflict among Chinese family caregivers regarding nursing home placement of older adults with dementia. Journal of Aging studies. 2011,25.436-44.

44. Chang Y. Caregivers' decisional conflict regarding nursing home placement: Saint Louis University; 2007.

45. Chang YP, Schneider JK. Decision-Making Process of Nursing Home Placement Among Chinese Family Caregivers. Perspect Psychiatr Care. 2010;46:108-18.

46. Armstrong M. Factors affecting the decision to place a relative with dementia into residential care. Nursing Standard. 2000;14:33-7. 
47. Luppa M, Luck T, Braehler E, Koenig HH, Riedel-Heller SG. Prediction of institutionalisation in dementia - A systematic review. Dementia and Geriatric Cognitive Disorders. 2008;26:65-78,

48. Gaugler JE, Duval S, Anderson KA, Kane RL. Predicting nursing home admission in the U.S: a meta-analysis. BMC Geriatrics. 2007;7:13.

9. Caron CD, Bowers BJ. Deciding whether to continue, share, or relinquish caregiving: caregiver views Qualitative Health Research. 2003:13:1252-71.

50. Graneheim UH, Johansson A, Lindgren BM. Family caregivers' experiences of relinquishing the care of a person with dementia to a nursing home: insights from a meta-ethnographic study. Scandinavian Journal of Caring Sciences. 2014;28:215-24.

51. Lundh U, Sandberg J, Nolan M. 'I don't have any other choice': spouses' experiences of placing a partner in a care home for older people in Sweden. Journal of Advanced Nursing. 2000;32:1178-86.

52. Buhr GT, Kuchibhatla M, Clipp EC. Caregivers' reasons for nursing home placement: Clues for improving discussions with families prior to the transition. Gerontologist. 2006;46:52-61.

53. Andersen R. Revisiting the behavioral model and access to medical care: does it matter? Journal of Health and Social Behaver 1095 $301-10$

54. Van Bilsen P, Hamers J, Groot W, Spreeuwenberg C. Demand of elderly people for residential care: an exploratory study. BMC Health Services Research. 2006;6:39.

55. Zwaanswijk M, Peeters JM, van Beek AP, Meerveld JH, Francke AL. Informal caregivers of people with dementia: problems, needs and support in the initial stage and in subsequent stages of dementia: a questionnaire survey. The Open Nursing Journal. 2013;7:6-13.

56. Brodaty $\mathrm{H}$, Thomson C, Thompson C, Fine M. Why caregivers of people with dementia and memory loss .

57. Hwang SS, Chang VT, Alejandro Y, Osenenko P, Davis C, Cogswell J, et al. Caregiver unmet needs burden, and satisfaction in symptomatic advanced cancer patients at a Veterans Affairs (VA) medical verter. Pallative and Supportive Care. 2003;1:319-29.

58. Vitaliano PP, Russo J, Young HM, Teri L, Maiuro RD. Predictors of burden in spouse caregivers of individuals with Alzheimer's disease. Psychology and Aging. 1991;6:392-402. the American Geriatrics Society. 2005;53:2098-105. 


\section{2}

Reasons for Institutionalisation of People with Dementia: Informal Caregiver Reports from Eight European Countries

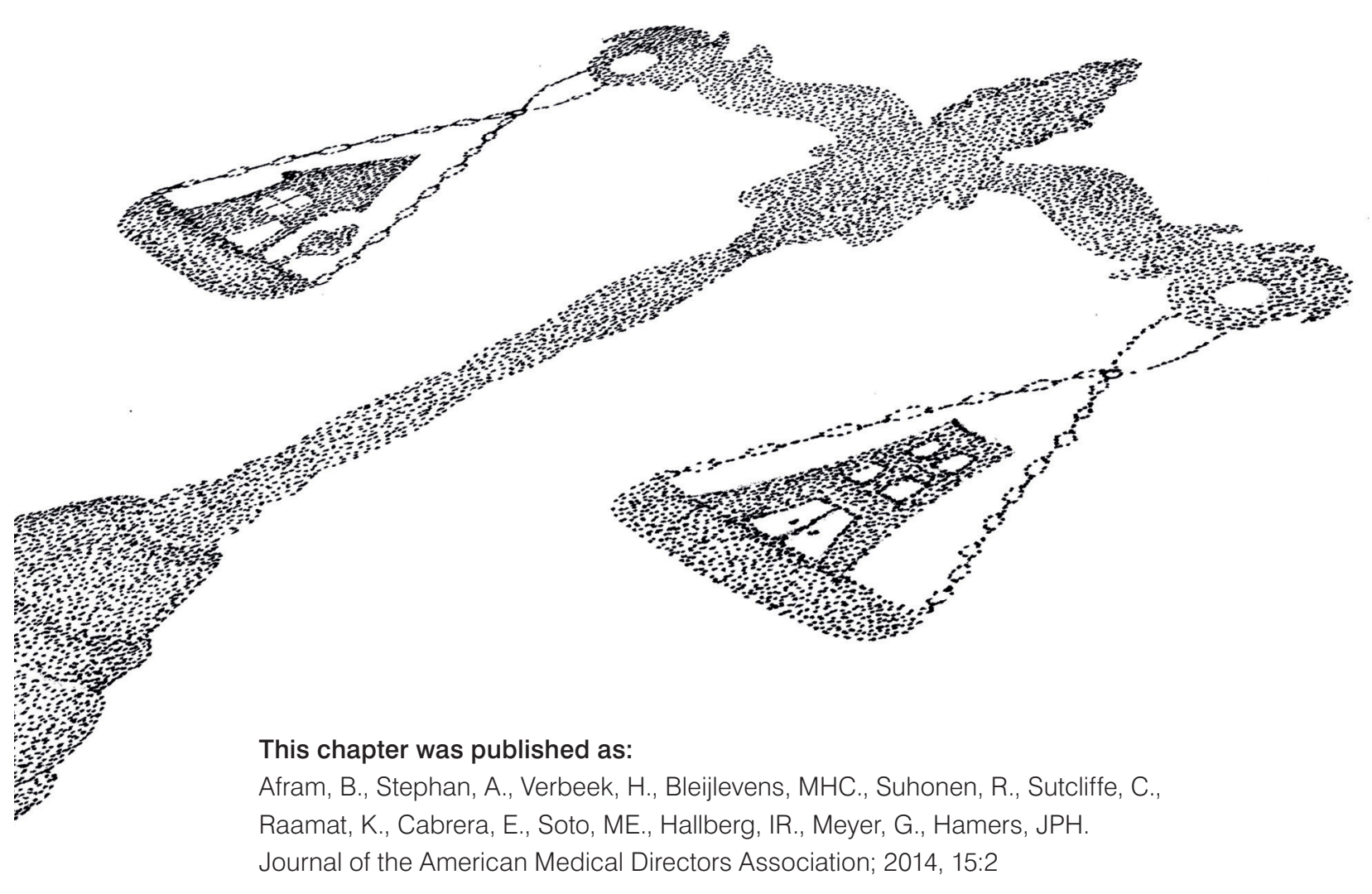




\section{Abstract}

Objectives: To explore reasons for institutionalisation of people with dementia according to informal caregivers as well as variation in reasons between countries.

Design: An explorative cross-sectional study was conducted in eight European countries

Setting: Per country a minimum of three long-term care facilities, offering care and accommodation as a package, participated in this study. Participating countries were selected to represent different geographic areas in Europe.

Participants: Of the 791 informal caregivers involved in the RightTimePlaceCare project of people with dementia who were recently admitted to a long-term care facility, 786 were included for this study.

Measurements: As part of a semi-structured interview, informal caregivers were asked the main were categorized according to a conventional coding approach. All reasons were then quantified and tested.

Results: Mainly patient related reasons were stated, such as neuropsychiatric symptoms (25\%), care dependency (24\%) and cognition (19\%). Neuropsychiatric symptoms were among the most often mentioned reasons in the majority of countries. Beside patient related reasons, caregiver burden and the inability of the informal caregiver to care for the patient were stated as reasons (both 15\%). Further analyses showed countries differ significantly in reasons according to informal caregivers. Additionally, reasons were analysed for spouses and child-caregivers, showing that spouses more often stated reasons related to themselves compared to child-caregivers.

Conclusion: Multiple reasons contribute to the institutionalisation for people with dementia, with several factors that may influence why there were country differences. Variation in the organization of dementia care and cultural aspects, or the relationship between the informal caregiver and person with dementia may be factors influencing the reasons. Because of a wide variation in reasons between countries, no onesize-fits-all approach can be offered to guide informal caregivers when facing the possibility of institutionalisation of the person with dementia.

\section{Introduction}

The process of institutionalising a relative with dementia can be considered one of the most difficult aspects in the so called informal caregiver career.1, 2 Informa caregivers may experience adverse effects when confronted with treatment decisions for others. ${ }^{3}$ Feelings of guilt, doubt, sadness, failure and betrayal (of marital commitment) are reported by informal caregivers of people with dementia in circumstances of

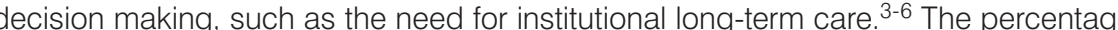
of people with dementia being admitted to institutional long-term care differs between countries, which might in part be explained by country differences in the organization of dementia care. Care systems across Europe vary, e.g. in structure, financing, an services provided. ${ }^{7-9}$ Furthermore no exact overall number on admission rate is available for Europe. However, with an ever increasing number of people suffering from dementia in Europe -from 9.95 million in 2010 estimated to rise to 18.65 millio in $2050-{ }^{10}$ the number of informal caregivers facing the institutionalisation of a person with dementia will increase as well.

Since informal caregivers have an important voice in the process of admitting their relative with dementia to institutional long-term care, 11 they are a valuable source of information regarding reasons for institutionalisation. However, cross-country information on the reasons for institutionalisation of people with dementia from the perspective of the informal caregiver is lacking. Knowing that the institutionalisation of a loved one impacts the informal caregiver, it seems necessary to offer tailored and need-driven guidance during the transition process from homecare to institutional long-term care. By offering support to informal caregivers during this process the likelihood of suitable and timely institutionalisation could be increased, ${ }^{12}$ and consequently the best possible care in the most suitable setting is provided. Current knowledge regarding reasons for institutionalisation is mainly derived from studies on predictors of institutionalisation, based on the results of standardized instruments..$^{13-1}$ More insight is needed regarding the perspective of the informal caregiver in order to understand their experiences and anticipate institutionalisation to complement our current knowledge.

Only some evidence is available on what informal caregivers consider reasons for institutionalisation.12, 17 A US study offered informal caregivers of veterans with dementia ( $n=572$ ) five predefined answers to indicate their reasons for institutionalising their relative with dementia. The most frequently chosen answers were: insufficient caring skills and health problems of the informal caregiver. Difficult patient behaviour was the third most selected reason. ${ }^{12}$ As part of a French study ( $\left.n=109\right)$, only $45 \%$ of the caregivers indicated a specific reason for institutionalisation, such as: increased dependency of the patient, patient behaviour and the health of the informal caregiver. Besides focusing on a specific group of patients, offering pre-defined answer possibilities 
or small sample sizes, these studies only focus on national data and lack an international perspective..$^{17}$

With existing variation between countries in culture, healthcare systems, family obligations to care and admission rates for people with dementia to institutiona long-term care, differences in reasons for institutionalisation can be expected. However, possible variation between countries in reasons for institutionalisation according to informal caregivers has not yet been explored. Since informal caregivers are important in the decision-making, exploring reasons for institutionalisation according to them offers a valuable starting point for developing guidance during this difficult period. This study is part of the RightTimePlaceCare project, designed to improve dementia care across Europe with a specific focus on the transition from home-care to institutional long-term care..$^{18}$ The current study aims to: 1) explore reasons for the institutionalisation of people with dementia, according to informa caregivers; 2) explore variation in reasons between eight European countries.

Results of this study could have important clinical implications, offering knowledge to be used for the development of guidance programs to support informal caregivers across Europe during that last period at home prior to the institutionalisation of the person with dementia.

\section{Methods}

\section{Design}

Embedded in the RightTimePlaceCare project, ${ }^{19}$ an explorative cross-sectional study was conducted in eight countries: England, Estonia, Finland, France, Germany, the Netherlands, Spain and Sweden.

\section{Sample}

As part of the RightTimePlaceCare project, dyads were recruited consisting of people with dementia who were recently admitted to long-term nursing care facilities and their main informal caregiver. ${ }^{19}$ Possible participants were identified by the long-term care facilities through their administration of new admissions. The study population for this study comprised the informal caregivers of each dyad. In order to target a similar population in all eight countries, the following inclusion and exclusion criteria and pre-defined definitions of terms were set.

Informal caregivers: All main informal caregivers were eligible for this study, provided they were involved in the care of a person with dementia who 1) had a formal diagnosis of dementia as determined by an expert assessment; 2) had a score of 24 or less on the Standardized Mini Mental State Examination (S-MMSE) 3 ) been newly admitted to a long-term nursing care facility, living there at least one month and no longer than three months and; 4) had an informal caregiver that visited at least twice a month. Informal caregivers of people with dementia admitted only for a limited period of time, such as rehabilitation or respite care, with the intention of moving back home were excluded.

Long-term care facilities: In this study a long-term care facility was defined as a place of collective living where care and accommodation is provided as a package by a public agency, non-profit or private company. ${ }^{20,21}$ Each country had to include at least three different long-term care facilities as to achieve some within country variation in the recruited sample.

\section{Procedure}

\section{Data collection}

Data were collected between November 2010 and January 2012. Prior to dat collection ethical approval was obtained in each country to conduct the study. Before each individual interview, written informed consent was obtained from informa caregivers

During a comprehensive structured face-to-face interview a specific open ended question regarding the institutionalisation was posed. Informal caregivers were asked: Please state the main reason for institutionalisation. Informal caregivers also answered socio-demographic related questions.

The interviews were performed by trained interviewers with at least a Bachelorsdegree in health or social care ${ }^{19}$ and were guided by a written manual. Interviewers were instructed to prompt respondents by asking further questions, in order to get to the main reason for institutionalising their relative to a long-term care facility.

\section{Data processing}

During the interviews answers were noted in the native language. Subsequently, answers were translated into English to enable comparative analysis across countries As instructed for this study, the translations were performed by no more than two researchers per country to assure consistency in wording and use of terms in the translated answers. ${ }^{22}$

\section{Coding and analysis}

The coding procedure for this study was an iterative process during which severa points of analysis, testing, evaluation and adaptions took place. Both a bottom-up (building from the data), and top-down approach (relying on literature) were used during this process. ${ }^{23}$ Figure 1 shows an overview of the steps taken.

First, a pilot was performed in order to establish feasibility of the planned procedure for this study. Two researchers from Germany and two from the Netherlands independently categorized $5 \%$ of the dataset of both countries and discussed their findings, resulting in an initial version of a codebook. This codebook was created 
using conventional content analysis, ${ }^{23}$ an open coding approach in which the categories are derived from the data at hand without preconceived categories.

After the pilot, conventional content analysis was used again to create a second version of the codebook based on $20 \%$ of the complete dataset. The codebook contained an overview of main categories covering reasons for institutionalisation clustered per theme. If possible and appropriate, main categories were further specified into sub-categories. For this process two researchers from the Netherlands independently categorized the selected cases using an open coding approach. The individual categorization was then discussed by the two Dutch researchers, and in case of disagreement, the rationale of the coding was negotiated until consensus was reached. The decisions made during these discussions were recorded in a manual, which was part of the codebook. Finally, a literature search on reasons for institutionalisation according to informal caregivers was performed afterwards to ensure no known reasons for institutionalisation were missing in this version of the codebook. Based on this search one sub-category was added to the codebook. The complete dataset was then categorized anew with the final codebook.

For the analysis, percentages were calculated of the proportion of informal caregivers stating a certain reason. All reasons within an answer were considered independently and no decision was made by the researchers on what the main reason was in case of multiple reasons in the answer. Analyses were performed on three levels: per theme, per main category and (if applicable) sub-category. This was done for the overall sample, as well as for the countries individually. In order to determine whether country differences were significant, ANOVA (for continuous data) and $x^{2}$-tests (for categorical data) were performed.

\section{Reliability and validity check}

Before starting with the implementation of the coding procedure on the entire dataset, a validation procedure was conducted to ensure reliability and validity of the data. The aim of the reliability and validation check was twofold: 1) to ensure the quality and reliability of the translations of the answers in the database from the native language to English and 2) to check or validate the interpretations of the answers by the raters. For this procedure a researcher involved in the RightTimePlaceCare project from each country was contacted. Each researcher was given an overview of 10\% of participant ID codes of that country, and was asked to go back to the original answer (in the native language) to translate the answer again into English. The new translations were then categorized, and the categorization of the new translations was compared to the categorization of the translation in the dataset. This step was introduced to ensure that the primary translations in the dataset were reliable translations of the original texts in the native languages. Furthermore, the principal researchers of the interviewing team of each country received an overview of already categorized cases

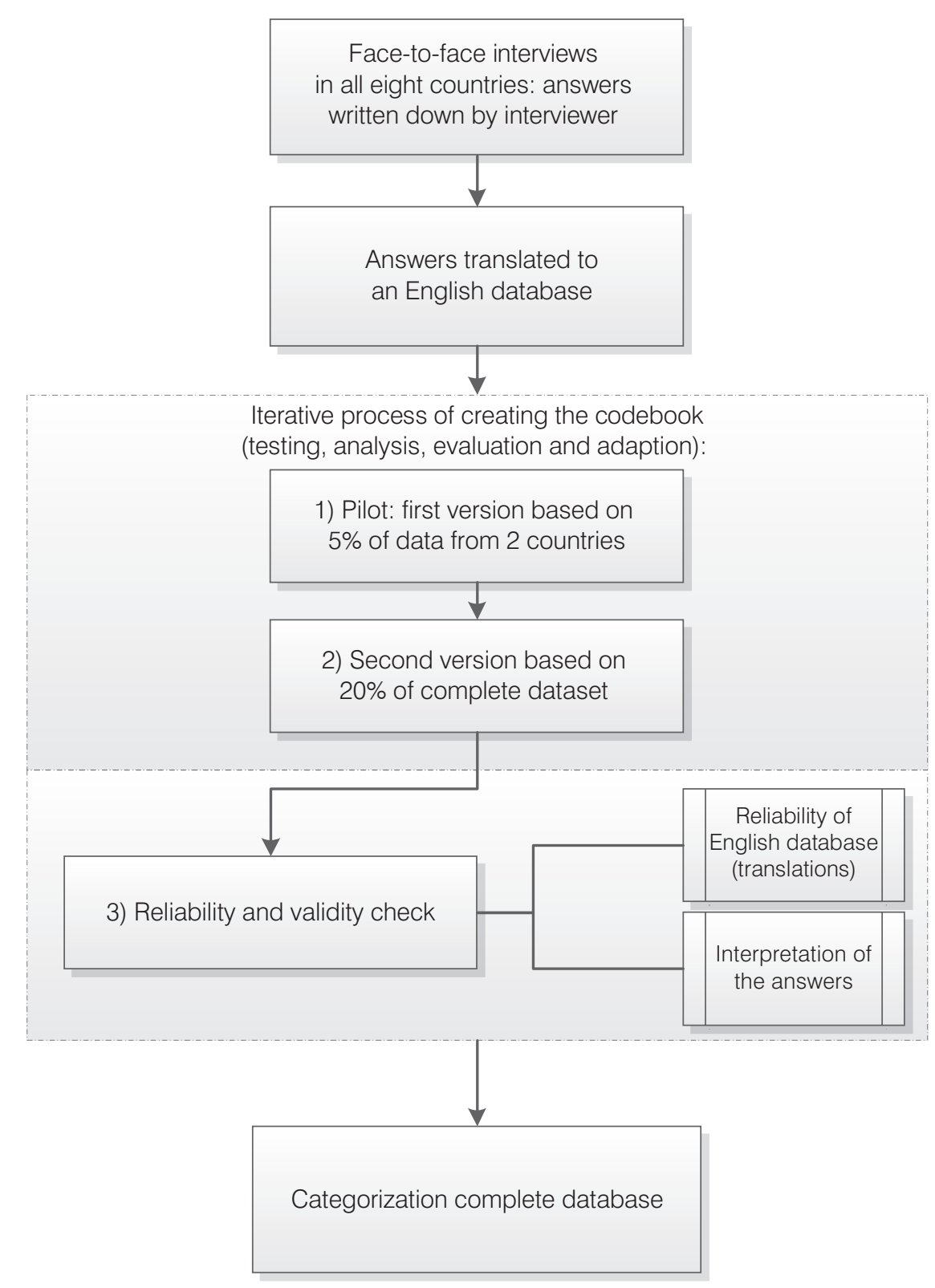

Figure 1 Flowchart of procedure 
from their own country. Each overview held the English translation of the answer and allotted categories. The researchers were then asked whether they agreed with the allotted categories, confirming agreement credibility. ${ }^{24}$ These two procedures showed a confirmation in categorization of respectively $83 \%$ and $94 \%$.

The inter-rater reliability for this study was addressed by means of Jaccard coefficients for similarity 25,26 (ranging from 0.86-0.94, indicating a high accordance between the raters). The Jaccard coefficient was chosen because this measure discards confirmation of absence of the category. Consistency in allotting categories was safeguarded by the decision to have the dataset of each country categorized by one of the two Dutch researchers. ${ }^{27}$ All these steps and precautions ensured that the procedure, data and its translations had a sound validity.

\section{Results}

\section{Sample characteristics}

Of the 791 interviews conducted for RightTimePlaceCare, 786 informal caregivers were eligible for this study. Table 1 presents the socio-demographic characteristics of the sample. Informal caregivers were predominantly female (65\%), had an average age of just over 61 years and were, for the largest part, a child of the person with dementia (63\%). Some variation between the samples of the countries was found with Sweden having older caregivers, and Estonia having younger caregivers. France deviates from the other countries in the distribution of gender, with equally as many males and females in the sample. In most countries the majority of informal caregivers did not have a paid job (54\%), whereas in Estonia and Sweden over half of the caregivers did have a paid job.

\section{Reasons for institutionalisation}

During the interviews, it emerged that the circumstance prompting the transition to institutional long-term care generally consisted of multiple reasons. Informal caregivers often gave several reasons for institutionalisation instead of one main reason, with $60 \%$ of the sample giving two or more reasons (range: $1-7$ reasons within the statement). Along the whole sample 1465 reasons were given, giving an average of 1.9 reasons per informal caregiver (ranging from 1.3 reasons in Spain and France to 2.4 reasons in Finland).

Three themes were identified: 1) patient related reasons; 2) informal caregiver related reasons; and 3) formal care related reasons. All answers given were allotted one of these themes. The majority of informal caregivers (84\%) gave one or more patient related reasons, $28 \%$ gave one or more informal care related reasons and formal care related reasons were mentioned by $9 \%$ of the informal caregivers. Table 2

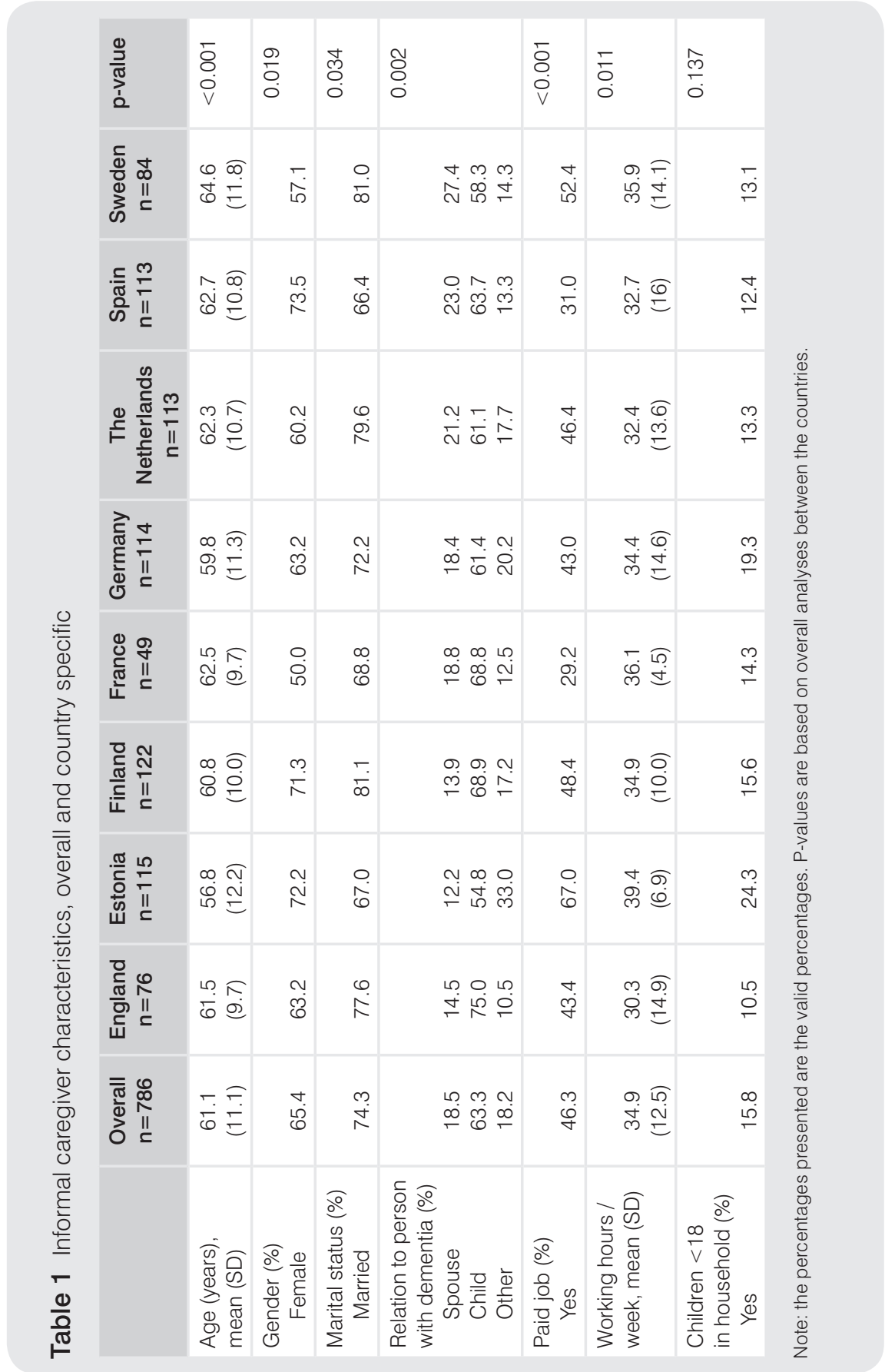


provides an overview of the most mentioned reasons per theme for the overall sample and per country. Results show a wide range between the countries when looking at the proportion of caregivers stating a specific reason. On a wider scale, Spanish caregivers often gave a reason related to themselves as a reason for institutionalisation $(50 \%)$, whereas in other countries the caregivers gave notably more reasons related to the person with dementia. In the following sections more in-depth results are described per theme.

\section{Patient related reasons}

The theme 'patient related reasons' consists of 13 main categories: neuropsychiatric symptoms, cognitive symptoms, health problems, overall deterioration, mobility problems, fall incidents, care dependency, inability to manage at home, staying alone not possible, endangerment, loneliness, (feelings of) insecurity, need for supervision/guidance/structure. The five most mentioned categories are described in more detail below. $X^{2}$-analyses showed there were significant differences between countries in all mentioned categories (Table 2).

Over the whole sample, $25 \%(n=200)$ of caregivers gave at least one neuropsychiatric symptom as a reason for institutionalisation. However, when looking a country differences, less than $3 \%$ of Estonian caregivers mentioned this category The most common specified neuropsychiatric symptom was 'wandering/runaway behaviour' (36\% of caregivers that mention neuropsychiatric symptoms, consequently being approximately $10 \%$ of the overall sample). The two other neuropsychiatric symptoms frequently specified were 'agitation/aggression' and 'sleep/night-time behaviour disorders' (each around 19\% of those caregivers mentioning a neuropsychiatric symptom). Country analyses show that especially caregivers in England specified wandering, whereas none of the French and Swedish caregivers indicated this symptom. Agitation/aggression was mostly mentioned by French caregivers. Sleep and night-time behaviour was mentioned by none of the Estonian caregivers whereas about a third of Dutch, Swedish and German caregivers specified this as a reason.

With 24\% ( $n=192)$, care dependency was the second largest patient related reason for institutionalisation. In France, care dependency was mentioned by only $6 \%$ of the caregivers, whereas in Finland it was mentioned by $40 \%$. Among $60 \%$ $(n=115)$ of caregivers mentioning care dependency a particular (instrumental) activity of daily living task was specified such as eating/drinking, hygiene and incontinence. Finnish caregivers specified care dependency most often (84\% of caregivers stating care dependency) and Estonian caregivers specified care dependency the leas (26\% of caregivers stating care dependency).

Across all countries, 19\% $(n=149)$ of informal caregivers mentioned cognitive symptoms as a reason for institutionalisation. In the country analyses Spain showed

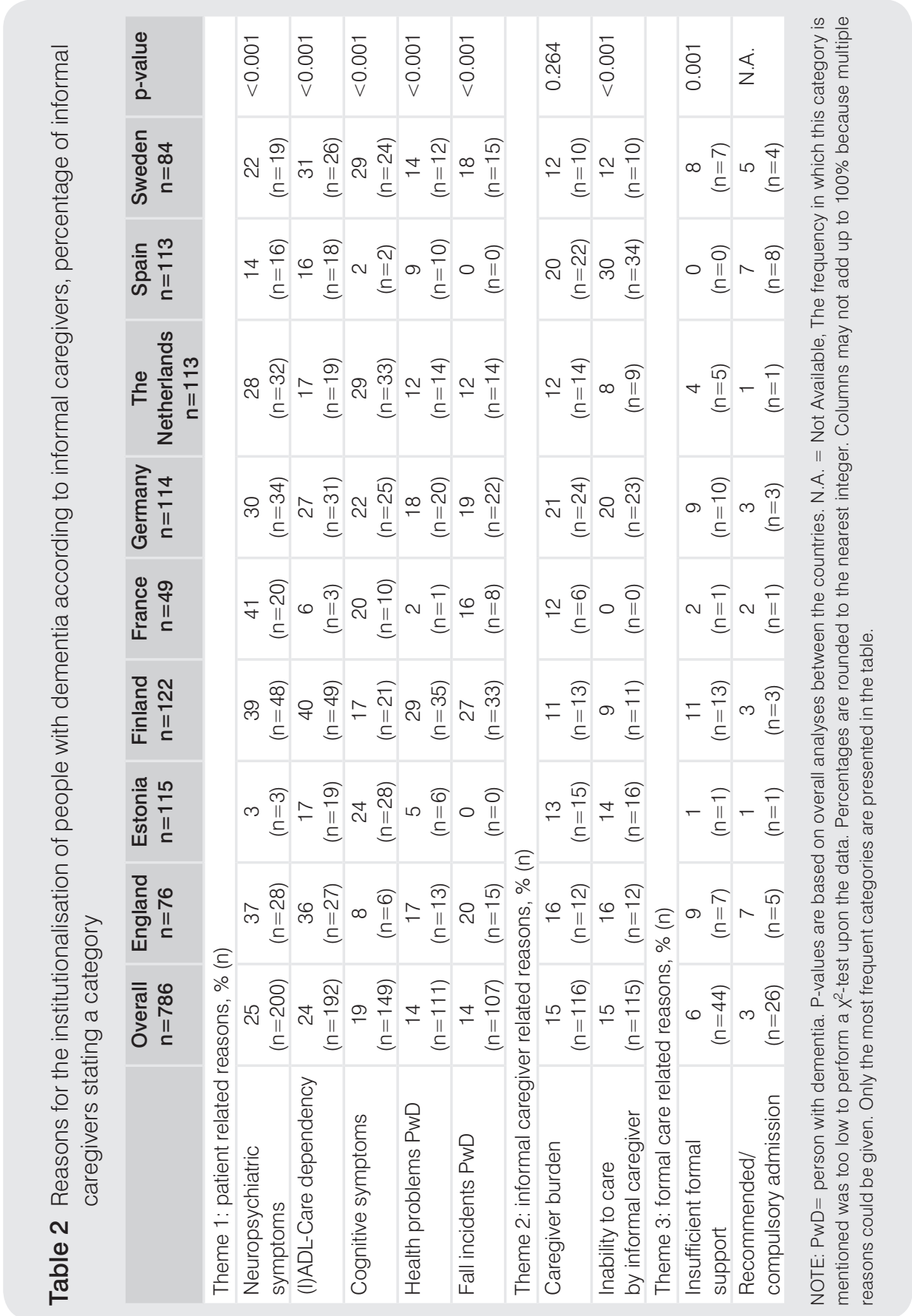


a deviation, with fewer than $2 \%$ of Spanish caregivers mentioning cognitive symptoms. On the other hand, around 29\% of Dutch and Swedish caregivers considered cognitive symptoms as a reason for institutionalisation. Further specification of the answers resulted in 56\% of caregivers mentioning cognitive symptoms stating 'disorientation/confusion' as a reason for institutionalization. Subsequently, this sub-category was mentioned so often, that it represents $11 \%$ of the overall sample. Of all caregivers, $14 \%(n=111)$ stated health problems of the person with dementia as a reason for institutionalisation. In Finland 29\% of informal caregivers reported patient health as a reason for institutionalisation compared to only $2 \%$ of French informa caregivers.

Across the overall sample, $14 \%(n=107)$ of all informal caregivers stated fall incidents as a reason for institutionalisation. It is notable that in Estonia and Spain this category was never mentioned.

\section{Informal caregiver related reasons}

During analysis, two main categories emerged related to the informal caregiver. Among all informal caregivers, 15\% $(n=116)$, considered burden as the reason for institutionalisation. Results of the $X^{2}$-analysis for burden showed no significant differences between the countries, indicating burden to be consistently mentioned in all countries (Table 2).

The second category related to informal caregivers is inability to care for the person with dementia, mentioned by $15 \%(n=115)$ of the overall sample. Answers in this category included statements such as caregivers not being capable to provide care for the person with dementia anymore due to health problems or lack of caring skills to cover all caring needs of the person with dementia. $x^{2}$-analysis showed that there were statistically significant differences between countries (Table 2). Differences between the countries were apparent with none of the French informal caregivers expressing inability to care as a reason for institutionalisation. Spanish informal caregivers, on the other hand, mentioned this category in 30\% of the caregivers. In total, $35 \%$ of caregivers mentioning inability to care specified their own condition, such as own health or physical abilities, being the reason why they were unable to care. Again, variation across countries is present, with $64 \%$ of the Finnish caregivers in this main category specifying the condition of the informal caregiver, against $11 \%$ of Dutch caregivers mentioning inability to care.

\section{Formal care related reasons}

Two categories related to formal care. Across the countries $6 \%(n=44)$ of informa caregivers declared that formal care was not sufficient prior to institutionalisation. This category comprised answers such as homecare was not sufficient and home services failed to meet the patient's needs.
When looking at the individual countries Finland, England, Germany and Sweden had the largest percentage of informal caregivers claiming insufficient formal care as a reason for institutionalisation (each around $9 \%$ ). In contrast, less than $1 \%$ of the Estonian informal caregivers and none of the Spanish caregivers noted insufficient formal support as a reason for institutionalisation.

Throughout the whole sample 3\% $(n=26)$ of informal caregivers mentioned that admission was recommended by someone other than themselves. Spanish and English informal caregivers were advised most often (around 7\% of the country samples). Among Dutch and Estonian informal caregivers, this category was mentioned the least (under $1 \%$ ).

\section{Reasons analysed by caregiver socio-demographics}

Relationship to the person with dementia also appeared to influence reasons for institutionalisation as shown in table 3 . More child-caregivers mentioned care dependency $(p<0.01)$, cognitive symptoms $(p<0.05)$ and fall incidents $(p<0.001)$, compared to spouses. When looking at the countries, cognitive symptoms and fall incidents were consistently mentioned more often by child-caregivers than spouses. In Spain, spouses mentioned care dependency more often than child-caregivers. No significant differences were found between spouses and child-caregivers for neuropsychiatric symptoms and health of the person with dementia.

Explicitly more spouses disclosed reasons related to themselves as a reason for institutionalisation compared to child-caregivers ( $p<0.001$, both the informal caregive related reasons in this theme combined). However country differences do exist with child-caregivers in Germany and Spain reporting their inability to care slightly more often than spouses

With regard to formal care, insufficient formal support was noted by relatively more child-caregivers $(p<0.05)$, with the exception of English caregivers who show the opposite trend.

No patterns were found for other socio-demographic aspects such as caregiver gender or having children under eighteen in the household. 
Table 3 Reasons for the institutionalisation of people with dementia according to informal caregivers, percentages specific to spouses and children

\begin{tabular}{|c|c|c|c|c|c|c|c|c|c|c|c|c|c|c|c|c|c|c|}
\hline & \multicolumn{2}{|c|}{ OVERALL } & \multicolumn{2}{|c|}{ England } & \multicolumn{2}{|c|}{ Estonia } & \multicolumn{2}{|c|}{ Finland } & \multicolumn{2}{|c|}{ France } & \multicolumn{2}{|c|}{ Germany } & \multicolumn{2}{|c|}{ The Netherlands } & \multicolumn{2}{|c|}{ Spain } & \multicolumn{2}{|c|}{ Sweden } \\
\hline & 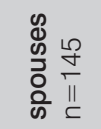 & 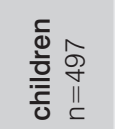 & 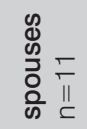 & 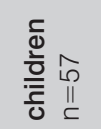 & 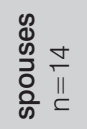 & 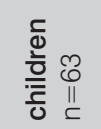 & 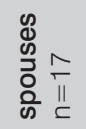 & 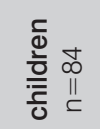 & 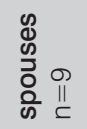 & 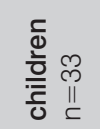 & 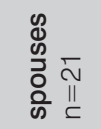 & 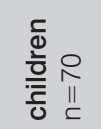 & 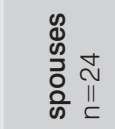 & 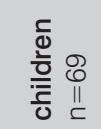 & 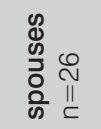 & 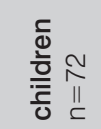 & 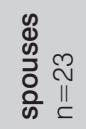 & 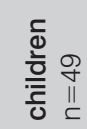 \\
\hline \multicolumn{19}{|c|}{ Theme 1: patient related reasons, \% (n) } \\
\hline Neuro-psychiatric symptoms & $\begin{array}{c}27 \\
n=39\end{array}$ & $\begin{array}{c}26 \\
n=129\end{array}$ & $\begin{array}{c}36 \\
\mathrm{n}=4\end{array}$ & $\begin{array}{c}37 \\
n=21\end{array}$ & $\begin{array}{c}7 \\
n=1\end{array}$ & $\begin{array}{c}3 \\
n=2\end{array}$ & $\begin{array}{c}29 \\
n=5\end{array}$ & $\begin{array}{c}44 \\
n=37\end{array}$ & $\begin{array}{c}44 \\
n=4\end{array}$ & $\begin{array}{c}42 \\
n=14\end{array}$ & $\begin{array}{c}38 \\
n=8\end{array}$ & $\begin{array}{c}26 \\
n=18\end{array}$ & $\begin{array}{c}33 \\
n=8\end{array}$ & $\begin{array}{c}26 \\
n=18\end{array}$ & $\begin{array}{c}15 \\
n=4\end{array}$ & $\begin{array}{c}11 \\
n=8\end{array}$ & $\begin{array}{c}22 \\
n=5\end{array}$ & $\begin{array}{c}20 \\
n=10\end{array}$ \\
\hline (I)ADL-Care dependency & $\begin{array}{c}14 \\
n=20\end{array}$ & $\begin{array}{c}26 * \star \\
n=129\end{array}$ & $\begin{array}{c}18 \\
n=2\end{array}$ & $\begin{array}{c}33 \\
n=19\end{array}$ & $\begin{array}{c}0 \\
n=0\end{array}$ & $\begin{array}{c}18 \\
n=11\end{array}$ & $\begin{array}{c}24 \\
n=4\end{array}$ & $\begin{array}{c}43 \\
n=36\end{array}$ & $\begin{array}{c}0 \\
n=0\end{array}$ & $\begin{array}{c}6 \\
n=2\end{array}$ & $\begin{array}{c}14 \\
n=3\end{array}$ & $\begin{array}{c}29 \\
n=20\end{array}$ & $\begin{array}{c}13 \\
n=3\end{array}$ & $\begin{array}{c}17 \\
n=12\end{array}$ & $\begin{array}{c}19 \\
n=5\end{array}$ & $\begin{array}{c}17 \\
n=12\end{array}$ & $\begin{array}{c}13 \\
n=3\end{array}$ & $\begin{array}{c}39 \\
\mathrm{n}=19\end{array}$ \\
\hline Cognitive symptoms & $\begin{array}{c}12 \\
n=17\end{array}$ & $\begin{array}{c}21^{\star} \\
n=104\end{array}$ & $\begin{array}{c}0 \\
n=0\end{array}$ & $\begin{array}{c}9 \\
n=5\end{array}$ & $\begin{array}{c}7 \\
n=1\end{array}$ & $\begin{array}{c}30 \\
n=19\end{array}$ & $\begin{array}{c}12 \\
n=2\end{array}$ & $\begin{array}{c}20 \\
n=17\end{array}$ & $\begin{array}{c}33 \\
n=3\end{array}$ & $\begin{array}{c}18 \\
n=6\end{array}$ & $\begin{array}{c}19 \\
n=4\end{array}$ & $\begin{array}{c}23 \\
n=16\end{array}$ & $\begin{array}{c}17 \\
n=4\end{array}$ & $\begin{array}{c}29 \\
n=20\end{array}$ & $\begin{array}{c}0 \\
n=0\end{array}$ & $\begin{array}{c}3 \\
n=2\end{array}$ & $\begin{array}{c}13 \\
n=3\end{array}$ & $\begin{array}{c}35 \\
\mathrm{n}=17\end{array}$ \\
\hline Health problems & $\begin{array}{c}13 \\
n=19\end{array}$ & $\begin{array}{c}15 \\
\mathrm{n}=75\end{array}$ & $\begin{array}{c}9 \\
n=1\end{array}$ & $\begin{array}{c}19 \\
n=11\end{array}$ & $\begin{array}{c}0 \\
n=0\end{array}$ & $\begin{array}{c}5 \\
n=3\end{array}$ & $\begin{array}{c}35 \\
n=6\end{array}$ & $\begin{array}{c}27 \\
n=23\end{array}$ & $\begin{array}{c}11 \\
n=1\end{array}$ & $\begin{array}{c}0 \\
n=0\end{array}$ & $\begin{array}{c}19 \\
n=4\end{array}$ & $\begin{array}{c}15 \\
n=10\end{array}$ & $\begin{array}{c}13 \\
n=3\end{array}$ & $\begin{array}{c}15 \\
n=10\end{array}$ & $\begin{array}{c}4 \\
n=1\end{array}$ & $\begin{array}{c}8 \\
n=6\end{array}$ & $\begin{array}{c}13 \\
n=3\end{array}$ & $\begin{array}{c}16 \\
n=8\end{array}$ \\
\hline Fall incidents & $\begin{array}{c}2 \\
n=3\end{array}$ & $\begin{array}{l}16^{\star * *} \\
\mathrm{n}=80\end{array}$ & $\begin{array}{c}9 \\
n=1\end{array}$ & $\begin{array}{c}19 \\
n=11\end{array}$ & $\begin{array}{c}0 \\
n=0\end{array}$ & $\begin{array}{c}0 \\
n=0\end{array}$ & $\begin{array}{c}6 \\
n=1\end{array}$ & $\begin{array}{c}27 \\
n=23\end{array}$ & $\begin{array}{c}0 \\
n=0\end{array}$ & $\begin{array}{c}21 \\
n=7\end{array}$ & $\begin{array}{c}0 \\
n=0\end{array}$ & $\begin{array}{c}20 \\
n=14\end{array}$ & $\begin{array}{c}4 \\
n=1\end{array}$ & $\begin{array}{c}17 \\
n=12\end{array}$ & $\begin{array}{c}0 \\
n=0\end{array}$ & $\begin{array}{c}0 \\
n=0\end{array}$ & $\begin{array}{c}0 \\
n=0\end{array}$ & $\begin{array}{c}22 \\
n=11\end{array}$ \\
\hline \multicolumn{19}{|c|}{ Theme 2: informal caregiver related reasons, \% (n) } \\
\hline Caregiver burden & $\begin{array}{c}37 \\
n=54\end{array}$ & $\begin{array}{l}11^{* \star *} \\
\mathrm{n}=55\end{array}$ & $\begin{array}{c}45 \\
n=5\end{array}$ & $\begin{array}{c}12 \\
n=7\end{array}$ & $\begin{array}{c}21 \\
n=3\end{array}$ & $\begin{array}{c}18 \\
n=11\end{array}$ & $\begin{array}{c}47 \\
n=8\end{array}$ & $\begin{array}{c}4 \\
n=3\end{array}$ & $\begin{array}{c}22 \\
n=2\end{array}$ & $\begin{array}{c}12 \\
n=4\end{array}$ & $\begin{array}{c}48 \\
n=10\end{array}$ & $\begin{array}{c}13 \\
n=9\end{array}$ & $\begin{array}{c}33 \\
n=8\end{array}$ & $\begin{array}{c}7 \\
n=5\end{array}$ & $\begin{array}{c}35 \\
n=9\end{array}$ & $\begin{array}{c}15 \\
n=11\end{array}$ & $\begin{array}{c}35 \\
n=8\end{array}$ & $\begin{array}{c}4 \\
n=2\end{array}$ \\
\hline $\begin{array}{l}\text { Inability to care by informal } \\
\text { caregiver }\end{array}$ & $\begin{array}{c}21 \\
n=30\end{array}$ & $\begin{array}{c}15 \\
\mathrm{n}=75\end{array}$ & $\begin{array}{c}36 \\
\mathrm{n}=4\end{array}$ & $\begin{array}{c}14 \\
n=8\end{array}$ & $\begin{array}{l}21 \\
n=3\end{array}$ & $\begin{array}{c}19 \\
n=12\end{array}$ & $\begin{array}{c}18 \\
n=3\end{array}$ & $\begin{array}{c}10 \\
n=8\end{array}$ & $\begin{array}{c}0 \\
n=0\end{array}$ & $\begin{array}{c}0 \\
n=0\end{array}$ & $\begin{array}{c}19 \\
n=4\end{array}$ & $\begin{array}{c}23 \\
n=16\end{array}$ & $\begin{array}{c}17 \\
n=4\end{array}$ & $\begin{array}{c}6 \\
n=4\end{array}$ & $\begin{array}{c}27 \\
n=7\end{array}$ & $\begin{array}{c}33 \\
n=24\end{array}$ & $\begin{array}{c}26 \\
n=6\end{array}$ & $\begin{array}{c}6 \\
n=3\end{array}$ \\
\hline \multicolumn{19}{|c|}{ Theme 3: formal care related reasons, \% ( $\mathrm{n}$ ) } \\
\hline Insufficient formal support & $\stackrel{2}{n=3}$ & $\begin{array}{c}7^{\star} \\
\mathrm{n}=35\end{array}$ & $\begin{array}{c}18 \\
n=2\end{array}$ & $\begin{array}{c}9 \\
n=5\end{array}$ & $\begin{array}{c}0 \\
n=0\end{array}$ & $\begin{array}{c}0 \\
n=0\end{array}$ & $\begin{array}{c}0 \\
n=0\end{array}$ & $\begin{array}{c}13 \\
n=11\end{array}$ & $\begin{array}{c}0 \\
n=0\end{array}$ & $\begin{array}{c}3 \\
n=1\end{array}$ & $\begin{array}{c}0 \\
n=0\end{array}$ & $\begin{array}{c}11 \\
n=8\end{array}$ & $\begin{array}{c}0 \\
n=0\end{array}$ & $\begin{array}{c}6 \\
n=4\end{array}$ & $\begin{array}{c}0 \\
n=0\end{array}$ & $\begin{array}{c}0 \\
n=0\end{array}$ & $\begin{array}{c}4 \\
n=1\end{array}$ & $\begin{array}{c}10 \\
n=5\end{array}$ \\
\hline $\begin{array}{l}\text { Recommended/ } \\
\text { compulsory admission }\end{array}$ & $\begin{array}{c}6 \\
n=8\end{array}$ & $\begin{array}{c}3 \\
n=15\end{array}$ & $\begin{array}{c}18 \\
\mathrm{n}=2\end{array}$ & $\begin{array}{c}5 \\
n=3\end{array}$ & $\begin{array}{c}0 \\
n=0\end{array}$ & $\stackrel{2}{n=1}$ & $\begin{array}{c}0 \\
n=0\end{array}$ & $\begin{array}{c}2 \\
n=2\end{array}$ & $\begin{array}{c}0 \\
n=0\end{array}$ & $\begin{array}{c}3 \\
n=1\end{array}$ & $\begin{array}{c}5 \\
n=1\end{array}$ & $\begin{array}{c}3 \\
n=2\end{array}$ & $\begin{array}{c}4 \\
n=1\end{array}$ & $\begin{array}{c}0 \\
n=0\end{array}$ & $\begin{array}{c}8 \\
n=2\end{array}$ & $\begin{array}{c}7 \\
n=5\end{array}$ & $\begin{array}{c}9 \\
n=2\end{array}$ & $\begin{array}{c}4 \\
n=2\end{array}$ \\
\hline
\end{tabular}

\section{Discussion}

This study aimed to explore reasons for institutionalisation of people with dementia according to informal caregivers within eight European countries. Variations between countries were found in reasons for institutionalisation, however overall results showed that caregivers mainly stated reasons related to the person with dementia.
This is contrary to some previous research in which more reasons related to informal care came forward. ${ }^{12}$ Informal caregivers often stated multiple reasons in their answer showing institutionalisation is often a result of a combination of reasons.

Despite the country differences, certain reasons seem to overarch country boundaries, with neuropsychiatric symptoms and care dependency being among the top five reasons in most countries. Neuropsychiatric symptoms seem to be the 
main reasons across the countries, with the exception of Estonia. This category also overarches the relationship of the informal caregiver to the person with dementia, with both spouses and children often indicating neuropsychiatric symptoms as a reason for institutionalisation. Moreover caregivers report more on active behaviour (e.g. wandering, aggression and sleep/night-time disturbances) compared to inactive behaviour (e.g. depression and apathy). The behaviours most mentioned are in accordance with studies linking challenging behaviour to caregiver burden. ${ }^{28}$

Beside country differences, relationship to the person with dementia also seems to influence reasons for institutionalisation. The most distinct difference is caregive burden, with notably more spouses reporting burden as a reason for institutionalisation compared to child-caregivers. This is possibly due to the fact that spouses are also elderly with probably health problems of their own, resulting in feelings of burden Furthermore, spouses generally live with the person with dementia prior to admission, which might explain a higher burden. Future research is needed to investigate this relationship in more detail.

A similar proportion of caregivers across the countries states caregiver burden as a reason. Whereas many previous studies show caregiver burden to be a strong predictor for institutionalisation, ${ }^{13,14,29,30}$ only $15 \%$ of caregivers actually declare their burden as a reason for institutionalisation. This is an interesting result because it may imply that caregivers do not (always) label what is considered 'burden' by forma caregivers as such. Caregivers do, however, often state patient related aspects which are linked to burden such as patient behavior ${ }^{30}$ and care needs, ${ }^{31}$ possibly indicating a level of specificity in which caregivers implicitly indicate the reasons for their burden. This result might be key in offering formal support to informal caregivers in the home situation especially during sensitive periods, such as the final period in which the person with dementia lives at home. If an informal caregiver does not consider, and therefore not label his/her situation as burdened, formal support should be adapted to match the perception of the informal caregiver and focus on those aspects linked to burden.

As described, many differences are apparent between countries. An explanation for variation in reasons could be the variation in the organization of dementia-care across Europe and therewith the availability and accessibility of (home) services to support informal caregivers in meeting the needs of the person with dementia. In Estonia for example, the availability of services is rather low, especially compared to other European countries. Also Estonian legislation states an obligation for family caregivers to care for their relatives. ${ }^{32}$ This might to a certain extent explain the results of our study, with Estonian caregivers not stating that many reasons fo institutionalisation. Along this same line, services may be available or accessible, but still not used by informal caregivers, due to unawareness of these services. ${ }^{33}$ Additionally certain evidence suggests that culture shapes the perceptions of caregiver responsibilities. ${ }^{30}$ For example, in our sample Spanish caregivers stated relatively more reasons regarding themselves whereas more western and Nordic countries state far more reasons related to the patient. Previous studies suggest that it is more conventional in Southern European countries to expect of family members to care for their elderly compared to the more Nordic and West-European countries. ${ }^{8,34}$ The results in this study also show differences between spouses and child-caregivers. This might be influenced by differences in expectations of caregiving, with spouses being more strongly committed to the care relationship than non-spouses ${ }^{35}$

Certain study limitations must be considered. The first point of importance is the act that the answers given were not recorded but noted by the interviewer during the interviews. Therefore the results are partly dependent on the description given by the interviewer, possibly influencing the way in which the answer is categorized, or whether the answer is further specified into a sub-category. The fact that answers had to be translated could be considered a limitation. However, a study on the influence of translation on validity and reliability of qualitative data found that there were no significant differences in the major categories between the translated and original (native) dataset. ${ }^{22}$ The precautions taken in this study minimize the effects of translation as much as possible and ensure a sound validity of the data. Also, the systematic approach and analysis of the open ended answers strengthen this study, even though it is not an in-depth qualitative study. Despite being asked for the main reason for admission, informal caregivers often stated multiple reasons within the answer. It would have been interesting to know whether certain reasons weighted more in the decision than others. For this study this distinction could not be made, since no particular inquiry was made about the priority or weight of each reason given. Recall bias has been reported as a possible limitation in studies about past experiences. ${ }^{36}$ However, in this study the informal caregivers were interviewed rather quickly after institutionalisation (within three months), minimizing recall bias. Also caregivers might give answers that are considered socially desirable (for that country/ culture). This may possibly result in some caregivers not wanting to admit that the care was too burdensome for them, or caregivers not wanting to 'blame' the persons with dementia, which may influence the answers given. In order to minimize these effects, interviewers were trained to reassure the informal caregivers and emphasize the importance of honest answers. Finally, it is important to note that no pre-admission information on the people with dementia was available, making it impossible to relate the answers given to patient related characteristics. Therefore, country differences as described in this study could be related to differences in the organization of care as well as to differences in patient characteristics between the country samples. 


\section{Conclusion and implications}

The contributions of this study imply that there is no definitive reason for the institutionalisation of a person with dementia, with multiple factors contributing to the decision. The wide variation of reasons found across the countries and between spouses and child-caregivers indicates that several aspects influence the final reason for the institutionalisation of the person with dementia. Despite a wide variation of reasons, neuropsychiatric symptoms seem a very important factor. This suggest that interventions focusing on behavioural changes of the people with dementia, and therein especially guiding and supporting informal caregivers to handle these changes, could be beneficial. Since research states that neuropsychiatric symptoms are linked to a higher burden, ${ }^{30}$ interventions focusing on educating and guiding informal caregivers on how to handle these symptoms may in turn lower caregiver burden. Likewise, care dependency, which is linked to caregiver burden as well, could possibly be targeted more efficiently. (I)ADL care is among the most time consuming services performed by informal care that could be fulfilled by professional care. This contributes to possible alleviation of caregiver burden.

Our results, furthermore, show that informal caregivers did not report lack of formal care at home as a main reason for institutionalisation. This applies to both those countries with a wide range of home-based dementia services available (e.g. the Netherlands) as those with limited services available (e.g. Estonia). The reason could lie in the unawareness of informal caregivers regarding available services, o informal caregivers not wanting to relinquish care. ${ }^{33,37}$ Possible cultural aspects may also influence who, informal caregivers believe, is responsible for delivering dementia care at home. Moreover, an important reason for not mentioning lack of formal care could be that the current range of available services does not meet the needs of informal caregivers. The question whether current services meet the needs of both people with dementia and informal caregivers is of great importance, especially in the light of the 'aging-in-place agenda that aims to let elderly people live in their own homes as long as possible. ${ }^{38}$ Investing in home-care in order to delay or even prevent institutionalisation will only be adequate if home-care is adjusted to people's care needs. If available services do not meet care needs and demands, these services will not be used and 'aging in place' will not reach its full potential.

Since informal caregivers have an important voice in the institutionalisation of their relative, the importance of tailored guidance by formal care to ease care transition must be stressed. Particularly, since we have some evidence suggesting that informal caregivers appreciate support offered by formal care during the decision process. ${ }^{2,} 39$ By exploring the reasons for institutionalisation according to informal caregivers themselves, this study offers some understanding of their reasoning regarding the motives for institutionalisation.
The aim across Europe is to aid both patient as well as informal caregiver as best as possible and offer the best possible dementia care. However, because of wide variation of reasons, no one-size-fits-all approach to support can be offered to informal caregivers, emphasizing the need for tailored and need driven guidance, keeping such aspects as culture and relationship to the patient in mind. 


\section{References}

1. Caron $C D$, Ducharme F, Griffith J. Deciding on institutionalization for a relative with dementia: The most difficult decision for caregivers. Canadian Journal on Aging-Revue Canadienne Du Vieillissement. 2006;25:193-205

2. Gaugler JE, Pearlin LI, Leitsch SA, Davey A. Relinquishing in-home dementia care: difficulties and perceived helpfulness during the nursing home transition. Americal Journal of Alzheimers Disease and Other Dementias. 2001;16:32-42.

3. Wendler D, Rid A. Systematic Review: The Effect on Surrogates of Making Treatment Decisions for Others. Annals of Internal Medicine. 2011;154:336-U208.

4. Tilse C. Meaning as outcome: Understanding the complexity of decision-making around residential placement in aged care. Australian Social Work. 2000;53:15-9.

5. Dellasega C, Nolan M. Admission to care: facilitating role transition amongst family carers. Journal of Clinical Nursing. 1997;6:443-51

6. Nolan M, Dellasega C. 'I really feel I've let him down': supporting family carers during long-term care placement for elders. Journal of Advanced Nursing. 2000;31:759-67.

7. Thomson S, Foubister T, Mossialos E. Financing health care in the European Union: challenges and policy responses: World Health Organization, 2009

8. Vellas B, Hausner L, Frolich L, Cantet C, Gardette V, Reynish E, et al. Progression of Alzheimer Disease in Europe: Data from the European ICTUS Study. Current Alzheimer Research. 2012;9:902-12.

9. http://www.alzheimer-europe.org/EN/Policy-in-Practice2/Country-comparisons. Accessed on March 26th, 2013

Alzheimer's Disease International. World Alzheimer Report 2009. London: Alzheimer's Disease International

1. Caron $\mathrm{CD}$, Bowers BJ. Deciding whether to continue, share, or relinquish caregiving: caregiver views Qualitative Health Research. 2003;13:1252-71

2. 'Buhr GT, Kuchibhatla M, Clipp EC. Caregivers' reasons for nursing home placement: Clues for improving discussions with families prior to the transition. Gerontologist. 2006;46:52-61

13. Luppa M, Luck T, Braehler E, Koenig HH, Riedel-Heller SG. Prediction of institutionalisation in dementia - A systematic review. Dementia and Geriatric Cognitive Disorders. 2008;26:65-78.

14. Gaugler JE, Yu F, Krichbaum K, Wyman JF. Predictors of Nursing Home Admission for Persons with Dementia. Medical Care. 2009;47:191-8

15. Yaffe K, Fox P, Newcomer R, Sands L, Lindquist K, Dane K, et al. Patient and Caregiver characteristics and nursing home placement in patients with dementia. Journal of the American Medical Association. 2002;287:2090-7.

16. Drame M, Lang PO, Jolly D, Narbey D, Mahmoudi R, Laniece I, et al. Nursing home admission in elderly subjects with dementia: predictive factors and future challenges. Journal of the American Medical Directors Association. 2012;13:83 e17-20.

17. Thomas P, Ingrand P, Lalloue F, Hazif-Thomas C, Billon R, Vieban F, et al. Reasons of informal caregivers for institutionalising dementia patients previously living at home: the Pixel study. International Journal o Geriatric Psychiatry. 2004;19:127-35.

8. http://www.righttimeplacecare.eul. Accessed on May 1st, 2013

19. Verbeek H, Meyer G, Leino-Kilpi H, Zabalegui A, Hallberg IR, Saks K, et al. A European study investigating patterns of transition from home care towards institutional dementia care: the protocol of a RightTimePlaceCare study. BMC Public Health. 2012;12:68.

20. OECD. The OECD Health Project Long term care for older people. Paris: Organisation for Economic Cooperation and Development; 2005

21. Statistical Office of the European Communities. Health Statistics: Key Data on Health 2002; Data 1970-2001. Office for Official Publications of the European Communities; 2003.

22. Twinn S. An exploratory study examining the influence of translation on the validity and reliability of qualitative data in nursing research. Journal of Advanced Nursing. 1997;26:418-23.
23. Hsieh HF, Shannon SE. Three approaches to qualitative content analysis. Qual Health Res. 2005;15:1277-88. 24. Graneheim UH, Lundman B. Qualitative content analysis in nursing research concepts, procedures and measures to achieve trustworthiness. Nurse Education Today. 2004:24:105-12.

25. Popping R. Traces of agreement: On the DOT-product as a coefficient of agreement. Quality and Quantity. 1983;17:1-18.

26. Landis JR, Koch GG. The measurement of observer agreement for categorical data. Biometrics. 1977:159-74.

27. Polit DF. Beck CT Nursing research. Generating and assessing evidence for nursing practice 9th ed: Lippincott Williams \& Wilkins, 2011

28. Wolfs C, Kessels A, Severens J, Brouwer W, De Vugt M, Verhey F, et al. Predictive factors for the objective

29. Rozzini L, Cornali C. Chilovi BV. Ghianda D, Padovani A, Trabucchi M. Predictors of institutionalization in demented patients discharged from a rehabilitation unit. Journal of the American Medical Directors Association 2006:7:345-9.

30. Etters $L$, Goodall D, Harrison BE. Caregiver burden among dementia patient caregivers: A review of the literature. J Am Acad Nurse Pract. 2008;20:423-8.

31. Torti Jr F, Gwyther L, Reed S, Friedman J, Schulman K. A multinational review of recent trends and reports in dementia caregiver burden. Alzheimer Disease and Associated Disorders. 2004;18:99.

32. Merrilees $\mathrm{J}$, Ketelle R. Advanced practice nursing: meeting the caregiving challenges for families $\mathrm{O}$ persons with frontotemporal dementia. Clinical Nurse Specialist. 2010;24:245-51.

33. Brodaty $\mathrm{H}$ Thomson C. Thompson C. Fine M. Why caregivers of people with dementia and memory los don't use services. International Journal of Geriatric Psychiatry. 2005;20:537-46.

34. http://www.alzheimer-europe.org/Policy-in-Practice2/Country-comparisons/Home-care/Role-of-families/(language)/eng-GB\#fragment-3. Accessed on May 13, 2013

35. Pot AM, Deeg DJ, Knipscheer CP. Institutionalization of demented elderly: the role of caregiver characteristics. International Journal of Geriatric Psychiatry. 2001;16:273-80.

36. Hassan E. Recall bias can be a threat to retrospective and prospective research designs. The Internet Journal of Epidemiology [Internet]. 2006; 3:339-412

37. Wolfs CA, de Vugt ME, Verkaaik M, Verkade PJ, Verhey FR. Empowered or overpowered? Service use needs, wants and demands in elderly patients with cognitive impairments. International Journal of Geriatric Psychiatry. 2010;25:1006-12

38. Moise P, Schwarzinger M, Um M. Dementia Care in 9 OECD Countries: A comparative analysis. OECD Health Working Papers. 2004.

39. Couture M, Ducharme F, Lamontagne J. The Role of Health care Professionals in the Decision-Making Process of Family Caregivers Regarding Placement of a Cognitively Impaired Elderly Relative. Home Health Care Management and Practice. 2012;31:197-218 


\section{3}

Older Persons with Dementia at Risk for Institutionalisation in Eight European Countries: A Cross-Sectional Study on the Perceptions of Informal Caregivers and Healthcare Professionals

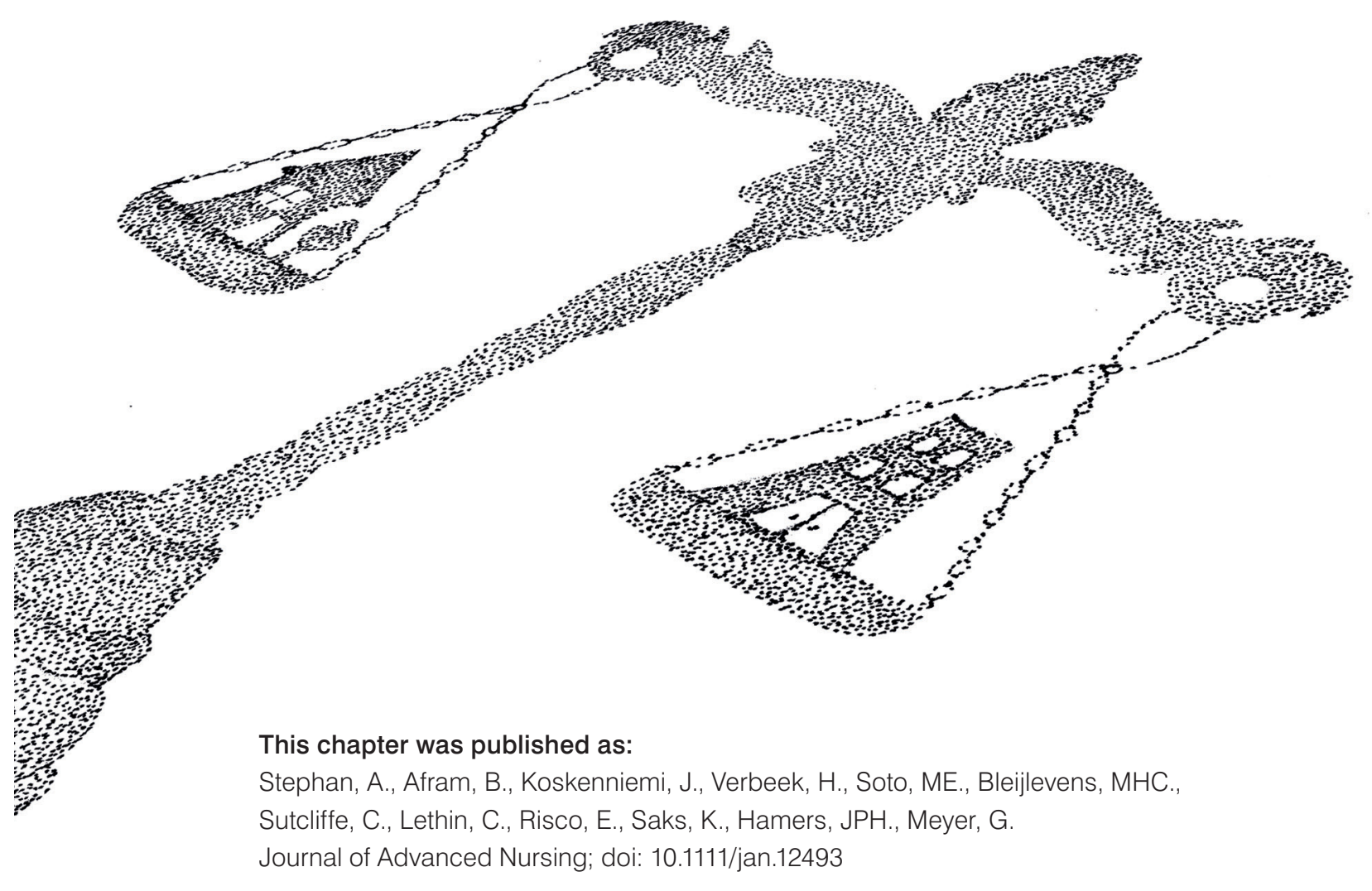




\section{Abstract}

Aims. To explore the perceptions of informal caregivers and healthcare professionals regarding potential reasons for the institutionalisation of older persons with dementia in eight European countries.

Background: Healthcare professionals may have an important role in facilitating informal caregivers' decision-making regarding institutionalisation. Little is known about the perceptions of informal caregivers and healthcare professionals prior to institutionalisation.

Design: Cross-sectional survey in eight European countries (November 2010-January 2012).

Methods: Healthcare professionals reported why they clinically judged persons with dementia at risk for institutionalisation. Informal caregivers reported potential reasons from their perspectives. Answers were openly coded and categorised. Variation between informal caregivers and healthcare professionals were investigated (agreement on at least one potential reason per case/proportion of maximum attainable kappa).

Results: Judgements of healthcare professionals and informal caregivers on 1160 persons with dementia were included. A total of 22 categories emerged. Approximately $90 \%$ of informal caregivers reported potential reasons. In $41 \%$ of the cases, informa caregivers and healthcare professionals agreed on at least one reason. Discrepancy was high for potential reasons related to caregiver burden. For the most frequent categories (caregiver burden, caregiver unable to provide care, neuropsychiatric symptoms, overall deterioration, care dependency) $24-41 \%$ of the attainable kappa was achieved. Differences between countries emerged indicating more favourable agreement in Finland, Sweden and Estonia and lowest agreement in England and Spain.

Conclusion: Agreement between healthcare professionals and informal caregivers on potential reasons for institutionalisation was low-to-moderate. Healthcare professionals are challenged to develop a detailed understanding of the perspectives and perceived burden of informal caregivers.

\section{Introduction}

Informal caregivers feel great responsibility towards their relative with dementia Hence, the decision to move to an institutional long-term care (ILTC) facility is a difficult one for informal caregivers, ${ }^{1}$ although the extent to which they are involved in the decision-making process varies. ${ }^{2}$ Healthcare professionals' (HCP) guidance in decision-making is perceived as supportive, and these professionals should offer careful reflections about relinquishing care and hence may reduce feelings of guilt 2-6 Little is known about whether informal caregivers and healthcare professionals experience the need for institutionalisation in the same way. ${ }^{3,4}$ It is unclear whethe these two groups perceive comparable reasons for potentially admitting the person with dementia to an ILTC facility.

\section{Background}

Healthcare systems throughout Europe support the concept of 'aging in place' 7 and therefore employ policies to enable older persons to live at home for as long as possible. ${ }^{8}$ As a consequence, long-term care is more often provided at home than in ILTC. ${ }^{9}$ The latter is usually considered by informal caregivers to be a last resort. ${ }^{10,1}$ However, relinquishing care to ILTC may become necessary at a certain point, for example in an advanced stage of dementia. A systematic review revealed an admission rate of persons with dementia to ILTC ranging from $20 \%$ in the first year after diagnosis up to $50 \%$ after five years..$^{12}$

The decision to permanently place a relative in an ILTC facility has been described as one of the most difficult decisions during the caregiving process ${ }^{10,13}$ and the final decision is often protracted. ${ }^{4}$ Informal caregivers of persons with dementia often feel unprepared and lonely when they have to make a decision about relinquishing care. ${ }^{2}$ They avoid making the decision on their own, seeking endorsement by relatives and HCP. ${ }^{14,15}$ Therefore, HCP may have an important role in initiating and facilitating the decision-making process. ${ }^{5}$ Support by HCP may be particularly relevant in legitimising and de-stigmatising the decision. 4, 10

After the decision has been made, informal caregivers may experience conflicted feelings of guilt, failure, sadness and relief and they often regret their decision.2, 13 Decisions made by HCP without the full participation of informal caregivers appea to increase negative feelings and induce new feelings such as treachery. ${ }^{3,4}$ However if the decision for admission is supported by all relevant persons involved in the caregiving, informal caregivers experience more balanced feelings. ${ }^{2}$, 3, 14 Hence decision-making may be considerably alleviated if HCP and informal caregivers share the same opinion. ${ }^{4}$ However, informal caregivers also appreciate different views ${ }^{1}$ and 
an exchange of perspectives may also contribute to enhanced decision-making. ${ }^{5}$ Thus, the decision-making process should be carefully initiated and supported by HCP and professional guidance is warranted. ${ }^{2-5,14,16}$

Few studies from Europe address the institutionalisation of persons with dementia especially prior to admission to ILTC. Varying healthcare structures throughout Europe may influence how the decision on institutionalisation is made. Institutionalisation rates considerably differ across Europe ${ }^{17}$ as do the reasons for institutionalisation reported by informal caregivers. ${ }^{18}$ Retrospective data collection was the most frequently employed design in exploring reasons for institutionalisation. . $^{18-20}$

Little is known about the perspectives of informal caregivers of persons with dementia immediately prior to institutionalisation. The aspects of caregiving that are perceived as potential reasons leading to ILTC admission are not well understood. Moreover, there is a lack of studies investigating the perspectives of both informal caregivers and HCP, respectively.

An increased understanding of the phase preceding the institutionalisation of persons with dementia is required. This knowledge is prerequisite for the development of strategies that could enable HCP to support the decision-making process of informal caregivers.

\section{The study}

\section{Aim}

This study aims to explore informal caregivers' and HCPs' perceptions of potential reasons for the institutionalisation of older persons with dementia (and the variation therein) in eight European countries.

\section{Design}

The study was nested into the European $7^{\text {th }}$ framework research project RightTimePlaceCare. ${ }^{21} \mathrm{~A}$ comprehensive cross-sectional survey was carried out in England (ENG), Estonia (EE), Finland (FI), France (FR), Germany (DE), the Netherlands (NL), Spain (ES) and Sweden (SE). Two types of dyads consisting of older persons with dementia and their main informal caregivers were interviewed using a comprehensive set of questions. The first group of persons with dementia was recently admitted to ILTC; the second group lived at home but was at risk for institutionalisation. Further details of the study protocol are published elsewhere. ${ }^{21}$ As part of the interview, the informal caregivers of the first group retrospectively reported on reasons for institutionalisation. The results have been reported recently. ${ }^{18}$ In the second group (the arm of the study reported here), informal caregivers described reasons that they perceived could potentially lead to institutionalisation

\section{Participants}

The participants of this study were the main informal caregivers of persons with dementia who lived at home (living in the same household or visiting the person with dementia at least twice per month). Inclusion criteria on the part of the persons with dementia were age $\geq 65$ years, diagnosed with dementia, Mini-Mental-State Examination ${ }^{22} \leq 24$ points, no primary psychiatric disease or Korsakoff syndrome and the receipt of any type of professional home care. ${ }^{21}$

For participation, a HCP involved in the care must have clinically judged the person with dementia to be at risk for admission to ILTC within the next 6 months (irrespective of whether an admission actually took place). The clinical judgment was performed without predefined categories and could have been provided by either single HCP or a professional team. Because we aimed to include the best-informed $\mathrm{HCP}$, informants belonged to different professional groups depending on the country-specific health and social care delivery structures.

\section{Data collection}

Data collection took place between November 2010 - January 2012. Organisations delivering care at home or community care services (or comparable healthcare services) were contacted in each country. HCP referred older persons with dementia and their informal caregivers who were willing to participate in the study. HCP were predominately registered nurses but also social workers or general practitioners They were working in different health/social care settings, e.g., nursing homecare organisations or day-care centres. In France, the participants were recruited by physicians in a large geriatric hospital. HCP were asked to specify why, according to their clinical judgment, the person with dementia was at risk of institutionalisation. The potential reasons from their perspectives were recorded prior to the interview with the informal caregiver.

Trained interviewers (holding at least a Bachelor's degree) performed structured face-to-face interviews with the informal caregivers. Information about quality of life, quality of care as well as social-, economical- and health-related aspects of the informa caregiver and the person with dementia were collected. ${ }^{21} \mathrm{~A}$ specific open-ended question directed at the informal caregivers was embedded in these interviews: In which situation do you think it might be necessary for the care recipient to move to an institutional long-term care facility? The interviewers were instructed to report the answers as verbatim as possible. Background characteristics of the informa caregivers (gender, age, relation to the person with dementia, employment status, living situation) were also assessed 


\section{Ethical considerations}

Each country obtained ethical approval from the responsible country-specific legal authorities. National regulations and standards were followed, as were the country-specific requirements regarding consent procedures. Informal caregivers gave written informed consent.

\section{Data analysis}

\section{Content analysis using an open coding procedure}

Answers in the native language were translated to English. To ensure consistency, translations were performed by one or two researchers per country. The reasons given by HCP and informal caregivers as to why admission to ILTC might be necessary were categorised applying an iterative coding procedure. First, two Dutch and two German researchers independently categorised the same 5\% from the material of both countries. An open coding approach was applied and the categories were developed from the data without preconceived concepts. ${ }^{23}$ Only minor deviations appeared and were discussed between the four researchers.

The two Dutch researchers consecutively applied the initial coding scheme to $20 \%$ of the complete material from all countries using a conventional content analysis. ${ }^{23}$ If necessary, a category was modified or further specified into sub-categories. The entire material was then categorised using the agreed final coding scheme. During the coding process, the categories were sorted into global themes. Modifications, the refining of definitions or merging of (sub-) categories were possible throughou the entire coding procedure. To ensure a clear and reproducible approach, coding decisions and rationales were documented in a manual describing all (sub-) categories. One of the two researchers categorised the dataset of a country to avoid deviations in categories due to country-specific translation styles or expressions. ${ }^{24}$

\section{Quantitative analysis}

We investigated whether informal caregivers of older persons with dementia and $\mathrm{HCP}$ in eight EU countries agree in their perceptions of potential reasons for institutionalisation. A stepwise analysis was performed. We explored: (1) whether the informal caregivers and HCP perceived a potential reason for institutionalisation in the same situation; (2) the agreement between the informal caregivers and HCP and examined whether both groups agree on at least one potential reason per case; (3) we further compared the most frequently perceived reasons and reported variation between informal caregivers and HCP; (4) in a last step, we explored the agreement between informal caregivers and HCP for the most frequently perceived reasons. Absolute positive agreement and Cohen's kappa ( $\mathrm{k}$ ) were calculated. ${ }^{25}$ Possible influence on kappa should be taken into account while judging its magnitude.26, 27 Bias between raters (the extent to which the raters disagree on the proportion of positive judgements) and the prevalence of categories may affect the interpretation of kappa values. ${ }^{26}$ In accordance with the literature-based recommendation, the maximum attainable kappa $\left(\mathrm{K}_{m}\right)$ was calculated to address these factors and to improve the interpretation. ${ }^{26,28}$ The $\mathrm{K}_{\mathrm{m}}$ is particularly useful for the comparison of different observers because it considers the extent to which the raters' ability to agree is constrained by pre-existing factors. ${ }^{26}$ The reference value is the proportion of the maximum possible agreement $\left(\mathrm{K} / \mathrm{K}_{\mathrm{m}}\right)$ that was actually achieved. According to a benchmark provided in a similar study, we considered a proportion of $\mathrm{k} / \mathrm{K}_{\mathrm{m}} \geq 0.6$ as an indicator of good agreement. ${ }^{28}$ Country differences were considered for all steps of the analysis. For significance testing of the sample differences between countries, $\mathrm{X}^{2}$ was used. Statistical analyses were performed with IBM Statistical Package for the Social Science for Windows (Version 20.0. Armonk, NY, USA: IBM Corp).

\section{Validity and reliability of the open coding procedure}

Before coding the entire material, two validation procedures were employed. First, the quality and reliability of translations from the native language to English were checked. Second, the final coding scheme was tested in terms of inter-coder agreement between the two Dutch researchers.

For the first procedure, one researcher from each country reviewed a randomly selected overview of $20 \%$ of the respective countries' data. The first $10 \%$ of the material contained the original answers in the native language and was translated to English once more. These new translations were then categorised by the two Dutch researchers and compared with the categorisation based on the first translations. An overall agreement of $83 \%$ was reached. Minor deviations in translations did not lead to meaningful category deviations. Another $10 \%$ of the respective country's materia contained the English translations and attributed categories. To assess the agreement credibility, the researchers of each country were asked whether they agreed with the assigned categories. ${ }^{29}$ The overall agreement was $94 \%$.

For the second procedure, the inter-coder agreement was assessed based on $20 \%$ of the data. The Jaccard coefficient was chosen because this measure takes only positive answers into account and discards agreement regarding the absence of categories. ${ }^{30}$ The Jaccard coefficient for both coders ranged from 0.86-0.94 indicating a high positive accordance between the coders. 


\section{Results}

\section{Sample characteristics}

A total of 1223 informal caregivers of older persons with dementia participated in the study. Due to missing or unclear answers from informal caregivers (which could no be coded) or missing clinical judgments of the HCP, 63 cases were excluded. Thus, 1160 complete cases were eligible for the analysis.

The characteristics of the informal caregivers are displayed in Table 1. The informal caregivers were predominantly women (ranging from 66\% in Sweden and England to $78 \%$ in Germany). There were more spouse caregivers in England, the Netherlands, Sweden and Spain, while more children were interviewed in Finland, France, Germany and Estonia. Approximately $30 \%$ of the sample in Estonia consisted of other types of caregivers (e.g., friends, siblings, children in law). The mean caregiver age was 64.4 years. The majority of caregivers lived together with the person with dementia (ranging from $46 \%$ in Finland to $87 \%$ in Spain).

\section{Results of the content analysis}

For both groups (HCP and informal caregivers) and in all countries, comparable categories were identified and a list of 22 categories was created. Each category and the total number of cases with assigned categories are displayed in Table 2. The categories were sorted into three global themes: perceived reasons related to older persons with dementia ( $n=14$ categories); perceived reasons related to informal caregivers ( $n=2$ categories); and perceived contextual reasons ( $n=6$ categories).

The majority of the categories were related to older persons with dementia. The theme 'caregiver-related reasons' covered 'caregiver burden' and 'caregiver unable to provide care'. 'Caregiver burden' described the type of answer that clearly referred to perceived burden or overstrain. 'Caregiver unable to provide care' referred to another type of answer that emphasised reasons such as the age or physical health status of the informal caregiver. Overall, perceived reasons related to older persons with dementia' and 'informal caregivers' were more frequently mentioned compared with perceived 'contextual reasons'

\section{Results of the quantitative analysis}

\section{1) Potential reasons for institutionalisation}

The vast majority of informal caregivers were able to verbalise at least one potentia reason for the institutionalisation of persons with dementia who had been judged to be at risk for institutionalisation by a HCP. Only $6.6 \%$ of the informal caregivers (76/1160) did not mention a potential reason and 45 of them stated that they had never thought about institutionalisation and could therefore not answer the question. Eighteen caregivers clearly excluded institutional care as a future option or did not want to think

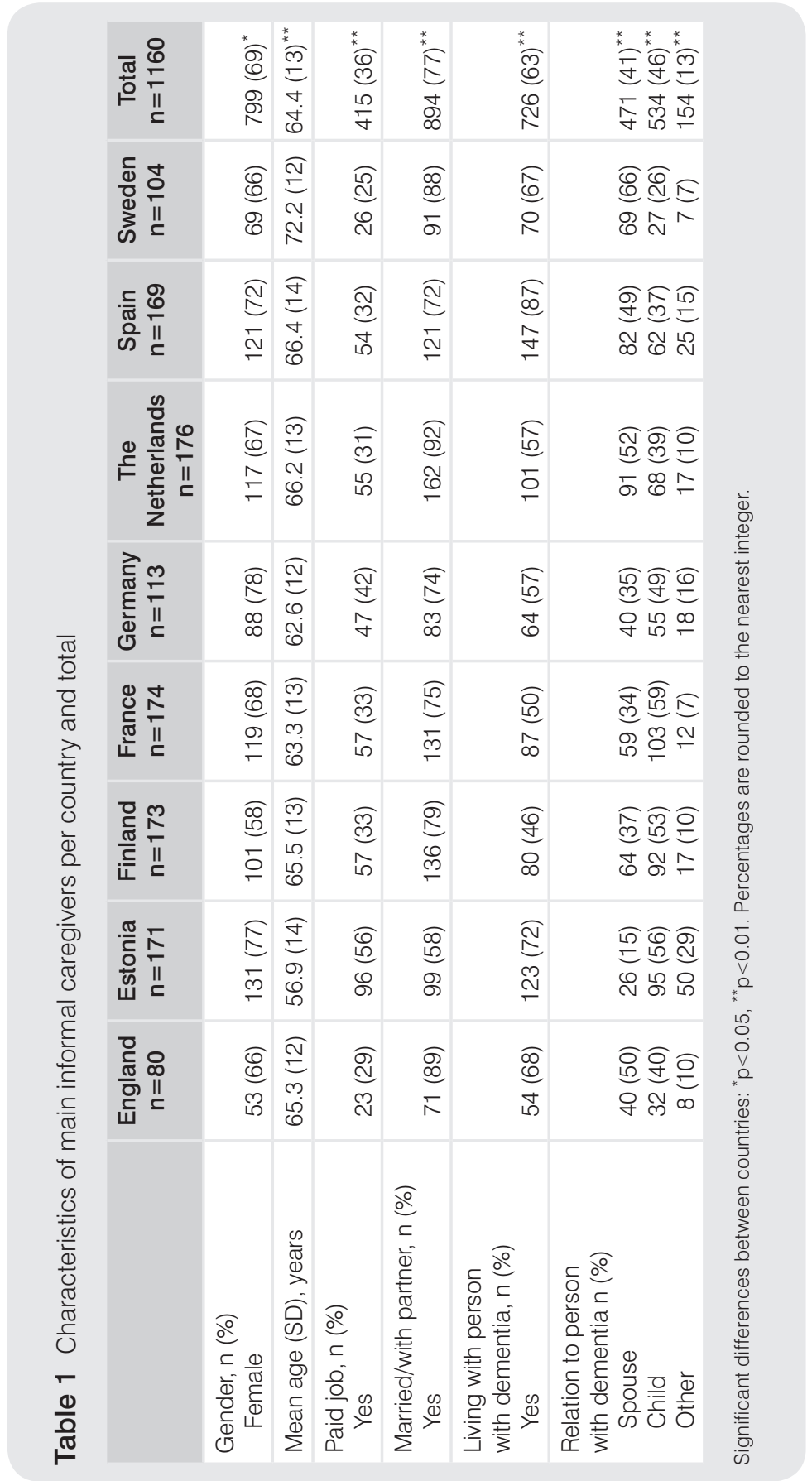




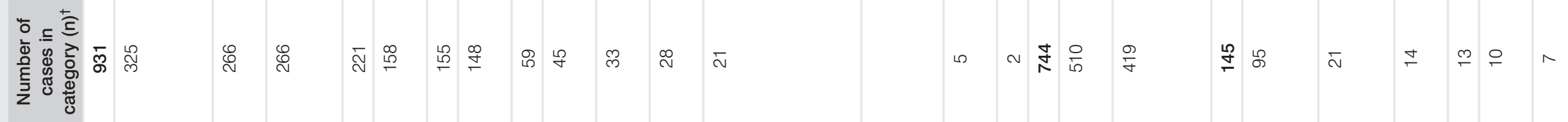

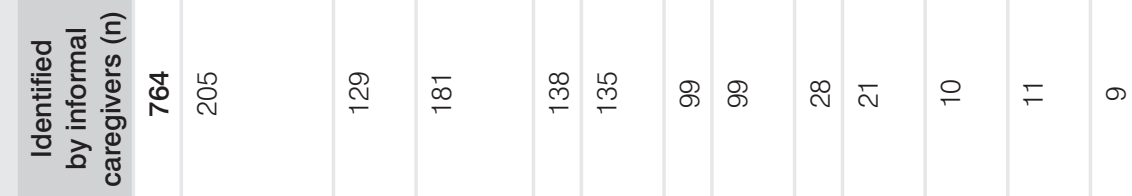

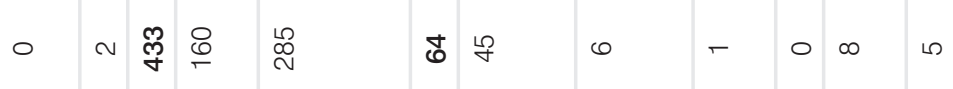

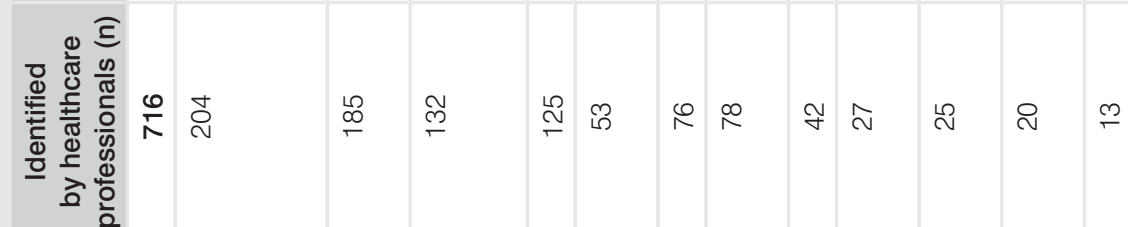

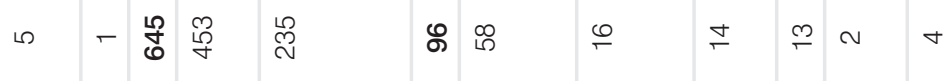

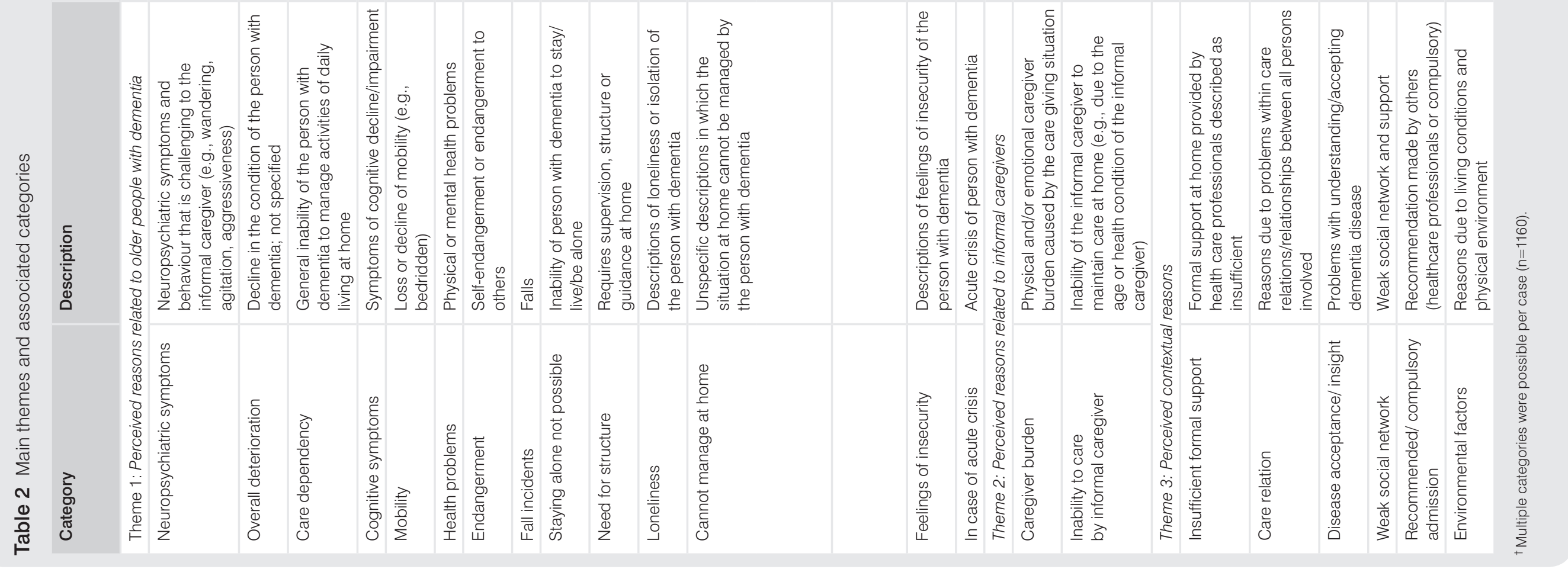


about it at that moment. Eight informal caregivers stated explicitly that there was currently no need for admission and five reported that the person with dementia was already registered on a waiting list but did not specify the reason why. Approximately $25 \%(43 / 174)$ of the informal caregivers in France did not answer this question, whereas the percentages ranged from 8\% (13/169) in Spain to 0\% in Estonia and Sweden

Hence, informal caregivers reported at least one potential reason for institutionalisation in approximately 93\% (1084/1160) of the cases. Approximately 57\% (666/1160) of the informal caregivers reported a single potential reason, 26\% (306/1160) reported two and 10\% (112/1160) reported three or more potential reasons. HCP specified their clinical judgments by reporting one potential reason in 58\% (667/1160), two potentia reasons in 28\% (332/1160) and three or more potential reasons in 14\% (161/1160) of the cases

\section{2) Agreement on case leve}

Informal caregivers and HCP agreed on at least one perceived reason in $41 \%$ (479/1160) of all cases. In the Netherlands and France, the level of agreement was comparable with the average (37\% and $44 \%$, respectively). The agreement between informal caregivers and HCP on at least one perceived reason was slightly higher in Germany (47\%), Sweden (50\%), Estonia (52\%) and Finland (53\%), while it was lower in England (34\%) and considerably lower in Spain (15\%).

\section{3) Most frequently perceived reason}

Overall, informal caregivers in particular (but also HCP) more often mentioned 'potential reasons related to persons with dementia than related to informal caregivers' (Table 2). The most frequently perceived potential reasons for institutionalisation per case were related to the categories 'caregiver burden', 'caregiver unable to provide care' and 'neuropsychiatric symptoms', 'overall deterioration' and 'general care dependency' of the persons with dementia. Differences between the judgments of informal caregivers and HCP emerged, which were most striking for the category 'caregiver burden'. HCP assessed 'caregiver burden' to be a potential reason for admission to an ILTC facility in approximately $39 \%$ of the cases, whereas informal caregivers mentioned their own burden in only $14 \%$ of the cases. In all countries, 'caregiver burden' was more frequently mentioned by HCP than by informa caregivers. The lowest difference in this was shown for Estonia (28\% vs. 22\%). 'Caregiver burden' was twice to three-fold as frequently reported by HCP than by informal caregivers in France (20\% vs. 10\%), Sweden (47\% vs. 22\%), England (34\% vs. $15 \%$ ), the Netherlands ( $45 \%$ vs. $18 \%$ ) and Finland (26\% vs. $9 \%)$. This difference between informal caregivers and HCP was larger in Germany (43\% vs. $9 \%$ ); the most distinct difference was revealed in Spain: HCP assessed 'caregiver burden 'in 72\% of the cases, but only $10 \%$ of the informal caregivers mentioned their own 'burden' as a potential reason for relinquishing care to ILTC.

'Caregiver unable to provide care' was more frequently reported by informa caregivers than HCP in England (30\% vs. 10\%), Spain (32\% vs. 15\%), Finland (26\% vs. $13 \%$ ), Sweden ( $33 \%$ vs. $24 \%$ ) and Estonia ( $29 \%$ vs. $22 \%)$. The distribution was reversed in France (6\% vs. 27\%) and nearly equal in Germany ( $40 \%$ vs. $35 \%$ ) and the Netherlands (12\% vs. $17 \%$ )

Deviations between the informal caregivers and HCP regarding the perceived eason related to the older persons with dementia-'neuropsychiatric symptoms' overall deterioration and general care dependency'-were marginal and ranged from $11-18 \%$ of the cases.

4) Level of agreement on the most frequently perceived reasons

The overall agreement between the informal caregivers and HCP was notably low (Table 3). The absolute positive agreement for the most frequently cited reasons ranged from $18 \%$ to $26 \%$. The proportion of the maximum possible agreement $\left(\mathrm{K} / \mathrm{K}_{\mathrm{m}}\right)$ ranged from $0.24-0.42$, indicating that only $24 \%$ to $41 \%$ of the maximum possible agreement was reached per category. However, in Finland, Estonia, France and Sweden, the proportion of the maximum possible agreement tended to be better in comparison with the remaining countries. Finnish informal caregivers and HCP even reached good agreement with regard to 'caregiver-related reasons' $\left(\mathrm{K} / \mathrm{K}_{\mathrm{m}}=0.71\right.$ and 0.64). The lowest proportions of the maximum possible agreement were achieved in Spain ( $\left.\mathrm{K} / \mathrm{K}_{\mathrm{m}} 0.03-0.34\right)$ and England $\left(\mathrm{K} / \mathrm{K}_{\mathrm{m}} 0.06 .-0.12\right)$.

\section{Discussion}

We analysed the judgements of HCP and informal caregivers regarding 1160 older persons with dementia from eight European countries. The vast majority of respective informal caregivers were able to report reasons for a potential admission. Only approximately $7 \%$ of the informal caregivers did not answer the question or even excluded ILTC as a future care option. This figure was considerably higher in France (25\%) compared with the remaining countries (0-8\%).

In $41 \%$ of the cases, informal caregivers and $\mathrm{HCP}$ agreed on at least one perceived reason. The agreement was slightly higher in Germany, Sweden, Estonia and Finland (approximately 50\%) but clearly lower in England and Spain (34\% and $15 \%$ ). Overall, the most frequently perceived potential reasons belonged to the categories 'caregiver burden' and 'caregiver unable to provide care' and to the categories related to the person with dementia: 'neuropsychiatric symptoms', 'overall deterioration' and 'general care dependency'. The variation between the perceptions 

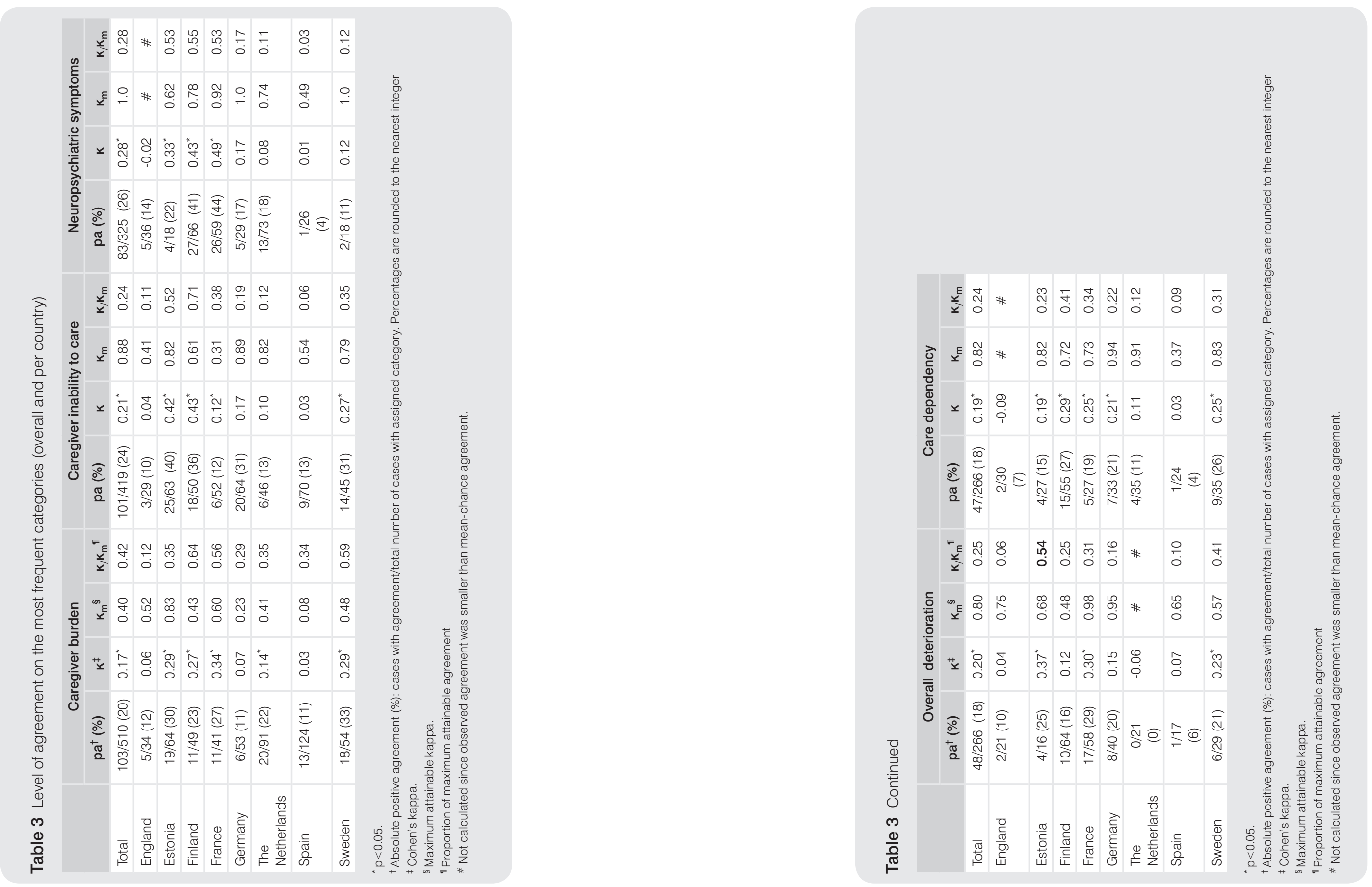
of informal caregivers and HCP were most striking for potential reasons related to the category 'caregiver burden'. Potential reasons in this category were clearly more frequently mentioned by HCP than by informal caregivers in all countries but especially in Spain, Germany and the Netherlands. The proportion of maximum possible agreement in reasons related to the most frequent categories was low to moderate. Slightly better agreement was revealed in Finland, Estonia, France and Sweden and the lowest proportions of maximum attainable agreement were measured in Spain and England.

To the best of our knowledge, this is the first study investigating the perceptions of informal caregivers of older persons with dementia and HCP on potential reasons for admission to ILTC and their agreement therein

Notably, informal caregivers more frequently reported 'potential reasons related to persons with dementia' than potential reasons related to their own. This finding is in accordance with the results by Afram et al. (2013) investigating the post-admission phase in the RightTimePlaceCare study and retrospectively exploring reasons for institutionalisation. The diversity of the derived categories describing the 'potential reason related to the persons with dementia' underlines the complexity of symptoms and conditions. Potential reasons reported by informal caregivers and HCP correspond with reported risk factors for institutionalisation and the revealed aspects were not surprising. ${ }^{12,1}$ 19, 3

Remarkably, the majority of informal caregivers in all countries were able to answer the question about possible admission. Hence, our findings suggest that initiating discussions about ILTC appears to be feasible, although informal caregivers perceived this question as difficult and requiring some time to answer; the interviewers occasionally had to ask a second time. It remains open whether informal caregivers perceived the need for admission to ILTC to be as urgent as the HCP (within 6 months), which may have contributed to the low agreement.

The high proportion of French informal caregivers who failed to provide an answer to the question may be due to a different recruiting procedure rather than to cultural differences. Participants in France were approached in a geriatric hospita and recruited by physicians, whereas other countries recruited participants via community care services.

Our study revealed distinct variation between the reported potential reasons of informal caregivers and HCP and only low to moderate agreement across countries, Thus, our results are contradictory to recent findings from a study investigating the perception of caregiving needs for persons with dementia; good agreement between the informal caregivers and HCP was reported. ${ }^{28}$ However, compared with Miranda-Castillo et al., we did not use a structured questionnaire and the assessment of caregiving needs may be easier than an assessment of potential reasons leading to a future admission to ILTC
Our study showed variation between the countries. Informal caregivers and HCP in Finland, Estonia and Sweden consistently revealed more agreement in al measures, while participants in England and in Spain consistently revealed the lowest agreement. These differences could be partially influenced by different long-term care structures. ${ }^{32,33}$ Some countries have a greater availability of structured support, which could result in continuous and closer contact with informal caregivers and persons with dementia. For instance, memory nurses are in place in Finland and act as key contact persons for the persons with dementia and their informal caregivers ${ }^{34}$, ${ }^{35}$ Furthermore, the obligations of families differ across countries. In Estonia, families are legally obliged to care for their relative with dementia. ${ }^{34}$ Therefore, access to an ILTC facility could be limited and only allowed in certain circumstances. Surprisingly, low agreement between informal caregivers and HCP was revealed in England where community mental health teams are employed and offer a range of interventions in a multi-disciplinary team. ${ }^{36,37} \mathrm{~A}$ multi-disciplinary and holistic approach incorporating the care of both the people with dementia and their informal caregivers may provide $\mathrm{HCP}$ with a wider perspective in identifying the perceived needs of both parties.

The variation in the perceptions of informal caregivers and HCP was particularly high for the category caregiver burden. Overall and in all countries, 'caregiver burden' was more frequently mentioned by HCP than informal caregivers. Former studies suggest that 'caregiver burden' is a risk factor for the institutionalisation of persons with dementia ${ }^{12,}{ }^{31}$ and early supportive interventions have been requested. ${ }^{38}$ However, in our study, only 9\% (Finland and Germany) - 22\% (Estonia and Sweden) of informal caregivers described their own burden; this result is in accordance with Afram et al. ${ }^{18}$. Informal caregivers may not perceive a burden or simply not name their situation burdensome, even if burden was identified from a professiona perspective. The different perceptions regarding burden could also be explained by the emotion-focused coping style of informal caregivers, in particular via avoidance or denial. ${ }^{39,40}$ Our results suggest that informal caregivers may disregard thei personal needs and feelings of burden and solely focus on the person with dementia for which they are caring.

The perceptions of 'caregiver burden' varied considerably across countries. The discrepancy between informal caregivers and HCP was most striking in Spain. Socia and cultural beliefs appear to strongly impact how informal caregivers perceive caregiving and cope with its associated burdens. ${ }^{41-43}$ In countries with a strong cultural belief that families have to care for a relative with dementia (such as Spain), a disregard for their own burden may be pronounced. Interestingly, Spanish informal caregivers retrospectively reported slightly more reasons for institutionalisation that were related to themselves, including their own burden. ${ }^{18}$

Our results indicate that informal caregivers and HCP perceive or prioritise different potential reasons for institutionalisation. These findings should be highlighted, keeping in 
mind that HCP referred only those persons with dementia who were judged to be at risk for institutionalisation within the next 6 months. Hence, it should be assumed that $\mathrm{HCP}$ reported potential reasons that are important in their clinical judgements. Based on their judgements, HCP most likely propose or initiate supportive interventions for informal caregivers and persons with dementia. However, it is obvious that informa caregivers will likely not seek or accept support as long as they do not perceive their own burden as a problem or are not prepared to speak about it. With regard to this issue, our findings could provide further insight into why informal caregivers do not use professional support. ${ }^{44,45}$ In light of the discrepancy between the perspectives of $\mathrm{HCP}$ and informal caregivers, the responsibility of HCP in offering need-tailored counselling and support should be stressed.

\section{Limitations and strengths}

Some limitations of our study should be considered. First, no descriptive information about the HCP was collected. Different types of HCP contributed to the clinica judgements; registered nurses were primarily used, but (depending on the country) social workers and physicians also contributed. Thus, we are not able to determine whether the professional background of the HCP influenced the results. Furthermore we did not collect any retrospective data about the duration or intensity of the care relationship between informal caregivers and HCP, nor did we collect prospective data over time. Therefore, whether the informal caregivers and HCP already discussed (or would discuss) the possibility of relinquishing care remains unknown. Nevertheless, we can assume that realistic results were generated by choosing a cross-sectiona design and relying on the best informed HCP per country, especially because it has been shown that different types of HCP are likely involved in the decision-making process. $^{5}$

Sample size deviated between countries with low participant numbers in England, Sweden and Germany. This could have influenced the kappa values as larger sample sizes are likely to yield more reliable results. ${ }^{26}$ Data were collected in defined regions of the respective countries as opposed to nationwide. Thus, our findings should be interpreted cautiously because they do not necessarily represent the entire country.

Answers from informal caregivers and HCP were not recorded and could have therefore been influenced by the interviewers' documentation. Language transfer bias cannot be ruled out because the answers collected across countries had to be translated into English. However, to ensure the quality of the translation process and the open coding procedure, a strict approach was employed with reliability checks and a validation procedure

\section{Conclusion}

Informal caregivers and HCP differ in their perceptions of potential reasons for the placement of older persons with dementia in an ILTC facility, particularly with regard to caregiver burden. Our findings are relevant because HCP have a decisive role in making decisions regarding institutionalisation. Our results may be integrated into the development of appropriate counselling strategies. Good communication skills are required to carefully initiate open discussions about the institutionalisation of persons with dementia. HCP should be conscious of their important function as counsellor for informal caregivers who offer valuable reflections of the current care situation but also provide different perspectives about future care options and timing. They can inform the decisions of informal caregivers and should avoid urging them to make unwanted decisions. Further research is required to investigate the discrepancies between the perceptions of informal caregivers and HCP; this research should focus in particular on the perception of burden. Further studies should consider social and cultural differences as well as different health and social care structures. 


\section{References}

1. Livingston G, Leavey G, Manela M, Livingston D, Rait G, Sampson E, et al. Making decisions for people with dementia who lack capacity: qualitative study of family carers in UK. British Medical Journal 2010;341.

2. Graneheim UH, Johansson A, Lindgren BM. Family caregivers' experiences of relinquishing the care of a person with dementia to a nursing home: insights from a meta-ethnographic study. Scandinavian Journal of Caring Sciences. 2014;28:215-24.

3. Lundh U, Sandberg J, Nolan M. 'I don't have any other choice': spouses' experiences of placing a partner in a care home for older people in Sweden. Journal of Advanced Nursing 2000:32:1178-86.

Caron CD, Ducharme F. Griffith J. Deciding on institutionalization for a relative with dementia: The most difficult decision for caregivers. Canadian Journal on Aging-Revue Canadienne Du Viellissement. 2006:25:193-205.

5. Couture M, Ducharme F, Lamontagne J. The Role of Health care Professionals in the Decision-Making Process of Family Caregivers Regarding Placement of a Cognitively Impaired Elderly Relative. Home Health Care Management and Practice. 2012:31:197-218.

6. Ducharme F, Couture M, Lamontagne J. Decision-making process of family caregivers regarding placement of a cognitively impaired elderly relative. Home Health Care Services Quarterly. 2012;31:197-218. OECD. Caring for Frail Elderly People: New Directions in Care, Paris: Organisation for Economic Co-operation and Development (OECD), 1994

8. Moise P, Schwarzinger M, Um M. Dementia Care in 9 OECD Countries: A comparative analysis. OECD Health Working Papers. 2004

9. Damiani G, Farelli V, Anselmi A, Sicuro L, Solipaca A, Burgio A, et al. Patterns of Long Term Care in 29 European countries: evidence from an exploratory study. BMC Health Services Research. 2011;11.

10. Ryan A. Transitions in care: Family carers' experiences of nursing home placement. Nursing Times Research. 2002,7.324-34.

11. Ryan AA, Scullion HF. Nursing home placement: an exploration of the experiences of family carers. Jounal of Advanced Nursing. 2000;32:1187-95

12. Luppa M, Luck T, Braehler E, Koenig HH, Riedel-Heller SG. Prediction of institutionalisation in dementia A systematic review. Dementia and Geriatric Cognitive Disorders. 2008;26:65-78.

13. Sury L, Burns K, Brodaty H. Moving in: adjustment of people living with dementia going into a nursing home and their families. International psychogeriatrics / IPA. 2013;25:867-76.

14. Butcher HK, Holkup PA, Park M, Maas M. Thematic analysis of the experience of making a decision to place a family member with Alzheimer's disease in a special care unit. Research in Nursing and Healt 2001;24:470-80.

15. Strang VR, Koop PM, Dupuis-Blanchard S, Nordstrom M, Thompson B. Family caregivers and transition to long-term care. Clinical Nursing Research. 2006;15:27-45.

16. Caron CD, Bowers BJ. Deciding whether to continue, share, or relinquish caregiving: caregiver views. Qualitative Health Research. 2003;13:1252-71

17. Vellas B, Hausner L, Frolich L, Cantet C, Gardette V, Reynish E, et al. Progression of Alzhelmer Disease in Europe: Data from the European ICTUS Study. Current Alzheimer Research. 2012;9:902-12.

18. Afram B, Stephan A, Verbeek H, Blejlevens MH, Suhonen R, Sutcliffe C, et al. Reasons for Institutionaization of People With Dementia: Informal Caregiver Reports From 8 European Countries. Journal of the American Medical Directors Association. 2014;15:108-16.

19. Buhr GT, Kuchibhatla M, Clipp EC. Caregivers' reasons for nursing home placement: Clues for improving discussions with families prior to the transition. Gerontologist. 2006;46:52-61.

20. Thomas P, Ingrand P, Lalloue F, Hazifâ Thomas C, Billon R, ViÄ@oban F, et al. Reasons of informa caregivers for institutionalising dementia patients previously living at home: the Pixel study. Internationa Journal of Geriatric Psychiatry. 2004;19:127-35.

21. Verbeek H, Meyer G, Leino-Kilpi H, Zabalegui A, Hallberg IR, Saks K, et al. A European study investigating patterns of transition from home care towards institutional dementia care: the protocol of a Right TimePlaceCare study. BMC Public Health. 2012;12:68.
22. Molloy DW, Alemayehu E, Roberts R. Reliability of a Standardized Mini-Mental State Examination traditional Mini-Mental State Examination. American Journal of Psychiatry. 1991;148:102-5

23. Hsieh HF. Shannon SE. Three approaches to qualitative content analysis. Qualitative Health Research. 2005; $15: 1277-88$.

24. Polit DF, Beck CT Nursing research: Generating and assessing evidence for nursing practice 9th ed: Lippincott Williams \& Wilkins, 2011.

25. Cohen J.A coefficient of agreement for nominal scales. Educational and Psychological Measurement 1960;20:37-46

26. Sim J, Wright CC. The kappa statistic in reliability studies: Use, interpretation, and sample size requirements. Physical Therapy. 2005;85:257-68.

27. Vach W. The dependence of Cohen's kappa on the prevalence does not matter. Journal of Clinical Epidemiology. 2005;58:655-61.

28. Miranda-Castillo C, Woods B. Orrell M. The needs of people with dementia living at home from user caregiver and professional perspectives: a cross-sectional survey. BMC Health Services Research 2013:13:43

29. Graneheim UH, Lundman B. Qualitative content analysis in nursing research: concepts, procedures and measures to achieve trustworthiness. Nurse Education Today. 2004:24:105-12

30. Popping R. Traces of agreement: On the DOT-product as a coefficient of agreement. Quality and Quantity. 1983;17:1-18

31. Gaugler JE, Yu F, Krichbaum K, Wyman JF. Predictors of Nursing Home Admission for Persons with Dementia. Medical Care. 2009;47:191-8.

32. Prince M. Prina M. Guerchet M. World Alzheimer Report 2013: Journey of Caring: An Analysis of Long-Term Care for Dementia. London: Alzheimer's Disease International. 2013.

33. Alzheimer 's Disease International. World Alzheimer Report 2009. London: Alzheimer 's Disease International; 2009

34. Alzheimer Europe Dementia in Europe Yearbook 2007 Social Support Systems in Europe 'A Europea Survey'. 2007.

35. The National Memory Programme. Creating a 'Memory Friendly' Finland. Helsinki Ministry of Social Affairs and Health; 2013

36. Tucker S, Baldwin R, Hughes J, Benbow SM, Barker A, Burns A, et al. Integrating mental health services for older people in England-from rhetoric to reality. Journal of Interprofessional Care. 2009;23:341-54.

37. Royal College of Psychiatrists and Royal College of Physicians. Raising the Standard: Specialis Services for Older People with Mental Illness. Report of the Faculty of Old Age Psychiatry. London; 2006 B. Miller EA, Rosenheck RA, Schneider LS. Caregiver burden, health utilities, and institutional service us in Alzheimer's disease. International Journal of Geriatric Psychiatry. 2012;27:382-93.

39. Kneebone II, Martin PR. Coping and caregivers of people with dementia. British Journal of Health Psychology. 2003;8:1-17.

40. Sun F, Kosberg JI, Kaufman AV, Leeper JD. Coping strategies and caregiving outcomes among rura dementia caregivers. Journal of Gerontological Social Work. 2010;53:547-67.

4. Janevic M. Racial, ethnic, and cultural differences in the dementia caregiving experience. The Gerontologist. 2001;41:334.

42. Etters L, Goodall D, Harrison BE. Caregiver burden among dementia patient caregivers: A review of the literature. Journal of the American Academy of Nurse Practitioners. 2008;20:423-8.

3. Corcoran MA. Caregiving styles: A cognitive and behavioral typology associated with dementia family caregiving. The Gerontologist. 2011:gnro02.

44. Brodaty H, Thomson C, Thompson C, Fine M. Why caregivers of people with dementia and memory loss don't use services. International Journal of Geriatric Psychiatry. 2005;20:537-46.

45. Robinson KM, Buckwalter KC, Reed D. Predictors of use of services among dementia caregivers. Western Journal of Nursing Research. 2005;27:126-40. 


\section{4}

Predicting Institutional Long-Term Care Admission in Dementia: A Mixed-Methods Study of Informal Caregivers' Reports

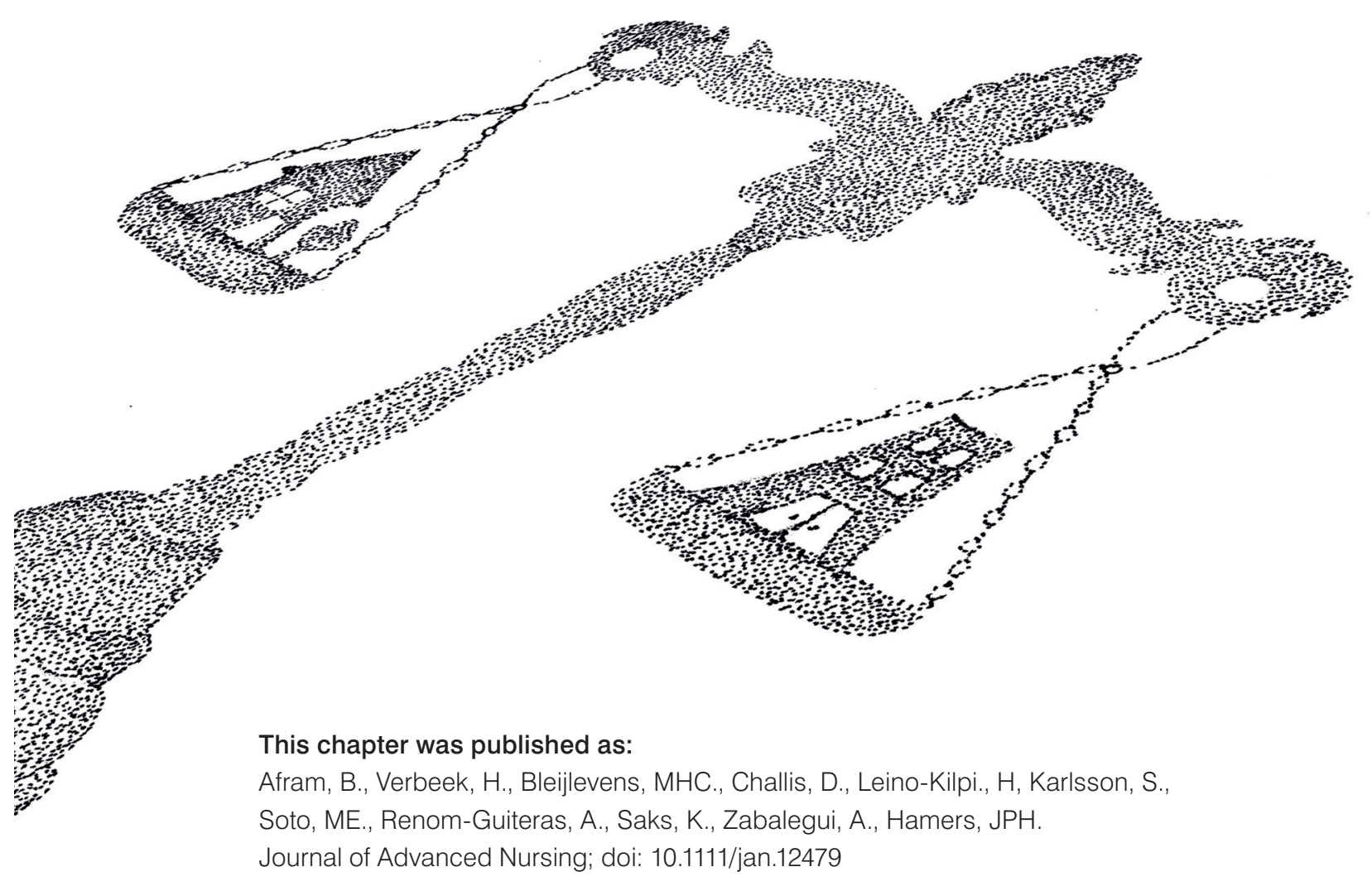




\section{Abstract}

Aim: To investigate agreement between: 1) expected- and actual reasons for admission of people with dementia according to informal caregivers; 2) scores on measurementinstruments prior to admission and actual reasons for admission according to informal caregivers.

Background: Timely admission of people with dementia is a crucial issue. Information is highly warranted on whether informal caregivers are capable of prior identification of causes of admission and, can thus be considered a reliable prospective source on causes of admission.

Design: A cohort study among informal caregivers of people with dementia who made a transition to institutional long-term care.

Methods: Qualitative data on expected and actual reasons for admission were collected via open-ended questions at baseline and follow-up. Furthermore, at baseline, data were collected using measurement-instruments to measure pre-admission characteristics. Interviews took place between November 2010 and April 2012. After categorizing the answers, the agreement between expected and actual reasons was calculated. Furthermore, bivariate associations were calculated between actual reasons for admission and scores on corresponding measurement-instruments.

Results/Findings: For most informal caregivers, there was agreement between their statements on expected- and actual reason for admission. A third of the caregivers showed no conformity. Bivariate associations showed that there is also agreement between the actual reasons for admission and scores on corresponding measurement-instruments.

Conclusion: Informal caregivers can be considered reliable sources of information regarding what causes the admission of a person with dementia. Professional care should anticipate informal caregivers' statements and collaborate with them to strive for timely and appropriate admission.

\section{Introduction}

Timely and appropriate admission of people with dementia (PwD) to institutional long-term care (ILTC) is of growing importance, with an ever increasing dementia population. ${ }^{1}$ Timely admission reflects the best possible care in the most appropriate setting, considering the benefits for both the person with dementia and his/her informal caregivers. Most countries, across Europe and other continents, subscribe to a policy of 'aging in place', aiming to postpone admission to ILTC for older people as long as possible. ${ }^{2}$ Though amiable as it is to support people in their own home as long as possible, the question of appropriate and timely admission is not explicitly raised in these policies. Especially in PwD, the care-needs at some point will surpass the possibilities of home-care, resulting in a need for ILTC. ${ }^{3,4}$ In order to provide the right care in the right setting at the appropriate time, it is valuable to know why admission to ILTC occurs from the perspective of those most closely involved in the transition process, the informal caregivers.

Informal caregivers are closely involved in the care of PwD, and should ideally be able to indicate what, in their individual situation, could be reasons leading to admission. Having an indication beforehand of what might determine admission to ILTC for PwD at the individual case-level could permit anticipation of these reasons and therefore increase the likelihood of timely admission. Anticipating these reasons might enable the best possible care to be delivered at home without overstraining informal care, and preventing certain crisis-situations. In order to achieve this, guidance and support of home-care professionals, such as community-based nurses or casemanagers, are essential.

\section{Background}

Much valuable evidence is already available regarding predictors for the admission of PWD to ILTC. ${ }^{5-7}$ Until now most of these studies have investigated predictors for admission retrospectively, after the event, and only general statements can be made about the characteristics of the group that was admitted compared to the group that was not. These studies indicate that, for example, overall, higher caregiver burden predicts admission. ${ }^{6-8}$ Similar effects are attributed to health and cognitive problems, higher care dependency and presence of depressive symptoms in the person with dementia. ${ }^{6,7,9,10}$ While these studies on predictors for admission provide us with valuable information, their design does not permit consideration of the reasons for admission at the individual case-level to verify whether these predictors were the actual reasons for admission according to those central to this process. 
Indications from prior research suggest that different factors might be identified when analysing informal caregiver reports of reasons for admission compared to statistical analyses on measurement instruments defining predictors for admission. ${ }^{11,12}$ In a US study, comparing caregiver reports to regression results, depressive symptoms were a significant predictor for admission according to the regression analysis However, depression was not stated in the caregiver reports of that same study. ${ }^{12}$

It is important to know whether informal caregivers are able to identify in advance what will cause the admission of PwD, and hence whether they can be considered a reliable source on cause of admission. If so, care and guidance for both PwD and informal caregivers can be tailored more specifically to each individual case. Considering there is a discrepancy between informal caregiver reports and statistical predictors of admission, further investigation of reasons for admission from the informal caregiver's perspective might be more appropriate. Informal caregivers can, prior to admission, be asked directly what they expect might be the reasons for admission; these reports can then be compared to their reports of the actual reasons for admission. Anothe approach is to investigate in a more indirect way whether informal caregivers can indicate what will cause admission. To achieve this, indicators from validated measurement instruments prior to admission can be compared with subsequen reports of informal caregivers on the actual reason for admission. This provides a measure of agreement between caregiver reports and measurement instruments.

\section{The study}

\section{Aims}

The aims of this study were to: 1) Investigate the correspondence between expected reasons for admission to ILTC and actual reasons for admission, both as stated by informal caregivers; 2) Analyse whether scores on measurement-instruments prior to admission are in accordance with actual reasons for admission as stated by informa caregivers. This information will strengthen our understanding of reasons for the admission of PwD from informal caregivers' perspective and provide insight on whether informal caregivers are a reliable source on what might cause admission.

\section{Design}

A cohort study was conducted among dyads of informal caregivers and PwD who made a transition from home-care to ILTC during the course of the study (at most three months after baseline). This study, which was embedded in the RightTimePlaceCare (RTPC) project (grant agreement 242153), ${ }^{13}$ was conducted in the following European countries: England, Estonia, Finland, France, Germany, the Netherlands, Spain and Sweden. Multiple countries were involved in the study, considering that time to admission of PwD is a widespread issue across Europe. A comparison between the countries was not an aim for this particular study, but a within-person comparison.

\section{Sample}

Participants were recruited from home-care organisations. ${ }^{13}$ PwD had to: 1) have a formal diagnosis of dementia in their medical record as diagnosed by an expert; 2) have a Standardised Mini-Mental State Examination (S-MMSE) score of 24 or less; 3) be considered at risk for institutionalization according to a professional caregive (e.g., registered nurse, general practitioner), meaning that professional caregivers had to indicate whether there was a substantial possibility of institutionalisation of the PwD within six months; 4) have an informal caregiver present who visited at leas twice a month and 5) have made a transition from home-care towards ILTC within three months after the baseline measurement. Informal caregivers were eligible if they provided care for a person with dementia, and visited that person at least twice a month.

\section{Data collection}

Data were collected by means of two comprehensive, structured, face-to-face interviews, comprising both open ended questions as well as standardised measurement instruments. Interviews took place between November 2010 and Apri 2012, with three months between baseline and follow-up. Data on cognitive status were collected from the person with dementia. All other information was collected from the informal caregiver. The interviews were conducted by trained interviewers who were either professionals or students in healthcare or social-care with at least a Bachelor's degree. ${ }^{3}$

\section{Open-ended questions}

The reasons for institutionalisation were inventoried by means of open ended questions. At baseline informal caregivers were asked about the possibility of transition to ILTC. Informal caregivers were asked, "In what situation do you think it might be necessary for the care recipient to move to an institutional nursing care acility?" i.e., the expected reasons for admission. Caregivers who at baseline indicated that they had never thought about admission, and that they could not imagine a situation in which admission would occur, were nonetheless prompted to consider it and try to give an answer. At follow-up, when PwD were actually admitted to ILTC, informal caregivers were asked to state what, in their opinion, the actual reason for institutionalisation was. Answers were written down by the interviewers in the native tongue as completely as possible during the interviews, and afterwards, were translated to English into a central database. 


\section{Measurement-instruments}

Characteristics prior to admission were measured at baseline by means of standard scales using the following instruments:

\section{Characteristics related to PwD}

The S-MMSE was used to measure cognitive status. ${ }^{14}$, 15 This 30 -item scale has scores ranging from 0-30 with higher scores indicating better cognitive status. The S-MMSE shows better reliability than the non-standardised MMSE ${ }^{15}$

Neuropsychiatric symptoms were assessed using the Neuropsychiatric Inventory Questionnaire (NPI-Q). ${ }^{16}$ This instrument consists of two 12-item subscales indicating the severity of the present symptoms (range 0-36) and the distress these symptoms cause the informal caregiver (range 0-60). Higher scores on the subscales indicate the presence of more (severe) behavioural disturbances and higher experienced distress by the informal caregiver. Test-retest correlations of 0.80 and 0.94 , respectively, are reported for the NPI-Q. ${ }^{16}$

The functional status of the PwD was measured using the Katz index of independence in activities of daily living. ${ }^{17}$ This 6-item scale has a range of 0-6, with higher scores indicating higher independence in activities of daily living. Cronbach's alpha's of 0.87-0.94 are reported for the Katz index. ${ }^{18}$

Comorbidity of the PwD was assessed with the Charlson Comorbidity Index $(\mathrm{CCl}),{ }^{19}$ ranging from 0-37, with higher scores indicating the presence of more (severe) comorbidities. Test re-test correlations of 0.91 are reported for the CCl. ${ }^{20}$

\section{Characteristics related to the informal caregiver}

Caregiver burden was measured by several instruments. The 22-item Zarit Burden Interview (ZBI) has a score ranging from 0-88, with higher scores indicating higher perceived burden. ${ }^{21}$ Cronbach's alpha's of 0.93 and intra-class correlation coefficients of 0.89 are reported for the ZBI. ${ }^{22}$

The Caregiver Reaction Assessment (CRA) is a scale designed to measure positive and negative reactions to caregiving. ${ }^{23}$ It consists of five subscales: caregiver's esteem (range 7-35), lack of family support (range 5-25), impact on finances (range 3-15), impact on schedule (range 5-25), and impact on health (range 4-20). With the exception of the subscale 'caregiver's esteem', higher scores on the subscales indicate higher perceived impact on that aspect (i.e. higher scores indicate more negative impact on caregivers' experience). A higher score on caregivers' esteem indicates a positive impact on the caregivers' experience. Cronbach's alpha's varying between 0.62 and 0.83 are reported for the CRA subscales. ${ }^{24}$

tems from the Resource Utilisation in Dementia (RUD) ${ }^{25}$ related to caregiving hours were used. These items capture the time spent by the informal caregiver on care, in three categories: Activities of Daily Living (ADL), Instrumental Activities of
Daily Living (IADL), and supervision of the PwD. For each of the three categories, informal caregivers are asked to specify on how many days they provided care in the past 30. If care is provided by the informal caregiver in a particular category, an additional question is asked to ascertain how many minutes are spent on average per care-day, in order to provide estimates of time spent per month on ADL-care, IADL-care and supervision. Intra-class correlation for these items of the RUD report figures between 0.74 and 0.93.26 Additionally, socio-demographic data (including age, gender and marital status) were collected about both the person with dementia and the informal caregiver.

\section{Ethical considerations}

Ethical approval and permissions to perform the study were obtained in each country based on national regulations. Written informed consent was acquired from informa caregivers (and, depending on the country's quidelines, PwD) before each interview.

\section{Data analysis}

\section{Agreement between expected and actual reasons for admission}

To address the first objective, both the expected reasons prior to admission and the actual reasons after admission as reported by informal caregivers were analysed. Each particular reason given in the answers was categorised separately, meaning that if an answer had more than one reason, each reason was considered independently. The answers were categorised by two Dutch researchers using conventional content analysis ${ }^{27}$ resulting in a codebook with an overview of all categories. First, an overview was composed with the most frequently stated reasons, both expected as well as actual reasons. For this end the percentage of informal caregivers stating a particular reason was calculated. This was done by means of summing the frequency of informal caregivers stating a category and dividing it by the total number of informal caregivers in the sample.

Second, a comparison was made within each case between reports of the expected reasons prior to admission and the actual reasons after admission. An overview was composed of uniformity, exploring the proportion of informal caregivers stating the same reasons at baseline (expected reasons) as they did at follow-up (actual reasons). Furthermore we analysed which reasons were most consistently mentioned within cases on both occasions (prior and after admission).

Agreement between caregiver reported reason and measurement-instruments The second objective investigates the agreement of informal caregivers' most frequently stated actual reasons for admission with characteristics measured prior to admission. For this purpose, bivariate relationships were explored between the most frequently stated actual reasons for admission and scores on corresponding meas 
urement-instruments prior to admission by comparing caregivers who did, and caregivers who did not state a particular reason. Using the Statistical Package for the Social Science for Windows (Version 20.0. Armonk, NY, USA: IBM Corp), t-tests were performed for normally distributed data and Mann-Whitney $U$ test for non-normally distributed data. A two-tailed significance level of $\mathrm{a}=.05$ was used for the analyses,

\section{Validity and reliability}

Several precautions were taken to ensure reliability and validity of the qualitative data. To ensure that the primary translations in the dataset were reliable translations of the original texts in the native languages, $10 \%$ of the complete dataset was re-translated. The coding of the new translations was then compared with the coding of the dataset, resulting in an 83\% agreement between original dataset and new translation (confidence interval for the proportion $80-84 \%$ ). Agreement credibility ${ }^{28}$ was addressed by providing already coded cases and checking agreement with the allotted categories, This procedure showed a $94 \%$ rate (confidence interval for the proportion 92-96\%). Inter-rater reliability was addressed by means of Jaccard coefficients for similarity 29, 30 which ranged from 0.86-0.94, indicating a high accordance between the raters.

Measurement-instruments used in this study have been validated by several studies. Instrument properties are listed in the 'Data Collection' section.

\section{Results}

\section{Sample}

The study sample consisted of 126 dyads of informal caregivers and PwD who have made a transition from home-care to ILTC within the three months between baseline and follow-up. Caregivers were mainly female, mostly married with an average age of 64 years (range 35-86). They cared for predominantly unmarried female PwD who had an average age of 83 years (range 65-100). The range in PwD comorbidity and cognitive status were 1-13 and 0-24, respectively. Table 1 presents the characteristics of the sample. The number of dyads in the sample from a particular country ranged from 4 (Spain) to 44 (France). Those from other countries were as follows: England $(n=11)$, Estonia $(n=6)$, Finland $(n=20)$, Germany $(n=7)$, the Netherlands $(n=21)$ and Sweden $(n=13)$

Of the 126 dyads, 111 informal caregivers stated expected reasons for admissio prior to transition. At follow-up, 113 of the 126 informal caregivers stated an actual reason for admission after transition. The information was missing at either baseline or follow-up for 15 and 13 caregivers respectively.
Table 1 Baseline characteristics of the PwD and the informal caregivers in the sample

Overall $(n=126)$

\begin{tabular}{|c|c|}
\hline \multirow{2}{*}{\multicolumn{2}{|c|}{ People with dementia demographics }} \\
\hline People with dementia demographics & \\
\hline Age (years), mean (SD) & $83.3(6.1)$ \\
\hline $\begin{array}{l}\text { Gender (\%) } \\
\text { Female } \\
\text { Male }\end{array}$ & $\begin{array}{l}61 \\
39\end{array}$ \\
\hline $\begin{array}{l}\text { Marital status (\%) } \\
\quad \text { Married } \\
\text { Unmarried }\end{array}$ & $\begin{array}{l}44 \\
56\end{array}$ \\
\hline $\begin{array}{l}\text { Living arrangement prior to admission (\%) } \\
\text { Alone } \\
\text { With caregiver } \\
\text { With family } \\
\text { Other }\end{array}$ & $\begin{array}{l}39 \\
45 \\
9 \\
7\end{array}$ \\
\hline Comorbidity (CCl, range 0-37), mean (SD) & $2.1(1.5)$ \\
\hline Cognitive status (S-MMSE, range 0-30), mean (SD) & $12.7(6.4)$ \\
\hline \multicolumn{2}{|l|}{ Informal caregiver demographics } \\
\hline Age (years), mean (SD) & $64.3(11.8)$ \\
\hline $\begin{array}{l}\text { Gender }(\%) \\
\text { Female } \\
\text { Male }\end{array}$ & $\begin{array}{l}70 \\
30\end{array}$ \\
\hline $\begin{array}{l}\text { Marital status (\%) } \\
\text { Married } \\
\text { Unmarried }\end{array}$ & $\begin{array}{l}82 \\
18\end{array}$ \\
\hline $\begin{array}{l}\text { Relation to Person with dementia (\%) } \\
\text { Spouse } \\
\text { Child } \\
\text { Other }\end{array}$ & $\begin{array}{l}35 \\
52 \\
13\end{array}$ \\
\hline $\begin{array}{l}\text { Paid job (\%) } \\
\text { Yes } \\
\text { No }\end{array}$ & $\begin{array}{l}31 \\
69\end{array}$ \\
\hline Working hours/week, mean (SD) & $40.8(17.6)$ \\
\hline $\begin{array}{l}\text { Lived with person with dementia prior to admission (\%) } \\
\text { Yes } \\
\text { No }\end{array}$ & $\begin{array}{l}54 \\
46\end{array}$ \\
\hline $\begin{array}{l}\text { Number of visits to PwD in two weeks' time prior to admission } \\
\text { (for caregivers not living with person with dementia), median }\end{array}$ & 6 \\
\hline $\begin{array}{l}\text { Children }<18 \text { in household (\%) } \\
\text { Yes } \\
\text { No }\end{array}$ & $\begin{array}{l}18 \\
82\end{array}$ \\
\hline
\end{tabular}




\section{General results of reasons for admission}

On average, informal caregivers gave 1.7 expected reasons for admission at baseline and 1.8 actual reasons at follow-up (both ranging from $1-4$ reasons). Both for expected as well as actual reasons for admission informal caregivers mainly stated patien related reasons ('neuropsychiatric symptoms', 'cognitive symptoms', 'health problems', 'overall deterioration', 'mobility problems', 'fall incidents', 'care dependency', 'inability to manage at home', 'staying alone not possible', 'endangerment', 'Ioneliness', and 'feelings of insecurity') and, informal caregiver related reasons ('caregiver burden' and 'inability to care for the PwD'). For both the expected reasons, as well as the actual reasons, 'neuropsychiatric symptoms', 'cognitive symptoms', 'care dependency' and 'caregiver burden' were among the top five most stated reasons. In addition overall deterioration of the PwD' was among the top five most stated expected reasons, and informal caregivers' 'inability to care for the PwD' was among the top five most stated actual reasons (see Table 2 for the actual reasons for admission).

Table 2 Most frequently stated actual reasons for admission according to informal caregivers

\begin{tabular}{|l|l|l|}
$\begin{array}{l}\text { Actual reasons for admission } \\
\text { at Follow-up }\end{array}$ & $\begin{array}{l}\% \text { of informal } \\
\text { caregivers }(\mathrm{n}=113)\end{array}$ & $\begin{array}{l}\text { Confidence interval } \\
\text { for the proportion }\end{array}$ \\
\hline Neuropsychiatric symptoms PwD & $27 \%(\mathrm{n}=31)$ & $19-36 \%$ \\
\hline Caregiver burden & $24 \%(\mathrm{n}=27)$ & $16-32 \%$ \\
\hline Inability to care for the patient & $19 \%(\mathrm{n}=21)$ & $11-26 \%$ \\
\hline Cognition PwD & $19 \%(\mathrm{n}=21)$ & $11-26 \%$ \\
\hline Care dependency PwD & $16 \%(\mathrm{n}=18)$ & $9-23 \%$ \\
\hline
\end{tabular}

NOTE: Multiple reasons for admission could be given per person, therefore percentage ads up to more than $100 \%$ and $n$ exceeds 113

\section{Objective 1: Agreement between expected and actual reasons}

\section{for admission}

To determine agreement between the expected (baseline) and actual (follow-up) reasons, cases with complete data were included in the analysis. Across the whole sample of 126 dyads, 108 complete cases were identified in which informal caregivers gave both an expected as well as an actual reason for admission. In 68 out of the 108 cases (63\%), agreement was found between the expected reasons prior to admission and the actual reasons after admission. Of these 68 cases, in 29 cases (43\%) the actual reasons for admission were exactly the same as the expected reasons prior to admission, meaning the exact same (combination of) categories were found both prior to, and after admission. In 8 out of 68 cases (12\%), all actual reasons were also mentioned as expected reasons; however additional reasons were stated at baseline which were not mentioned at follow-up. In 15 out of the 68 cases (22\%) all expected reasons were also stated as actual reasons, with additional reasons mentioned at follow-up that were not present at baseline. The remaining 24\% (16 out of 68 cases) had at least one corresponding reason between the expected and actual reasons for admission.

On the other hand, in 40 out of the 108 cases (37\%), no agreement was found between expected and actual reasons for admission. In other words, for over a third of all caregivers, none of the reasons given after admission corresponded with reasons given prior to admission.

Secondary bivariate analyses were performed to determine whether informa caregiver characteristics (caregiver gender, caregiver age, whether caregiver and person with dementia lived together prior to admission or not, and how the caregiver is related to the person with dementia) were influential on the level of agreement between the expected and actual reasons for admission showed. No significant results were found in these analyses.

In addition, the most consistently stated reasons were examined. These were reasons that were most often stated by the same informal caregivers both as an expected reason as well as an actual reason. Results showed that 'endangerment' was, relatively speaking, most consistently stated. Of the 11 caregivers stating 'endangerment' as an actual reason, 10 had also stated this as an expected reason (91\% agreement-rate). Three reasons showed an agreement-rate around $60 \%$ patient's cognitive symptoms' (13 out of 26), 'patient's care dependency' (11 out of 18 ), and 'patient's overall deterioration' (9 out of 15). There were 31 informal caregivers stating 'neuropsychiatric symptoms' as an actual reason, of which 17 had also stated it as an expected reason ( $55 \%$ conformity-rate). All other categories had a conformityrate less than $50 \%$

\section{Objective 2: Agreement between actual reasons for admission and} cores on measurement-instruments prior to admission

Results of the bivariate analyses between the most frequently stated reasons and the measurement-instruments are found in Table 3. For each indicator analyses were performed for the subsample that had a score on that instrument. The results are explained in more detail below.

\section{Neuropsychiatric symptoms}

Informal caregivers who stated behavioural aspects of the person with dementia as a reason for institutionalisation, reported significantly more (severe) neuropsychiatric 
Table 3 Actual reasons stated by informal caregivers and the relation to corresponding measurement instruments

\begin{tabular}{|c|c|c|c|c|c|c|}
\hline $\begin{array}{l}\text { Actual reason according to } \\
\text { informal caregiver (follow-up) }\end{array}$ & Corresponding (sub)scale & $\begin{array}{l}\text { Mean score } \\
\text { on scale at baseline } \\
\text { if reason is given }\end{array}$ & $\begin{array}{c}\text { Mean score } \\
\text { on scale at baseline } \\
\text { if reason is not given }\end{array}$ & $\begin{array}{l}\text { Median } \\
\text { of scale at baseline } \\
\text { if reason is given }\end{array}$ & $\begin{array}{c}\text { Median } \\
\text { of scale at baseline } \\
\text { if reason is not given }\end{array}$ & $p$-value \\
\hline \multirow[t]{2}{*}{ Neuro-psychiatric symptoms } & $\begin{array}{l}\text { NPI-Q severity (-36) } \\
(n=113)\end{array}$ & $\begin{array}{l}16.10 \\
(n=31)\end{array}$ & $\begin{array}{l}11.06 \\
(n=82)\end{array}$ & $\begin{array}{c}18 \\
(n=31)\end{array}$ & $\begin{array}{c}12 \\
(n=82)\end{array}$ & $0.003^{\wedge}$ \\
\hline & $\begin{array}{l}\text { NPI-Q distress }(\underline{0}-60) \\
(n=113)\end{array}$ & $\begin{array}{l}21.45 \\
(n=31)\end{array}$ & $\begin{array}{l}12.28 \\
(n=82)\end{array}$ & $\begin{array}{c}19 \\
(n=31)\end{array}$ & $\begin{array}{c}12 \\
(n=82)\end{array}$ & $<0.001^{\wedge}$ \\
\hline \multirow[t]{10}{*}{ Burden } & $\begin{array}{l}\text { ZARIT (o-88) } \\
(n=113)\end{array}$ & $\begin{array}{l}42.61 \\
(n=27)\end{array}$ & $\begin{array}{c}33.27 \\
(n=86)\end{array}$ & $\begin{array}{c}38 \\
(n=27)\end{array}$ & $\begin{array}{c}32.5 \\
(n=86)\end{array}$ & $0.009^{\wedge}$ \\
\hline & $\begin{array}{l}\text { NPI-distress (0-60) } \\
(\mathrm{n}=113)\end{array}$ & $\begin{array}{c}17.41 \\
(n=27)\end{array}$ & $\begin{array}{c}13.98 \\
(n=86)\end{array}$ & $\begin{array}{c}19 \\
(n=27)\end{array}$ & $\begin{array}{c}13 \\
(n=86)\end{array}$ & $0.146^{\wedge}$ \\
\hline & $\begin{array}{l}\text { CRA-Support ( } \underline{5}-25) \\
(\mathrm{n}=110)\end{array}$ & $\begin{array}{c}13.52 \\
(n=25)\end{array}$ & $\begin{array}{c}11.39 \\
(n=85)\end{array}$ & $\begin{array}{c}13 \\
(n=25)\end{array}$ & $\begin{array}{c}11 \\
(n=85)\end{array}$ & $0.060^{\wedge}$ \\
\hline & $\begin{array}{l}\text { CRA-Finance ( } \underline{3}-15) \\
(n=113)\end{array}$ & $\begin{array}{c}6.26 \\
(n=27)\end{array}$ & $\begin{array}{c}6.38 \\
(n=86)\end{array}$ & $\begin{array}{c}6.5 \\
(n=27)\end{array}$ & $\begin{array}{c}6 \\
(n=86)\end{array}$ & $0.847^{\wedge}$ \\
\hline & $\begin{array}{l}\text { CRA-Esteem (7-35) } \\
(n=108)\end{array}$ & $\begin{array}{l}24.25 \\
(n=24)\end{array}$ & $\begin{array}{l}25.39 \\
(n=84)\end{array}$ & $\begin{array}{c}26 \\
(n=24)\end{array}$ & $\begin{array}{c}26 \\
(n=84)\end{array}$ & $0.382^{\wedge}$ \\
\hline & $\begin{array}{l}\text { CRA-Schedule(5-25) } \\
(n=110)\end{array}$ & $\begin{array}{l}19.50 \\
(n=27)\end{array}$ & $\begin{array}{l}14.67 \\
(n=83)\end{array}$ & $\begin{array}{c}20 \\
(n=27)\end{array}$ & $\begin{array}{c}15 \\
(\mathrm{n}=83)\end{array}$ & $0.001^{\#}$ \\
\hline & $\begin{array}{l}\text { CRA-Health }(4-20) \\
(n=112)\end{array}$ & $\begin{array}{c}12.85 \\
(n=27)\end{array}$ & $\begin{array}{c}9.53 \\
(n=85)\end{array}$ & $\begin{array}{c}12.85 \\
(n=27)\end{array}$ & $\begin{array}{c}9.53 \\
(n=85)\end{array}$ & $0.001^{\#}$ \\
\hline & $\begin{array}{l}\text { RUD time on } A D L \pm \\
(n=112)\end{array}$ & $\begin{array}{c}2.3 \\
(n=26)\end{array}$ & $\begin{array}{c}1.75 \\
(n=86)\end{array}$ & $\begin{array}{c}1 \\
(n=26)\end{array}$ & $\begin{array}{c}0.2 \\
(n=86)\end{array}$ & $0.152^{\#}$ \\
\hline & $\begin{array}{l}\text { RUD time on IADL } \pm \\
(n=109)\end{array}$ & $\begin{array}{c}3.27 \\
(n=25)\end{array}$ & $\begin{array}{c}2.46 \\
(n=84)\end{array}$ & $\begin{array}{c}2 \\
(n=25)\end{array}$ & $\begin{array}{c}1.06 \\
(n=84)\end{array}$ & $0.041^{\#}$ \\
\hline & RUD time on supervision $\pm(n=106)$ & $\begin{array}{c}9.2 \\
(n=26)\end{array}$ & $\begin{array}{c}3.34 \\
(n=80)\end{array}$ & $\begin{array}{c}8 \\
(n=26)\end{array}$ & $\begin{array}{c}0.13 \\
(n=80)\end{array}$ & $0.002^{\#}$ \\
\hline Cognition & $\begin{array}{l}\text { S-MMSE (0-30) } \\
(n=99)\end{array}$ & $\begin{array}{c}15.35 \\
(n=20)\end{array}$ & $\begin{array}{l}11.75 \\
(n=79)\end{array}$ & $\begin{array}{c}15.5 \\
(n=20)\end{array}$ & $\begin{array}{c}13 \\
(n=79)\end{array}$ & $0.024^{\wedge}$ \\
\hline Care dependency & $\begin{array}{l}\text { KATZ (0- } \underline{6}) \\
(n=109)\end{array}$ & $\begin{array}{c}3.67 \\
(n=16)\end{array}$ & $\begin{array}{c}3.11 \\
(n=93)\end{array}$ & $\begin{array}{c}4 \\
(n=16)\end{array}$ & $\begin{array}{c}3 \\
(n=93)\end{array}$ & $0.338^{\#}$ \\
\hline
\end{tabular}


symptoms prior to institutionalisation than those informal caregivers not stating behavioural aspects as a reason for institutionalisation (mean difference $5.04 p<0.01$ ). The results on the NPI-Q distress scale showed similar results, with significantly higher distress scores for caregivers stating neuropsychiatric symptoms as a reason compared to those caregivers who did not (mean difference $9.17 p<0.001$ ).

\section{Caregiver burden}

Caregiver burden was compared against several scales: the ZARIT burden scale, the $\mathrm{NPI}$-Q distress scale, the CRA subscales, and three RUD questions which measure care-hours provided per day. The results of informal caregivers citing burden as a reason for institutionalisation show significantly higher scores on the ZARIT compared to caregivers who did not identify burden as a reason for institutionalisation (mean difference $9.34 \mathrm{p}<0.01$ ). The results for the CRA-schedule and the CRA-health subscales show a similar trend, with caregivers citing burden indicating greater negative impact of caregiving on their own schedule (mean difference $4.83 p<0.01$ ) and health (mean difference $3.32 p<0.01$ ). Caregivers who stated burden as a reason for institutionalisation, spent more hours providing IADL care (mean difference 0.81 $p<0.05$ ) and supervision (mean difference $5.86 p<0.01$ ) to the person with dementia prior to admission compared to those not stating burden. The scores on the other scales did not differ significantly between informal caregivers who stated burden as a reason for institutionalisation and those who did not.

\section{Cognitive function}

The PwD whose informal caregivers cited cognitive symptoms as a reason for institutionalisation scored significantly higher on the S-MMSE. This indicates better cognitive function, compared with the persons with dementia whose caregiver did not state cognitive symptoms as a reason for institutionalisation (mean difference 3.6 $p<0.05)$

\section{Care dependency}

The difference in functional independence of the person with dementia, measured with the KATZ, was not significant between those informal caregivers who did and did not state care dependency as a reason for institutionalisation.

No corresponding scale or question was identified within the RTPC survey to perform this analysis for the reason 'inability of the informal caregiver to care for the person with dementia'

\section{Discussion}

Results of this study show that informal caregivers are, for the most part, quite able to provide good indications of what will cause admission of PwD to ILTC. When directly asked for expected reasons for admission, approximately two-thirds of the sample was able to identify what will cause the admission of their loved one with dementia, although the degree of accuracy between expected and actual reasons for admission varied. In some cases caregivers stated, for example, that they expected admission in case of either a fall or increased aggressive behaviour. If indeed a fall was the actual reason for admission, it was not considered a 100\% accuracy rate (since there were more expected reasons stated than actual reasons). Another example is that more actual reasons were stated than expected reasons. An informal caregiver could expect that the reason for admission will be the wandering behaviour of the person with dementia, if it is indeed the case that the person wandered but if burden was also stated as an actual reason for admission, it was also not considered a 100\% accuracy rate. Nonetheless, in both examples the informal caregivers could give a eliable indication of what caused admission. On the other hand, in about a third of the sample there was absolutely no match between the expected reasons and actual reasons for admission. Since we stated that having an indication beforehand of what will cause admission increases the likelihood of timely admission, knowing what causes the discrepancy between caregivers' expected and actual reasons is also an important issue. In this study no significant results were found that determine whether informal caregivers with certain characteristics might be better at indicating what will cause admission However, this does not mean that there are no other factors that do. Future studies might look further into what determines whether informal caregivers are able to correctly indicate beforehand what will cause admission.

It must be noted that many of the informal caregivers in this study indicated that they had never thought about admission. Prior research suggests that most informal caregivers do not think about or plan the admission of the person with dementia beforehand, and that admission often occurs without preparations, as a result of crisis situations. ${ }^{31}$ The informal caregiver's awareness of what might cause admission will be important for the process of timely admission. This awareness could result in informal caregivers being more attentive to the signs for admission. Therefore, it might be beneficial to make informal caregivers think about, and articulate what could cause admission, keeping in mind that there can always be unforeseen causes or admission. Nevertheless, the statements of informal caregivers on what might cause admission could be taken as a reliable source by professional home-care providers as indications of what care is needed. Beside using this information to tailo care to needs, professional care should look for ways of collaboration with informa caregivers regarding the transition process, such as starting a dialogue about 
institutionalisation or involvement and support in the decision process for institutionalisation.

The bivariate relations between the reports of informal caregivers and the scores on measurements suggest that some of these scales can give a good indication of the reason for admission, as indicated by earlier work. ${ }^{11}$ This is so for both NPI-Q subscales and neuropsychiatric symptoms. Certain burden (sub)scales are also promising as indicators for reason for admission. The effects on a caregiver's health, disrupted schedule and time spent on supervision are aspects that cause burden to be considered a reason for admission. A notable finding was the fact that caregivers stating cognition as a reason for admission were caring for PwD with a higher mean score on the S-MMSE than PwD of informal caregivers who did not state cognition as a reason for admission. While studies on predictors for long-term care admission state that lower cognition predicts admission, ${ }^{6,7}$ we found a discrepancy between the score of the S-MMSE and the statement of informal caregivers. A possible reason for this lies in the relative change in cognitive decline as perceived by the informa caregiver. In those PwD who start to lose cognitive ability, the change will be perceived as more evident than for those PwD who are already further in the process. It is conceivable that for those cases in which cognition was stated as a reason, there actually was a change in cognition. This could not be verified in this study, since that information was not available.

\section{Limitations of the study}

Certain aspects have to be mentioned that limit the current study. The first limitation concerns the skewed distribution of participants from each country, with France making up a third of the sample. Secondly, the short follow-up period of three months led to a small sample size of this study. The decision for this time-frame within the study was made for practical reasons, but with hindsight, a follow-up period of six or nine months would have been better. These limitations restricted the capacity to differentiate both between, and within countries. There are indications that country differences exist regarding admission, ${ }^{32}$ and differentiation between countries could have strengthened the study, though analysing country differences was not an initia aim. This may limit the interpretation of the results, keeping in mind that contextual factors could have exerted effects. However, intra-individual variation corrects for culture in the sense that each participant acts as his/her own control in this study. Furthermore, each reason informal caregivers stated was considered individually and given equal weight, even though it is clear that admission occurs for a combination of reasons (be it separate additional problems or cause-to-effect problems), and no a single independent reason. However, no inquiry was made about prioritising stated reasons during the interviews. The design of this study did not allow in-depth analyses into this question. Future research is needed in order to better understand how different reasons possibly interact and influence each other, and how the presence of certain problem might indicate other problems. Finally, not all reasons given by informal caregivers could be paired with a measurement instrument, so as to analyse the situation prior to admission with their stated reasons.

\section{Conclusions}

This study investigated whether informal caregivers of PwD receiving homecare are able to indicate, both explicitly and implicitly, what will cause admission prior to the vent itself. Both methods show promising results and offer a good method to see what may cause admission of PwD on the individual case-level. This information offers the opportunity to anticipate these reasons, which in turn, can increase the Ikelihood of timely admission. Nurses and other community-based professionals, such as case-managers, could use these reasons to offer more tailored home-based care, but also to support and collaborate with informal care during the period of care ransition. With this information, programmes can be designed which enable nursing professionals to guide informal caregivers during care transition. The knowledge that informal caregivers are able to indicate what will cause admission is therefore of much value to formal caregivers. Furthermore, knowing what will cause admission offers the possibility for nursing professionals to tailor the care to the needs of PwD and their informal caregivers. Keeping in mind that informal caregivers are also in need of professional support and guidance, knowing in what area an informa caregiver requires support is essential. Taking note that most informal caregivers currently do not yet receive guidance in the care transition process and that research shows that such guidance is appreciated, ${ }^{33,34}$ addressing the issue of admission can be a starting point in the process of guidance and collaboration. Making informa caregivers aware and conscious about a possible upcoming care transition could make this process smoother. How this guidance during the transition process should be designed depends on the needs experienced by informal caregivers.

The idea of offering counselling and guidance to informal caregivers is not novel, yet it does not seem highly prevalent, especially during the period of care transition. It has to be noted that the care transition period does not end at the moment of institutionalisation but continues, with that period not only being new for PwD, but also for informal caregivers. The home situation changes for example, as do the types of caregiving tasks. This period is not uncomplicated ${ }^{35}$ and professiona support could be valued. In the future, there is likely to be a need to implement new strategies for cognitive empowerment of informal caregivers. These strategies should allow a continuous interaction between informal caregivers and professionals. To design proper professional guidance requires more understanding of caregivers 
needs, particularly at the point of care transition. For this reason it is important to study the experienced needs of informal caregivers during the care transition period from home-based care towards ILTC.

\section{References}

1. Alzheimer 's Disease International. World Alzheimer Report 2009. London: Alzheimer 's Disease International; 2009.

Moisse P. Schwarzinger M. Um M. Dementia Care in 9 OECD Countries: A comparative analysis. OECD Health Working Papers. 2004.

3. Knapp M, Comas-Herrera A, Somani A, Banerjee S. Dementia: international comparison. 2007.

Alzheimer's Association. 2010 Alzheimer's disease facts and figures. Alzheimer's and Dementia : the Journal of the Alzheimer's Association. 2010;6:158-94.

5. Gaugler JE, Duval S, Anderson KA, Kane RL. Predicting nursing home admission in the U.S: meta-analysis. BMC Geriatrics. 2007:7:13

6. Luppa M. Luck T, Braehler E, Koenig HH. Riedel-Heller SG. Prediction of institutionalisation in dementia - A systematic review. Dementia and Geriatric Cognitive Disorders. 2008;26:65-78

7. Gaugler JE, Yu F, Krichbaum K, Wyman JF. Predictors of Nursing Home Admission for Persons with Dementia. Medical Care. 2009;47:191-8.

8. Coehlo DP, Hooker K, Bowman S. Institutional placement of persons with dementia - What predicts occurrence and timing? Journal of Family Nursing. 2007;13:253-77.

9. Dorenlot $P$. Harboun M. Bige V. Henrard JC, Ankri J. Major depression of dementia as a risk factor for early institutionalization patients living in the community. International Journal of Geriatric Psychiatry 2005;20:471-8

10. Gaugler JE, Kane RL, Kane RA, Newcomer R. Early community-based service utilization and its effects on institutionalization in dementia caregiving. Gerontologist. 2005;45:177-85,

11. Buhr GT, Kuchibhatla M. Clipp EC Caregivers' reasons for nursing home placement: Clues for improving discussions with families prior to the transition. Gerontologist. 2006;46:52-61.

12. Cohen-Mansfield J, Wirtz PW. The Reasons for Nursing Home Entry in an Adult Day Care Population Caregiver Reports Versus Regression Results. Journal of Geriatric Psychiatry and Neurology 2009:22:274-81.

13. Verbeek H, Meyer G, Leino-Kilpi H, Zabalegui A, Hallberg IR, Saks K, et al. A European study investigating patterns of transition from home care towards institutional dementia care the protocol of a RightTimePlaceCare study. BMC Public Health. 2012:12:68

14. Folstein MF, Folstein SE, McHugh PR. Mini-Mental State: a practical method for grading the cognitive state of patients for the clinician: Pergamon Press, 1975.

15. Molloy DW, Alemayehu E, Roberts R. Reliability of a Standardized Mini-Mental State Examination compared with the traditional Mini-Mental State Examination. American Journal of Psychiatry. 1991,148. $102-5$

16. Kaufer DI, Cummings JL, Ketchel P, Smith V, MacMillan A, Shelley T, et al. Validation of the NPI-Q, a brief clinical form of the neuropsychiatric inventory. Journal of Neuropsychiatry and Clinical Neurosciences. 2000;12:233-9

17. Katz S, Ford AB, Moskowitz RW, Jackson BA, Jaffe MW. Studies of lllness in the Aged. The Index of Ad: A Standardized Measure of Biological and Psychosocial Function. Journal of the American Medical Association. 1963;185:914-9.

18. Wallace M, Shelkey M. Reliability and validity of Katz ADL index. AJN The American Journal of Nursing 2008; 108

9. Charlson ME, Pompei P, Ales KL, Mackenzie CR. A new method of classifying prognostic comorbidity in longitudinal studies: development and validation. Journal of Chronic Diseases. 1987;40:373-83.

20. Katz JN, Chang LC, Sangha O, Fossel AH, Bates DW. Can Comorbidity Be Measured by Questionnaire Rather than Medical Record Review? Medical Care. 1996;34:73-84.

21. Zarit SH, Reever KE, Bach-Peterson J. Relatives of the impaired elderly: correlates of feelings of burden. Gerontologist. 1980;20:649-55

22. Seng BK, Luo N, Ng WY, Lim J, Chionh HL, Goh J, et al. Validity and Reliability of the Zarit Burden Interview in Assessing Caregiving Burden. Annals of the Academy of Medicine Singapore. 2010:39:758-63. 
23. Given CW, Given B, Stommel M, Collins C, King S, Franklin S. The caregiver reaction assessment (CRA) for caregivers to persons with chronic physical and mental impairments Research in Nursing and Healh 1992;15:271-83

24. Nijboer C, Triemstra M, Tempelaar R, Sanderman R, Van den Bos G. Measuring both negative and positive reactions to giving care to cancer patients: psychometric qualities of the Caregiver Reaction Assessment (CRA). Social Sciences and Medicine. 1999;48:1259-70.

25. Wimo A. Wetterholm AL Mastey $\vee$ Winblad B. Evaluation of the resource utilization and caregiver time in Anti-dementia drug trials- a quantitative battery In. Wimo A, Jonsson. B, Karlsson, G Winblad B. editor. The Health Economics of Dementia. London: John Wiley and Sons, 1998

26. Wimo A, Jonsson L, Zbrozek A. The resource utilization in dementia (RUD) instrument is valid for assessing infornal care time in community-living patients with dementia. Journal of Nutrition Health ard Aging. 2010;14:685-90.
Hsieh HF Shannon SE Three approaches to qualitative content analysis. Qualitative Health Research.

27. Hsieh HF, Shannon SE. Three approaches to qualitative content analysis. Qualitative Health Research Graneheim UH

Geim UH, Lundman B. Qualitative content analysis in nursing research: concepts, procedures and Measues to achieve trustworthiness. Nurse Education Today. 2004;24:105-12.

29 Landis JR, Koch GG. The measurement of observer agreement for categorical data. Biometrics. 1977:159-74.

30. Popping R. Traces of agreement: On the DOT-product as a coefficient of agreement. Quality and Quantity. 1983:17:1-18.

. Dellasega C, Nolan M. Admission to care: facilitating role transition amongst family carers. Journal of

32. Burns A, Mittelman M, Cole C, Morris J, Winter J, Page S, et al. Transcultural Influences in Dementia Care osservations from a Psychosocial Intervention Study. Dementia and Geriatric Cognitive Disorders

33. Gaugler JE, Pearlin LI, Leitsch SA, Davey A. Relinquishing in-home dementia care: difficulties and perceived helpfulness during the nursing home transition. American Journal of Alzheimers' Disease and Other Dementias. 2001;16:32-42

34. Couture M, Ducharme F, Lamontagne J. The Role of Health care Professionals in the Decision-Making Process of Family Caregivers Regarding Placement of a Cognitively Impaired Elderly Relative. Hom Health Care Management and Practice. 2012;31:197-218

35. Sury L, Burns K, Brodaty H. Moving in: adjustment of people living with dementia going into a nursing home and their families. International psychogeriatrics. 2013;25:867-76. 


\section{5}

Needs of Informal Caregivers During Transition from Home Towards Institutional Care in Dementia: A Systematic Review of Qualitative Studies

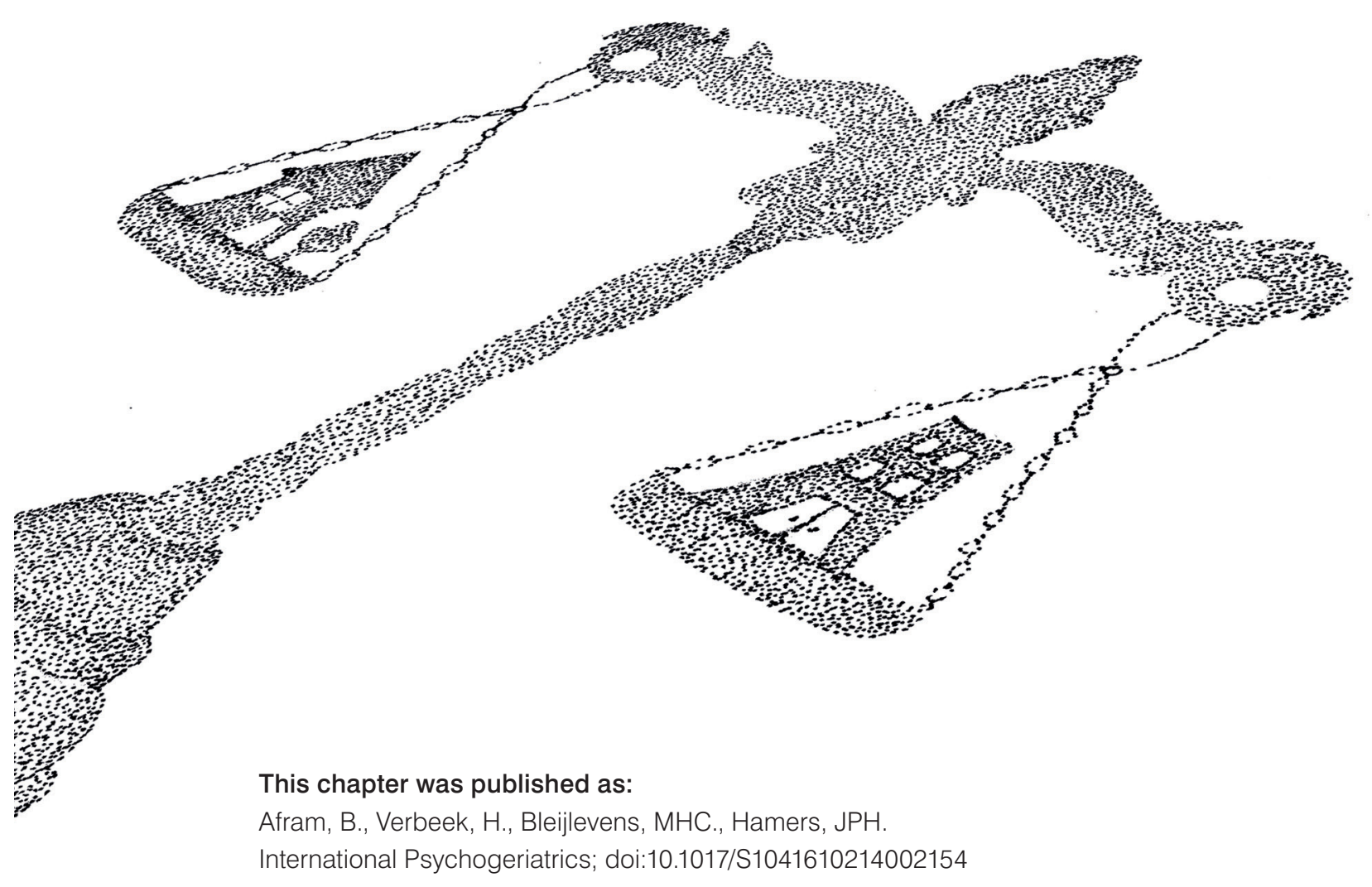




\section{Abstract}

Background: Alongside providing care, informal caregivers of people with dementia often need support and guidance themselves, especially during difficult periods such as the care transition from home towards a nursing home. Knowledge on needs of informal caregivers during this period is sparse. This study aims to provide insight into problems and needs of informal caregivers caring for people with dementia during care transition from home-based care to institutional long-term care.

Methods: A systematic electronic search in CINAHL, Cochrane, Medline, PsycINFO, Pubmed and Web of Knowledge. All qualitative articles up to September 2013 were considered. The included articles underwent a quality appraisal. Thematic analysis was used to analyse problems and needs described in the articles.

Results: Thirteen publications were included providing 14 topics comprising needs and problems of informal caregivers during the care transition period. The most stated topics were: 'emotional concerns' (e.g., grief and shame about the decision), 'knowledge/information' ( e.g., understanding the care system) and 'support' (e.g. need for counselling). Similar topics were found prior and after admission, with examples specific to the either the home or nursing home situation.

Conclusions: The care transition period should be considered a continuum, as similar needs and problems were identified prior and after admission. This should be kept in mind in developing support and guidance for informal caregivers during this process. Whereas currently the situation prior and post admission are seen and treated as adjacent stages, they should be considered one integrated stage. Multicomponent programmes should be offered that are designed in a continuous way, starting prior to admission, and continuing after.

\section{Introduction}

Informal care, which is usually provided by family, will always have a central role in dementia care and can even be considered the cornerstone of dementia care ${ }^{1}$ with, for example, $80 \%$ of home care being provided by family in the US. ${ }^{2}$ With a global rise in dementia, from 35.6 million in 2010 to an estimated 115.4 million in $2050,{ }^{3}$ the number of informal caregivers will rise as well. Since informal caregivers of people with dementia (PwD) not only provide care, but are themselves often in need of support and guidance as well, ${ }^{4-7}$ the rising number makes it ever more important to learn how formal care can be designed to support informal care. This is especially rue during the more intense and difficult periods, such as during the care transition period of the person with dementia from home-based care towards institutional long-term care (ILTC). In this article, the care transition period is considered any amount of time starting from the period prior to admission when admission is contemplated, up to an adjustment period after actual admission. After admission many changes, ranging from the organisational aspects of the move such as emptying the house and selling the house/stopping the rent up to the emotiona aspects such as getting used to the fact of living alone, can have significant impact on the informal caregiver. Besides the changes for informal caregivers, PwD also undergo changes, such as a new living environment. The time needed to adjust to these changes is dependent on the individual situation of the informal caregiver and the person with dementia. The care transition period is therefore not a set period of time for everybody.

The care transition period of PWD from home-based care to ILTC is a difficult one for informal caregivers. They are challenged with deciding what the appropriate living environment for the person with dementia is in which the needs of the person with dementia are best met. Caregivers have to decide whether and when it is the right moment for admission and they often experience adverse feelings of guilt, sadness and self-doubt due to the decision. ${ }^{8-11}$ Evidence shows that informal caregivers

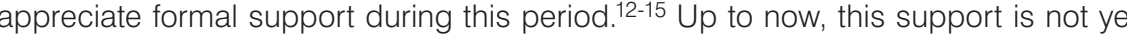
fully developed and structurally offered to informal caregivers as needs are unclea and there is a lack of understanding what support should be offered.

Knowledge explicitly on the needs of informal caregivers during care transition from home-based care to ILTC is needed. Present studies conducted on needs of informal caregivers report on the ongoing home-situation, ${ }^{16-18}$ or institutional settings. ${ }^{19,20}$ Others studied the needs of PwD themselves. ${ }^{21-23}$ Studies regarding informal caregivers' needs during care role-transition in dementia have focused on the moment of diagnostic disclosure. ${ }^{24,} 25$ These show how early diagnosis offers caregivers the opportunity to feel more competent to care and experience less psychological problems. ${ }^{25}$ Knowledge on needs during the care transition period is still sparse. 
After admission caregivers still express a need to be involved in the care.12, 26 Informal caregivers' role thus continues even after admission, although it may be different from the home situation with informal caregivers taking on other types o tasks. Therefore, needs during the transition period may also be different. Needs can be defined in various ways, such as demand for existing services, ${ }^{27}$ the result of problems related to health status and quality of health care, evoking need for furthe professional care ${ }^{28}$ or "a condition that is important to the subject and that is not being satisfied in the subject's present environment". ${ }^{16}$ Needs are derived from problems or dissatisfaction with the situation, making problems and needs inextricably linked.

In this review we aim to provide insight into the problems and needs as experienced by informal caregivers who care for PwD during the care transition period from home-based care to ILTC. We focus on qualitative studies as they provide n-depth insight into caregiver experiences.

\section{Methods}

\section{Search procedure}

A systematic electronic search in CINAHL, Cochrane, Medline, PsycINFO, Pubmed and Web of Knowledge was carried out. No restrictions were posed upon publication date in this search, with all possible literature up to the date of the search (September 2013) being considered. Search terms included the following: informal care* OR family care* OR family OR partner OR next of kin OR caregiver* AND dementia OR Alzheimer OR cognitive impair* AND need* OR difficult* OR support OR wants OR problems OR demands AND transition* OR institutionali* OR placement OR admission OR entry AND long-term care OR institutional care OR care home* OR nursing home*. In addition, manual reference searches were performed as to find further eligible studies.

\section{Selection criteria}

First, all publications were screened on eligibility criteria independently by two researchers (BA and HV) based on title and abstract. Next, selected publications were screened full text, and after deliberation, consensus was reached between the two researchers on which publications should be included in the review.

Publications were included if they met the following criteria: 1) The study population had to contain informal caregivers of PwD. Informal care is considered the care provided by informal caregivers, such as spouses/partners, other members of the household and other relatives, friends, neighbours and others, usually but no necessarily with an already existing social relationship with the care recipient 29 ;2) The study had to investigate experiences of informal caregivers regarding the care transition process from home-based care to ILTC, describing the problems or needs of informal caregivers; and 3) Studies had to consider PwD during the care transition period, in which home-based care may become insufficient or inadequate and the admission to ILTC may have to be, or was prompted. All publications meeting the above mentioned criteria, written in English, Dutch or German, were considered.

Publications were excluded if: 1) the sample did not primarily consist of informal caregivers of PwD. Those publications not solely consisting of caregivers of PwD had to at least differentiate between caregivers caring for people with, and without dementia in their results: 2) The studies focussed on predictors for institutionalisation; 3) The study did not use qualitative methods to gather data; 4) The target populations were people with Korsakoff's syndrome, people suffering from severe depression, mental disability or young onset dementia; 5) The research primarily focused on the beginning of the dementia process; and 6 ) Studies on transition to temporary/respite care or end-of-life/hospice care.

\section{Quality appraisal}

Publications included in the review underwent a quality appraisal using criteria based on an existing checklist as described by Bunn et al. to assess qualitative studies, ${ }^{30}$ Two researchers (BA and $\mathrm{HV}$ ) independently scored publications on the following eight criteria: 1) Scope and Purpose (e.g., clear statement of research question); 2) Design/Method (e.g., appropriate use of qualitative methods); 3) Sample (e.g. clear description of sample); 4) Data collection (e.g., adequate description of data collection methods); 5) Analysis (e.g., analytic methods are made explicit); 6) Reliability/Validity e.g., presents how categories/themes are developed); 7) Generalizability (limits for generalizability clearly stated); and 8) Credibility/Plausibility (e.g., results and conclusions are supported by evidence). Each criterion was scored as sufficient (1) or insufficient (0). For each publication, results were compared and the two researchers discussed discrepancies afterwards until consensus was reached. Scores on the appraisal could range from 0 up to a maximum of 8 points.

\section{Analysis}

Thematic analysis was used to analyse the data. Initially, the problems and needs as described in the result sections of all publications were identified. Both quotations of respondents that were presented in the publications, as well as the own wording of the authors in the result sections were considered as data for this review. Those identified sections were then independently coded by two researchers (BA and MB), using open coding. Next, the terms assigned by the two researchers were discussed. Finally, the codes were grouped to create topics. In case of discrepancy the two researchers involved in the coding procedure, supplemented by a third researcher (HV), deliberated to reach consensus. 


\section{Results}

\section{Search results, general characteristics and quality appraisal}

Figure 1 shows a flowchart with an overview of the search and selection of publications.

The included 13 publications were published between 2000 and 2012, and originated in five countries, of which most came from the US (46\%). Other countries were Australia, Canada, China and Korea. Overall most of the included studies used semistructured interviews to collect their data (85\%).

The results of the quality appraisal showed that 11 studies were of sound quality scoring 6 points or higher out of the maximum of $8(85 \%),{ }^{12-15,26,31-36}$ of which three scored the maximum amount of points (see Table 1). The remaining two studies yielded only 3 out of 8 points (15\%) ${ }^{37,38}$ and were therefore classified as lower quality studies.

\section{Thematic analysis}

Overall, 14 main topics were found (see Table 2). The topics stated most frequently were: 'emotional concern' $(\mathrm{n}=12)$, 'knowledge/information' $(\mathrm{n}=12)$ and 'support' $(n=11)$. Other topics that were mentioned in more than half the publications were: 'health care professional relation', 'appropriate care', 'family' and 'finance' related. The remaining topics were found in fewer publications. The findings of the thematic analysis are discussed in more detail below, starting with the topics appearing in most publications, then continuing with those topics mentioned less frequently. Per opic, the results of the publications scoring high on the quality appraisal are reported first. The two publications scoring lower on the quality appraisal did not add additional topics. However, they were kept in the analysis as they provided different examples within the themes.

\section{Parallels between problems and needs}

The included publications stated both problems encountered by informal caregivers, as well as explicit needs expressed by informal caregivers during care transition. The difference lay in the phrasing. For example, whereas caregivers in one publication stated that they were disappointed with the quality of care of ILTC, 32 in other publications this was phrased as an explicit need such as a need for more staff so the quality of care would improve. ${ }^{13}$ Both state an issue that can be classified under the same theme, only one phrasing it as a problem, the other as a specific need. Since need could be considered as derived from a problem, both needs and problems are described together. The distinction between the situation prior and after admission is, where applicable, continuously made throughout the topics.
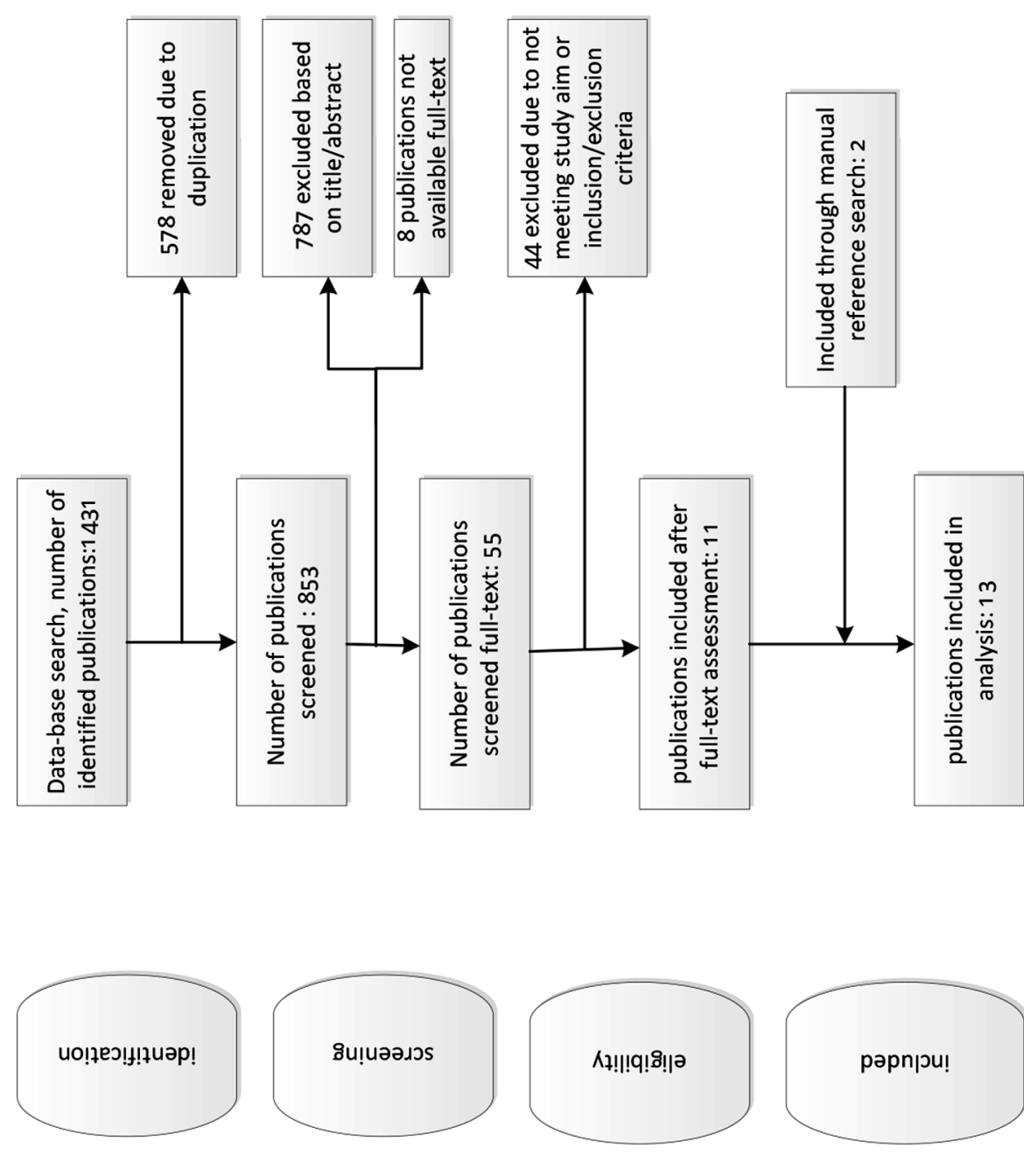

Figure 1 Flowchart of search and selection procedure

\section{Problems and needs experienced by informal caregivers during} the transition period

\section{Emotional concerns}

Prior to admission emotional concerns could be explicitly related to the decision placement or be more general. Several publications reported on emotional concerns explicitly related to decision/placement such as grief, stress, anguish and 


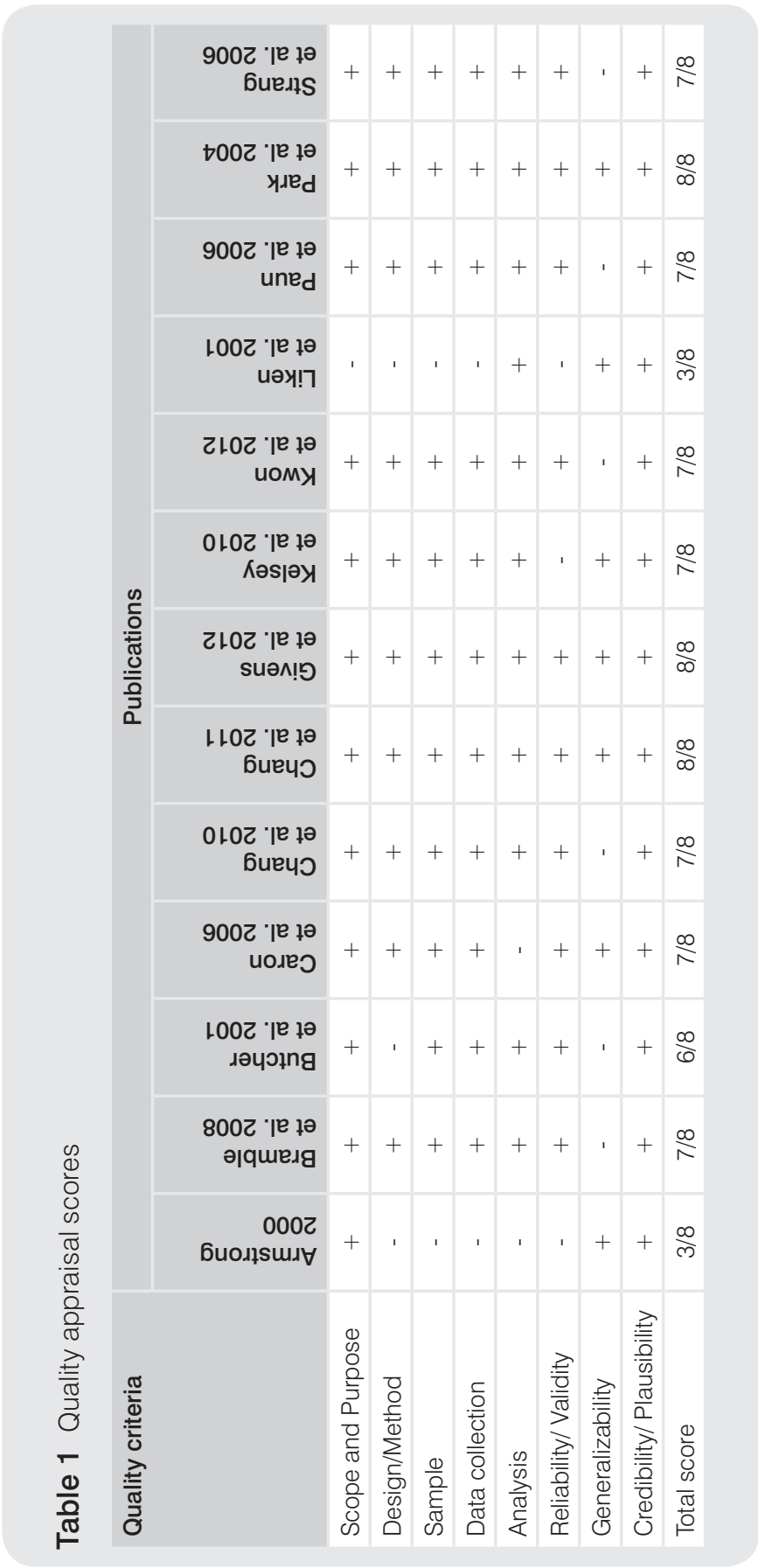

shame, 12-14, 26, 32, 34, 35 for example, calling the experience of the transition traumatic. ${ }^{14}$ Studies originating in Asian countries also specified cultural values (filial piety) to be at the centre of this emotional distress, ${ }^{32,34,35}$ as illustrated by the following quote: ".... Someone suggested that we should send her to the nursing home. I thought it was a good idea but I was afraid to do so.... some would say, 'You must be un-filial because you sent her to a nursing home.' Although I really wanted to, I did not dare to do so". ${ }^{32}$ Emotional concerns that are not explicitly related to the decision for admission were also reported on, 15, 32, 34-38 such as stating exhaustion of the mind, self-blame as a result of their reaction towards the PwD and feelings of pressure. ${ }^{15,34}$ Feelings of apprehension such as the feeling of being out of control, 'not being heard' or awareness that the whole situation is overwhelming for them were also reported. 35,36 The two publications scoring lower on the quality appraisal added emotiona concerns in the form of: difficulty accepting information, ${ }^{37}$ losing patience and explaining how it felt as if they were on an 'emotional roller-coaster' 38

After admission emotional concerns could also be explicitly related to decision of placement, such as self-blame, self-doubt and regret about the placement decision. ${ }^{15}$ 32-34 Other problems reported were feelings of loneliness due to missing the PwD, isolation and powerlessness.12, 13, 15 Informal caregivers also showed concerns related to ILTC, stating worries about safety for example, ${ }^{15}$ others expressed concerns about the PWD in their absence. As stated by one informal caregiver: " because you're not there, you wonder what's happening ... so you worry" ${ }^{36}$ Caregivers also describe visiting the ILTC facility as a difficult experience. ${ }^{36}$

\section{Knowledge/information}

Prior to admission problems ranged from a lack of knowledge about dementia, ${ }^{26,}, 38$ o not being informed about financial options such as social welfare. ${ }^{32}$ Most frequently, however, the lack of knowledge concerned not knowing available care options or care alternatives for ILTC.13, 14, 32, 33, 35, 37 One caregiver for example stated: "I didn't think there were any facilities like this in my town. I didn't know. Nobody told us about this stuff and I didn't know who to ask, so we just found this place through hearsay". ${ }^{35}$ Understanding the system, as in knowing the policies, rules and regulations was also reported as a need or problem. ${ }^{14,15}$ As reported in one publication, most caregivers stated they were not informed at the time of the admission about the transfer policy nor were they given written information about the transfer policy. ${ }^{14}$

After admission one study reported on the need of informal caregivers to improve on their knowledge and understanding about dementia. ${ }^{12}$ The need to know and understand the rules and expectations of the ILTC system was expressed afte admission as well, complemented with how this learning process was frustrating to most of them. 15,36 


\section{Support}

Prior to admission support was mentioned in several publications. 12-15, 26, 31, 34-37 Some specifically reported a need for, or lack of support from their social environment, as in family and friends. ${ }^{13,15,31,34,35}$ For example, mutual support for caregiving being actively and systematically sought in the family. ${ }^{34}$ Other caregivers stated a need for formal support, ${ }^{12-15,32,35,37}$ such as being educated about dementia ${ }^{14}$ or a need fo counselling. ${ }^{12}$

After admission support was also expressed as a need. Certain caregivers expressed a need for support from their social environment. ${ }^{15,} 36$ Be it from family, friends or peers. However, support was often stated just as a need for support, without explicitly specifying what this support should look like.

\section{Health care professional relation}

Prior to admission the relationship with health care professionals $(\mathrm{HCP})$ was expressed in terms of lack of contact with, and information from staff. ${ }^{12,} 32,35$ Another type of problem in the relation with HCP could arise when the evaluation of the care situation diverged between the informal caregivers and HCP. ${ }^{31}$

After admission issues were often due to dissatisfaction with communication, such as a lack thereof, or feeling 'unheard' by HCP.12, 15, 26 Others felt that HCP did no encourage them to be involved with the care of the PwD after admission and desired to build understanding, rather than clash with staff. ${ }^{12}$ Some expressed it as an appreciation for a warm and friendly relation with the staff ${ }^{13}$ or difficulties in establishing a positive relationship. ${ }^{34}$ One study scoring lower on the quality appraisal stated how informal caregivers felt frustrated with the way HCP treated them. ${ }^{38}$

\section{Appropriate care}

Prior to admission, problems and needs were expressed regarding appropriate care meaning formal care that meets the needs or expectations of the informal caregiver. In order to be considered helpful, caregivers insisted that any formal support should be available and accessible, flexible, continuous and co-ordinated among the various service providers, and have an acceptable waiting time for services withou unreasonable delays. ${ }^{31}$ Others made statements regarding limited or unsuccessfu respite care. ${ }^{12,37}$ Limited numbers of ILTC beds, and a distrust of the quality of care of ILTC were also reported as issues. ${ }^{32}$ In one of the studies scoring lower on the quality appraisal the caregivers reported the problem of formal help coming at the wrong time. One participant reported "....because you could never say when you needed help and they came when you had done everything" . ${ }^{37}$ This publication further reported how day-care was perceived as the most helpful service. Respite care was required to fulfil the need of having time for themselves and knowing beforehand when this time will be, ${ }^{37}$ making it possible to anticipate and plan for this 'alone' time.

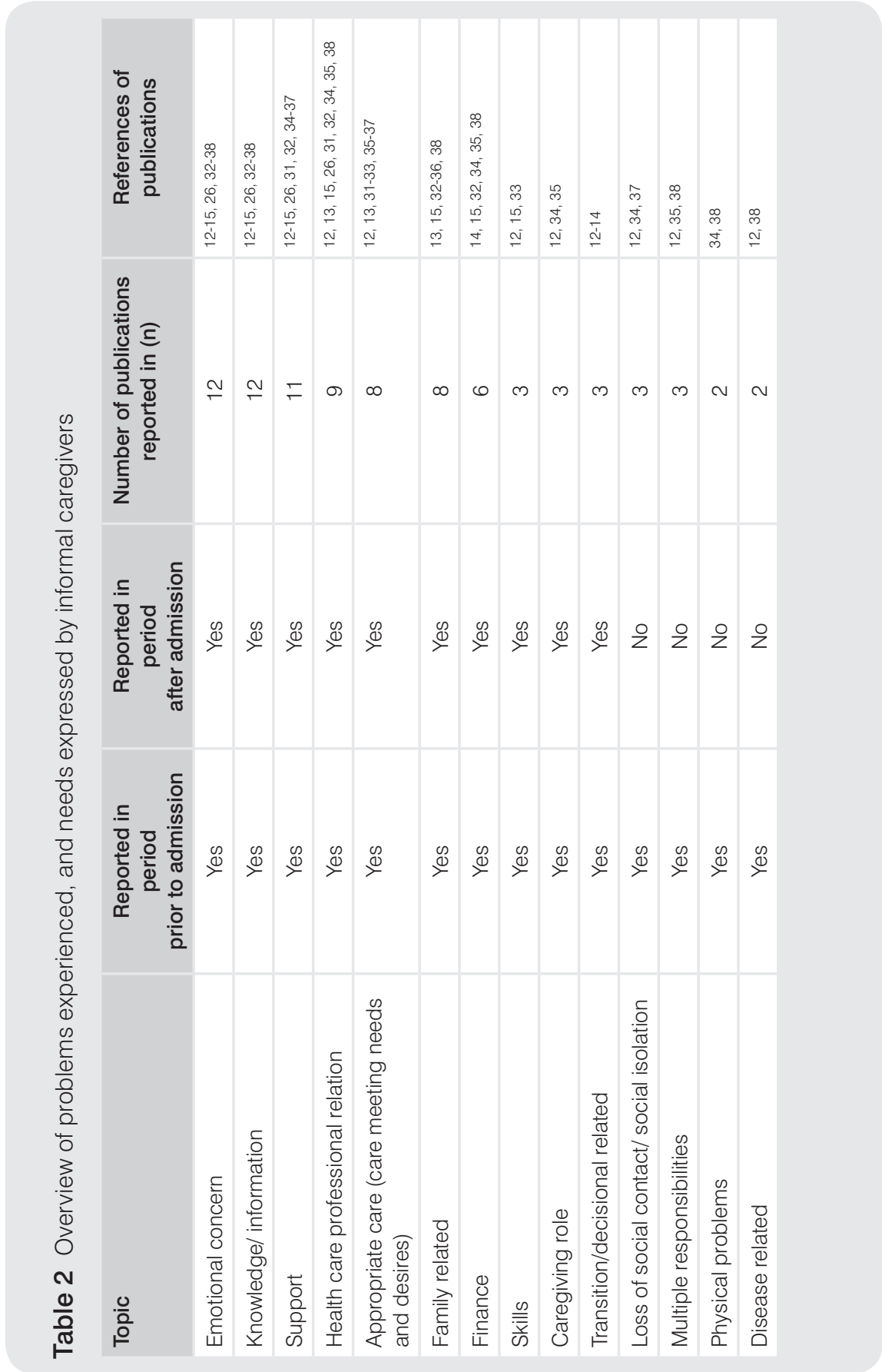


After admission, informal caregivers conveyed disappointment with the quality of care of ILTC. $32,33,36$ As reported in one publication, informal caregivers state how they feel that nursing staff in the ILTC facility do not have time and are overworked. ${ }^{36}$ One study inventoried appropriate care by asking for suggestions for how the care in ILTC can be improved..$^{13}$ Informal caregivers expressed a desire for a higher staff to resident ratio, which would improve the care conditions.

\section{Family related}

Prior to admission issues related to the family could be specifically due to the decisional process or placement. These problems were primarily due to disagreement about the decision. ${ }^{13,15,32-35}$ Some even stated that the situation resulted in damaged relations in the family. 32,35 Informal caregivers expressed needs in terms of the entire family sharing the decision ${ }^{13}$ and family involvement in the decision. ${ }^{36}$ Beside issues directly related to admission, other family related issues were reported as well. $33,34,38$ Mostly the problem lay in insufficient assistance, such as the inability to find substitute caregivers within the family. ${ }^{34}$

After admission, one of the lower quality publications reported on damaged relations. The caregiver stated: "Our family has dissolved over this whole thing. To this day, my sisters are not talking to me". ${ }^{38}$

\section{Finance}

Prior to admission, several family caregivers reported finance related issues. ${ }^{14,32,34}$ ${ }^{35,38}$ For example, the inability to afford private care at home ${ }^{34}$ or inability to afford nursing care as illustrated by the following quotation: "I have to provide the living expenses for my own family. My wife does not work because she needs to take care of the children. I know it would be better for my father to live in a good nursing home but I do not think I would be able to pay for it" .32

After admission financial problems were reported as well, which were primarily a result of the high costs of ILTC, 15, 34, 35, 38 with some reporting extreme financial strain

\section{Skills}

Prior to admission, informal caregivers expressed needs for skills.12, 15 Especially in terms of communication, such as practicing assertive communication, but also learning how to communicate better with the person with dementia. One publication ${ }^{33}$ specified a problem in terms of a lack of skills to perform caregiving tasks.

After admission, informal caregivers had a need for skills in communication, assertiveness and self-care. ${ }^{15}$ Regarding that last point, informal caregivers fo example reported that they want to know how to take care of their own mental and physical health.

\section{Caregiving role}

Prior to admission, some informal caregivers reported problems related to the caregiving role. ${ }^{34}, 35$ These problems arose, for example, from taking over new responsibilities that traditionally speaking were unfamiliar. One male caregiver reported "I can't even say how difficult things were. Cleaning ... and giving baths.... If I were a woman maybe things would have been easier, but being a man, I was going crazy". ${ }^{35}$

After admission, informal caregivers in one publication generally expressed a desire to be involved in their relative's care even after admission to ILTC; for example in communicating their relative's disabilities and needs to the staff. ${ }^{12}$ Others expressed how hard it was to adjust to a new and different caregiving role. Since informa caregivers are no longer the primary caregivers after admission, they had to relinquish the caregiver role that they used to assume at home. Some caregivers stated that it was not so easy to give up that role and adjust to the new rules in ILTC. ${ }^{34}$

\section{Transition related}

Prior to admission, informal caregivers in general felt unprepared for the transition.12, 13 In one publication it is reported that due to having to decide in a crisis, caregivers felt the situation "happened rather quickly".12 Caregivers reported specific needs to become more prepared, for example becoming acquainted with the ILTC prior to when it would be necessary to place their loved ones there.13 Others stated a need to talk with spouses or adult children of current residents to learn about the facility. ${ }^{14} \mathrm{~A}$ need for reassurance regarding the move, such as a 'neutral' person validating the move was also reported regarding the situation prior to admission. ${ }^{14}$

After admission, transition needs were expressed by one publication..$^{13}$ A need for reassurance regarding the move was expressed, meaning that informal caregivers needed to know they had made the right decision.

\section{Loss of social contact/social isolation}

This topic was only mentioned regarding the situation prior to admission, with statements about the informal caregiver such as a slow loss of independence, loss of social contact ${ }^{12}$ and isolation from surroundings. ${ }^{34}$ In one of the publications scoring lower on the quality appraisal, caregivers explained how friends seemed to stop coming over and stopped calling. ${ }^{37}$

\section{Multiple responsibilities}

Having multiple responsibilities also showed to be a problem 12, 35, 38 Caregivers, for example, described difficulties in juggling their own family and work commitments and the increasing needs of the care recipient. This topic was only reported on prio to admission. 


\section{Physical problems}

Physical problems were reported only prior to admission and were expressed as an exhaustion of the body over time. ${ }^{34} \mathrm{~A}$ lower quality study further reported the inability to control health problems. ${ }^{38}$

\section{Disease related problems}

This topic consisted of problems along the line of not recognizing the progress of the decline of the person with dementia, late identification of challenges associated with caring for a person with dementia and even denial of the dementia.12, 38 This topic was only found regarding the period prior to admission.

\section{Discussion}

This review identified three important domains of difficulties and needs as expressed by caregivers during the care transition period: 'emotional concerns', 'knowledge/ information' and 'support'. Prior studies on needs of informal caregivers, some in fields other than dementia, report similar types of needs, 5, 6, 8, 17, 20, 23 highlighting the importance of these needs and problems. Other often recurring topics in this review were: 'Health care professional relation' 'Appropriate care' 'Family related' and 'Finance'. The remaining topics were mentioned in less than half of the included publications

Over the course of the transition period we found similar topics and even similar needs and problems when looking at the situation prior to admission and the period after admission. Considering the many changes that occur in the relatively shor timeframe of the care transition, changes in needs and problems may be expected. The similarity in issues prior and after admission shows the transition period to be a continuum, and that despite some shifts in problems and needs, the period just before and just after admission should not be considered separately.

The findings of this review highlight the emotional turbulence informal caregivers go through when it comes to the decision regarding, and admission to ILTC. In all but one included publication, emotional concerns were mentioned in one way or another. Also, this topic was present prior as well as after admission, showing emotiona issues to be continuously present along the process of care transition and no dissolving after the decision is made. Emotional concerns can be considered a result of issues and circumstances. In this review we made the distinction between decision and non-decision related concerns, in which the decision can be considered the issue causing emotional turbulence. Non-decisional related emotional concerns can be related to other topics found in this review. Family related issues, such as disagreement, or more strongly, a damaged relation with other family members, can clearly be linked to emotional concerns. But also a lack of information, lack of appropriate care and dissatisfaction with the relationship with HCP, can lead to frustrations within the informal caregiver.

The need and lack of knowledge and information was another recurring topic, ranging from information on care options to knowledge about dementia. Whereas some issues were only relevant prior to admission, such as the need for care alternatives for ILTC, other issues were brought up both prior and after admission, such as understanding and knowing the policies, rules and regulations of the care system. As concluded by studies on service use in general among people with cognitive impairment, caregivers' non-use of services lies partly in unawareness of treatment options available to them 39,40 There are many websites, discussion groups, information flyers and other channels of information made available by forma care; however, it is clear that more guided ways of getting the information to informa caregivers may be necessary. The issue could lie in reaching the right persons at the appropriate moment, and not so much in a lack of available information. Now it seems the responsibility of informal caregivers to get the information they need however, they might not know where to look for this information or are looking for the wrong information. Perhaps there is a bigger role for general practitioners or case-managers in this task, making the information more one-on-one, tailored and initiated by formal care.

The need for support both from the social environment as from formal care was reported multiple times. While support is frequently mentioned, it is important to note that the form of support was often not made explicit, with only some defining it for example as support in supervising the person with dementia when they were not around ${ }^{31}$ up to professional counselling. ${ }^{12}$ Whether informal caregivers could not or did not specify what support they want, or whether interviewers did not prompt for further specification when informal caregivers stated a need for support is not clear. Evidence suggests that caregivers predominantly state aspects related to PwD, such as behavioural aspects, care-dependency and cognitive decline, as reasons for admission ${ }^{41}$ suggesting a need for support regarding these aspects. The reported problems and needs, on the other hand, are more related to caregivers themselves. There seems to be a discrepancy between reported reasons for admission and eported needs during the care transition period. Support therefore may be needed along the line of aiding informal caregivers to handle the situation, with a focus on those aspects that are considered reasons for admission but cannot be altered. Further research is needed to investigate what the support should entail and when and by whom it should be offered.

Unmet needs of caregivers may impede the ability to care for and support the persons with dementia, due to, for example, emotional and physical effects of caregiving. ${ }^{42,43}$ This in turn may result in unmet needs of the person with dementia as 
well, leading to earlier ILTC admission or even the demise of the person with dementia. ${ }^{44}$ This all stresses the importance of meeting the needs of informal caregivers. Studies show that caregivers may not indicate a need for improving care, ${ }^{39}$ however many caregivers do express a need for additional professiona support. ${ }^{5,} 6$ There may be a need for stronger promotion of services available, and therewith improving the knowledge on what is available, keeping in mind that countries can have a wide or limited range of formal services. Like stated before, the spreading of knowledge may have to be more driven from professionals, and not as much relying on the informal caregiver to find the information that is made available. Still, with the need of support being so prominently present in this review, forma support and guidance specific to the transition period should be developed. While at present, the situation up to admission and the situation after admission are stil viewed as two adjacent periods of care, with home-based care at the one side and ILTC on the other, service providers should aim for a more integrated trajectory of care. Looking at other interventions aimed at informal caregivers, we see that multicomponent interventions, comprising education, training, support an respite, "support caregiver's mood and morale and reduce burden". The components mentioned encompass all three main topics of problems and needs as found in this review and therefore offer a basis for developing care transition specific support and guidance. These programmes could have multiple functions, such as guidance in the actual decision, target the emotional effects such as guilt during this process, ease informal caregivers into their new role, and equip them with the tools needed to collaborate with HCP in ILTC (e.g. communication and assertiveness).

\section{Limitations}

This review has some limitations. It should be kept in mind that many studies aimed at describing experiences during the care transition period and not so much report explicitly on (un)met needs of informal caregivers. This may mean that more issues are experienced by informal caregivers that were not expressed in the publications. Still, when describing the care transition period, one may expect that the most important issues were mentioned, regardless of not being explicitly asked about. Furthermore, some themes were illustrated with multiple examples, while others were not. Support, for example, was often stated just as a need for support, without explicitly stating support in what area or how this support should look like. Lastly, we note a lack of European studies in the final included publications. Studies performed in Europe were identified during the search procedure, but were excluded as they did not meet the inclusion criteria. The studies did not target the transition period from home towards institutional care or focused on the needs of PwD instead of their informal caregivers. ${ }^{5}, 6,21-23,39$ Still the publications included had their origin in three continents, giving us results of informal caregivers from different cultures, care opportunities, care systems and organization. The similarity of needs and problems expressed by this diverse selection of caregivers, gives confidence in some generalizability of the results for not included countries with similar situations.

\section{Conclusions}

Informal caregivers of PwD tend to express needs or issues during the care transition period regarding emotional concerns, knowledge and information and support. Though one may expect changes in needs during care transition due to the turbulent nature of this period, similar topics and even similar needs and problems were reported prior and post admission. This suggests care transition to be a continuum and not consisting of two separate conditions. Support should be designed in a uninterrupted way, starting prior to admission and continuing after, which could result in better continuity of care. Since it is multicomponent interventions that prove effective for informal caregivers, ${ }^{1}$ these should also be offered specific to the care transition period. These programmes could target multiple aspects (the decision, the emotional effects, how to collaborate with HCP), and use the topics found in this review as a starting point for their development. 


\section{References}

Alzheimer's Disease International. World Alzheimer Report 2013 Journey of Caring An analysis of long-term care for dementia. London: Alzheimer's Disease International; 2013.

2. Alzheimer's Association. 2012 Alzheimer's disease facts and figures. 2012.

3. Alzheimer's Disease International. World Alzheimer Report 2009.Alzheimer's Disease International

Thompson GN, Roger K. Understanding the needs of family caregivers of older adults dying with dementia. Palliative and Supportive Care. 2013:1-9.

5. Zwaanswijk M, van Beek APA, Peeters J, Meerveld J, Francke AL. Problemen en wensen van mantelzorgers van mensen met dementie: Een vergelijking tussen de beginfase en latere fasen in het ziekteproces. Tijdschrift Voor Gerontologie en Geriatrie. 2010:41:162-71

6. Peeters JM, Van Beek APA, Meerveld JHC, Spreeuwenberg PMM, Francke AL. Informal caregivers of persons with dementia, their use of and needs for specific professional support: a survey of the National Dementia Programme. BMC Nursing. 2010;9:9p.

7. Rose KM, Palan Lopez R. Transitions in Dementia Care: Theoretical Support for Nursing Roles. Online Journal of Issues in Nursing. 2012;17:1

8. Dellasega C, Nolan M. Admission to care: facilitating role transition amongst family carers. Journal of Clinical Nursing 1997:6:443-51

9. Nolan M, Dellasega C. 'I really feel I've let him down': supporting family carers during long-term care placement for elders. Journal of Advanced Nursing. 2000;31:759-67.

10. Tilse C. Meaning as outcome: Understanding the complexity of decision-making around residentia placement in aged care. Australian Social Work. 2000;53:15-9.

11. Wendler D, Rid A. Systematic Review: The Effect on Surrogates of Making Treatment Decisions for Others. Annals of Internal Medicine. 2011:154:336-U208.

12. Bramble M. Moyle W. McAllister M. Seeking connection: family care experiences following long-term dementia care placement. Journal of Clinical Nursing. 2009;18:3118-25.

3. Butcher HK, Holkup PA, Park M, Maas M. Thematic analysis of the experience of making a decision to place a family member with Alzheimer's disease in a special care unit. Research in Nursing and Health. 2001;24:470-80

14. Kelsey SG, Laditka SB, Laditka JN. Caregiver perspectives on transitions to assisted living and memory care. American Journal of Alzheimers' Disease and Other Dementias. 2010;25:255-64.

15. Paun $\mathrm{O}$, Farran CJ. Hearing and healing the hurts of dementia, part 1: nursing home placement of persons with Alzheimer's disease. Alzheimers Care Quarterly. 2006;7:104-14.

16. Hileman JW, Lackey NR, Hassanein RS. Identifying the needs of home caregivers of patients with cancer. Oncology Nursing Forum. 1992;19:771-7.

17. Ventura AD, Burney S, Brooker J, Fletcher J, Ricciardelli L. Home-based palliative care: A systematic literature review of the self-reported unmet needs of patients and carers. Palliative Medicine. 2013.

8. Shankar J, Muthuswamy SS. Support needs of family caregivers of people who experience menta illness and the role of mental health services. Families in Society. 2007;88:302-10.

19. Henriksson A, Benzein E, Ternestedt BM, Andershed B. Meeting needs of family members of persons with life-threatening illness: A support group program during ongoing palliative care. Palliative and Supportive Care. 2011;9:263-71

20. Verhaeghe S, Defloor T, Van Zuuren F, Dujnstee M, Grypdonck M. The needs and experiences of family members of adult patients in an intensive care unit: a review of the literature. Journal of Clinica Nursing. 2005;14:501-9

21. Hancock GA, Reynolds T, Woods B, Thornicroft G, Orrell M. The needs of older people with menta health problems according to the user, the carer, and the staff. International Journal of Geriatric Psychiatry. 2003;18:803-11.

22. Hancock GA, Woods B, Challis D, Orrell M. The needs of older people with dementia in residential care. International Journal of Geriatric Psychiatry. 2006;21:43-9.
23. van der Roest HG, Meiland FJM, Comijs HC, Derksen E, Jansen APD, van Hout HPJ, et al. What do community-dwelling people with dementia need? A survey of those who are known to care and welfare services. International Psychogeriatrics. 2009:21:949-65.

24. Ducharme F, Beaudet L, Legault A, Kergoat M-J, Lévesque L, Caron C. Development of an intervention program for Alzheimer's family caregivers following diagnostic disclosure. Clinica Nursing Research. 2009;18:44-67.

25. de Vugt ME, Verhey FR. The impact of early dementia diagnosis and intervention on informa caregivers. Progress in Neurobiology. 2013.

26. Givens JL, Lopez RP, Mazor KM, Mitchell SL. Sources of stress for family members of nursing home residents with advanced dementia. Alzheimer Disease and Associated Disorders 2012.26.254-9. 7. Godfrey M. Callaghan G. Exploring unmet need. Joseph Rowntree Foundation York UK 2000

28. Deeken JF, Taylor KL, Mangan P, Yabroff KR, Ingham JM. Care for the caregivers: A review of eeds, and quality of life of informa sellrepor, istrut OECD. Long-term care for older people. Paris; 2005

30. Bunn. F. Goodman C Sworn K Rat G Brayne C Robinson L, et al Psychosocial factors that shape patient and carer experiences of dementia diagnosis and treatment: a systematic review of qualitative studies. Plos Medicine. 2012;9:e1001331-e.

31. Caron CD, Ducharme F, Griffith J. Deciding on institutionalization for a relative with dementia: the most difficult decision for caregivers. Canadian Journal on Aging. 2006;25:193-205.

32. Chang Y.P, Kraenzle Schneider J, Sessanna L. Decisional conflict among Chinese family caregivers regarding nursing home placement of older adults with dementia. Journal of Aging Studies. 2011;25:436-44.

33. Chang Y-P, Kraenzle Schneider J. Decision-making process of nursing home placement among Chinese family caregivers. Perspectives In Psychiatric Care. 2010;46:108-18.

34. Kwon SH, Tae YS Nursing Home Placement: The Process of Decision Making and Adaptation among Adult Children Caregivers of Demented Parents in Korea. Asian Nursing Research. 2012;6:143-51.

35. Park M, Butcher HK, Maas ML. A thematic analysis of Korean family caregivers' experiences in making the decision to place a family member with dementia in a long-term care facility. Research in Nursing and Health. 2004,27:345-56.

36. Strang VR, Koop PM, Dupuis-Blanchard S, Nordstrom M, Thompson B. Family caregivers and transition to long-term care. Clinical Nursing Research. 2006;15:27-45.

37. Armstrong M. Factors affecting the decision to place a relative with dementia into residential care Nursing Standard. 2000;14:33-7.

38. Liken MA. Caregivers in crisis: Moving a relative with Alzheimer's to assisted living. Clinical Nursing Research. 2001;10:52-68.

39. Wolfs CAG, de Vugt ME, Verkaaik M, Verkade P-J, Verhey FRJ. Empowered or overpowered? Service use, needs, wants and demands in elderly patients with cognitive impairments. International Journa of Geriatric Psychiatry. 2010;25:1006-12.

40. Brodaty H, Thomson C, Thompson C, Fine M. Why caregivers of people with dementia and memory loss don't use services. International Journal Of Geriatric Psychiatry. 2005;20:537-46.

41. Afram B, Stephan A, Verbeek H, Bleillevens MHC, Suhonen R, Sutcliffe C, et al. Reasons for Institutionalization of People With Dementia: Informal Caregiver Reports From 8 European Countries. Journal of the American Medical Directors Association. 2014;15:108-16.

42. Hwang SS, Chang VT, Alejandro Y, Osenenko P, Davis C, Cogswell J, et al. Caregiver unmet needs, burden, and satisfaction in symptomatic advanced cancer patients at a Veterans Affairs (VA) medica center. Palliative and Supportive Care. 2003;1:319-29.

43. Vitaliano PP, Russo J, Young HM, Teri L, Maiuro RD. Predictors of burden in spouse caregivers of individuals with Alzheimer's disease. Psychology and Aging. 1991;6:392-402.

44. Gaugler JE, Kane RL, Kane RA, Newcomer R. Unmet care needs and key outcomes in dementia. Journal of the American Geriatrics Society. 2005;53:2098-105. 


\section{6}

Informal Caregivers' Needs During Care Transition to Institutional Long-Term Care in Dementia: A Focus Group Study

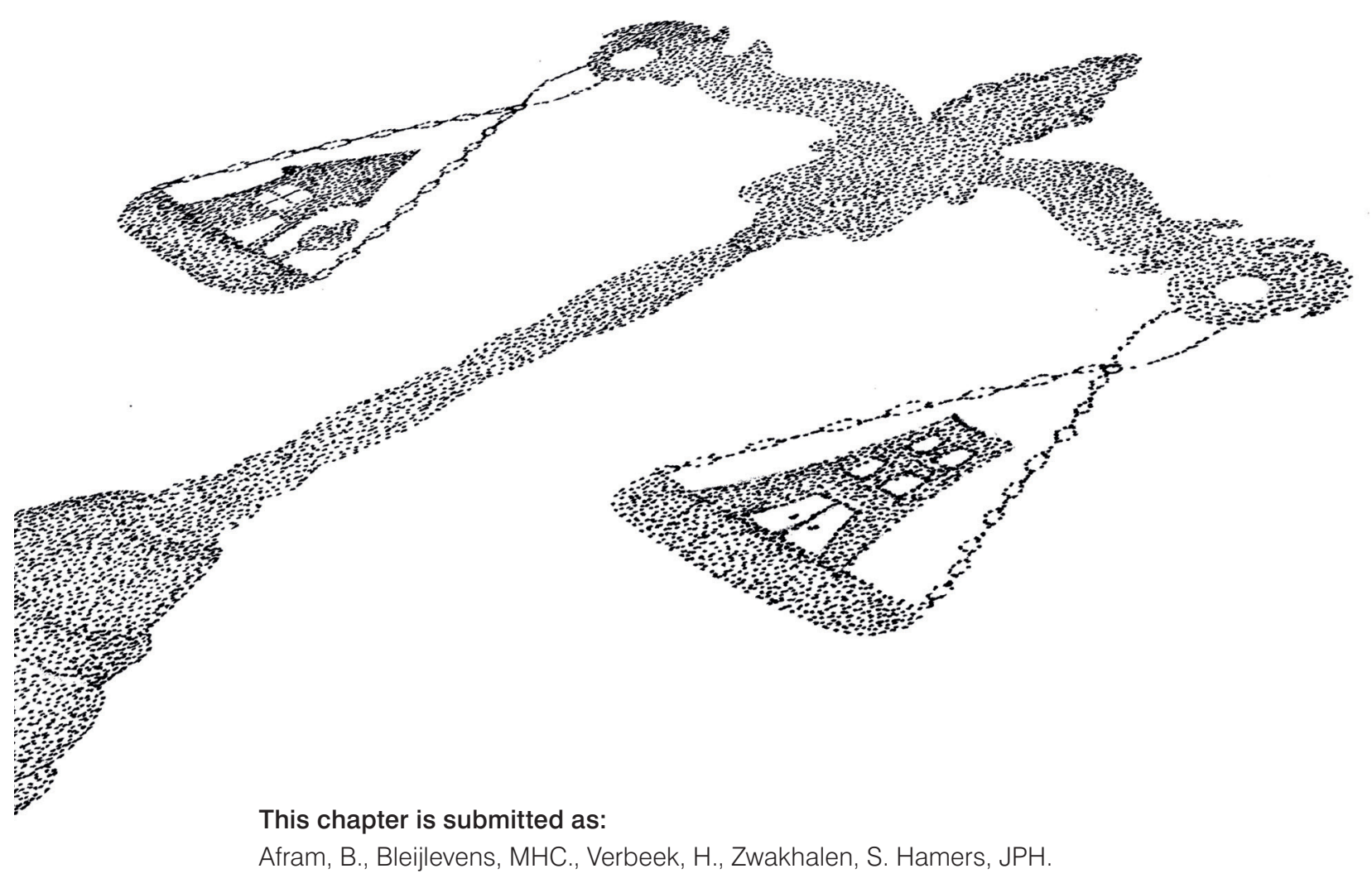




\section{Abstract}

Objectives: The transition period of a person with dementia from home towards institutional long-term care can be considered one of the most difficult processes for informal caregivers. In order to aid informal caregivers during this process, it is important to design the support based on the needs of the informal caregivers. Up to now it remains unclear what specific needs informal caregivers experience during the transition from home to institutional long-term care. This paper aims to provide in-depth descriptions of the needs expressed by informal caregivers of people with dementia during care transition from home-based care toward institutional long-term care.

Methods: During two focus group interviews, needs were identified of Dutch informa caregivers during the care transition period. Participants were identified and recruited from the pool of informal caregivers willing to participate in the RightTimePlaceCare study. Eligible participants were contacted by phone and invited for participation after receiving additional information.

Results: Similar needs were identified prior and post care transition. Needs regarded possibilities and manner of communication, more person centred care, the complexity of the current healthcare system and structure, social network, and caring impact on the informal caregiver.

Conclusions: This study emphasizes the need for a tailored approach for meeting the needs in which the care transition period is considered a continuum, starting a home and continuing in institutional long-term care. Two points for attention herein are the defragmentation of the care system and attention to the triad of care, being the care receiver, informal caregiver and healthcare professional.

\section{Introduction}

Informal caregivers are considered the cornerstone of dementia care ${ }^{1}$ with a prominent role in the care for people with dementia (PwD) throughout the entire dementia process, including the decision for the placement of the person with dementia in institutional long-term care (ILTC). ${ }^{2-5}$ As dementia progresses there will come a point when the care needs of the person with dementia cannot be optimally met in the home situation, exceeding the possibilities of home-based care. When care at home becomes less optimal in meeting the care needs of the person with dementia, the so called care transition period from home-based care to ILTC will start. In this article, the care transition period is considered any amount of time starting from the period prior to admission when admission is contemplated, up to an adjustment period after actual admission. The care transition period thus not solely consists of the decision for, and actual move toward ILTC. This period is not clear cut and differs from case to case, which means it is not a set period of time.

The care transition period toward ILTC is one of the most invasive and challenging processes for informal caregivers. 3, 6, 7 While still at home, the decision for transition is the most difficult for informal caregivers. This is especially true if the decision cannot be discussed with the person making the care transition, as is the case for PwD, and informal caregivers are unsure about what the person with dementia would want. ${ }^{8}$ After the actual transition, informal caregivers reportedly experience guilt, doubt, sadness, feelings of betrayal and a sense of failure because of the decision. ${ }^{8-11}$ This means that beside providing care, informal caregivers will also develop needs for professional care and guidance themselves. Particularly during care transition professional guidance is very much appreciated by informal caregivers. ${ }^{12-14}$ Providing this professional guidance requires an understanding of the needs and related problems experienced by informal caregivers, to develop programs and protocols for professional support.

Presently, most studies on needs, both of care receivers as informal caregivers, do not consider the whole transition period but either focus on the period prior to admission, ${ }^{15-17}$ or the period after admission. ${ }^{18,} 19$ Knowledge on the perceived needs and related problems of informal caregivers specific to the whole care transition period is currently lacking

Because informal caregivers reportedly appreciate support and guidance during care transition, there needs to be an understanding of the encountered needs and related problems. This article therefore aims to provide in-depth descriptions of the needs expressed by informal caregivers of PwD during care transition from homebased care toward ILTC. 


\section{Methods}

\section{Study design}

Two focus group interviews were held in the southern region of the Netherlands which were nested within the RightTimePlaceCare (RTPC) project. ${ }^{20}$ Given the exploratory nature of the study aim, acquiring multiple views and processes regarding needs, a focus group design was used. Focus groups allow caregivers the opportunity to explore and clarify their views by means of exchanging experiences with other participants, ${ }^{21}$ providing that multi-view data sought for

\section{Sample}

Participants of the focus groups consisted of informal caregivers of PwD. Participants were identified and recruited from the pool of informal caregivers willing to participate in the RTPC study. Informal caregivers were eligible if they were the primary informa caregivers involved in the care for a person with dementia. The PwD they cared for had to either 1) recently be admitted to ILTC; or 2) receive professional care at home, but were considered at risk for admission to ILTC, meaning that a healthcare professional indicated that there was a substantial possibility of the person with dementia to be admitted to ILTC within six months. Of the twelve informal caregivers invited to participate in the focus groups, ten actually participated in the group discussions (five informal caregivers in each session). One of the invited caregivers that did not participate was sick on the day of the focus group, the other forgot the appointment. Smaller groups (four to six participants) were chosen as these are easier to handle by moderators and increase the likelihood of interaction between participants. ${ }^{22}$ Participants were purposively sampled to maximize diversity in living condition of the PwD (i.e. at home and in ILTC), age of the informal caregiver and relation to the person with dementia (e.g. spouse, sibling, child). Eligible informa caregivers were contacted by phone, to provide them with more information about the focus group, and were invited to participate.

\section{Focus groups procedure}

A moderator with previous experience in leading focus groups led both focus group discussions. The first focus group took place at one of the participating nursing homes; the second session took place at the university. A semi-structured interview guide was used to lead the discussions. During the focus groups, the experiences of informal caregivers with healthcare professionals and care services were discussed. The questions asked focused specifically on the care transition period, asking about what informal caregivers need and consider important during this period (e.g. regarding support, information and guidance). Furthermore, informal caregivers were asked about when healthcare was working at its best and at its worst and what characterized these situations. The communication and collaboration in healthcare and with healthcare professionals were discussed as well. Where needed additional, or follow-up questions were asked to help the participants in answering the questions Alongside the moderator, MB and SZ were present during the focus group discussions to support the moderator in the discussion and make field notes during the sessions. Prior to the focus group discussions participants were informed on what they could expect during the session and asked consent for audiotaping the focus group discussion. Participants were also assured that the data will be confidential and that reporting of findings will be anonymous. After receiving consent, the focus group discussions commenced and lasted approximately two hours each (time prior to taping not included)

\section{Analysis procedure}

The audio files were transcribed verbatim. To answer the research aim content analysis was used to thematically organize the needs of informal caregivers during care transition. The verbatim transcripts were the 'units of analysis', ${ }^{23}$ which BA and MB examined independently. To be immersed in the data BA and MB read the transcripts multiple times, sometimes alongside the audio files. Then BA and MB organized the data into 'meaning units' consisting of complete statements of participants. ${ }^{23}$ These 'meaning units' were condensed to so called 'condensed meaning units', which entails shortening the units while still preserving the core meaning ${ }^{23}$. These condensed meaning units were then organized into themes and subthemes. The emerging themes came about through conventional content analysis. Conventional content analysis avoids using preconceived categories, but derives the (names of) themes straight from the data at hand, ${ }^{24}$ making it an appropriate method for exploratory studies. After individual coding, BA and MB together with HV compared the results. Differences were discussed by reviewing transcripts and individual notes to reach consensus. The entire process was iterative going back and forth in the transcripts to find the needs, and to categorize, cluster rename and structure them into themes.

"Thick descriptions" were aimed for in describing the themes. This approach no only offers an overview of themes, but in addition tries to offer more interpretations within the specific context of the care transition of $\mathrm{PwD}$ and the experiences thereo by informal caregivers. ${ }^{25}$ 


\section{Results}

\section{Sample}

Table 1 shows characteristics of both the informal caregivers and the PwD they cared for. Informal caregivers had an average age of 61 years, were predominantly female (80\%), and $50 \%$ was the child of the person with dementia. These informal caregivers cared for PwD with an average age of 79 years, who were predominantly female $(60 \%)$ of which the majority $(60 \%)$ was living in an ILTC facility.

\section{Needs during care transition}

Five salient themes were found, describing needs and related problems encountered by informal caregivers during the care transition period. The themes were: communication, person centred care, current healthcare system and structure, social network, and caring impact on the informal caregiver.

During the focus group discussion informal caregivers initially struggled with expressing their needs when they were asked directly what they would need during the care transition in terms of services and other forms of professional support. Nonetheless, when they were guided more by follow-up questions, they were more able to formulate their specific needs.

Over all, similar themes of needs were expressed prior and after admission. For example, both in the home situation as in ILTC, caregivers expressed a desire for contact with healthcare professionals to receive feedback regarding the care for the person with dementia. Accordingly, the results are presented as a continuum, without making the specific distinction between the period prior to, and the period after admission. Furthermore, for some informal caregivers certain needs remained unfulfilled whereas other caregivers had services available to meet similar needs. No distinctions are made between met and unmet needs in our results

Table 2 shows a detailed overview of the findings, showing the themes, as well as subthemes. Additionally, an illustrational quote is presented per theme. The themes can be interlinked with each other, as will be described here.

Dissatisfaction with the manner of communication of, and by healthcare professionals was a recurring topic, as were the possibilities for communication, with caregivers stating for example needs for regular contact moments and communication in the form of a dialogue. In the light of this study it can be argued that bad or insufficient communication could influence other themes found in this study. Under the theme person centred care, for example, informal caregivers expressed a need for healthcare professionals to look for solutions regarding the care of PwD. Miscommunication between healthcare professionals could impede their ability to look for care solutions, showing an importance of communication in person centred care. Communication

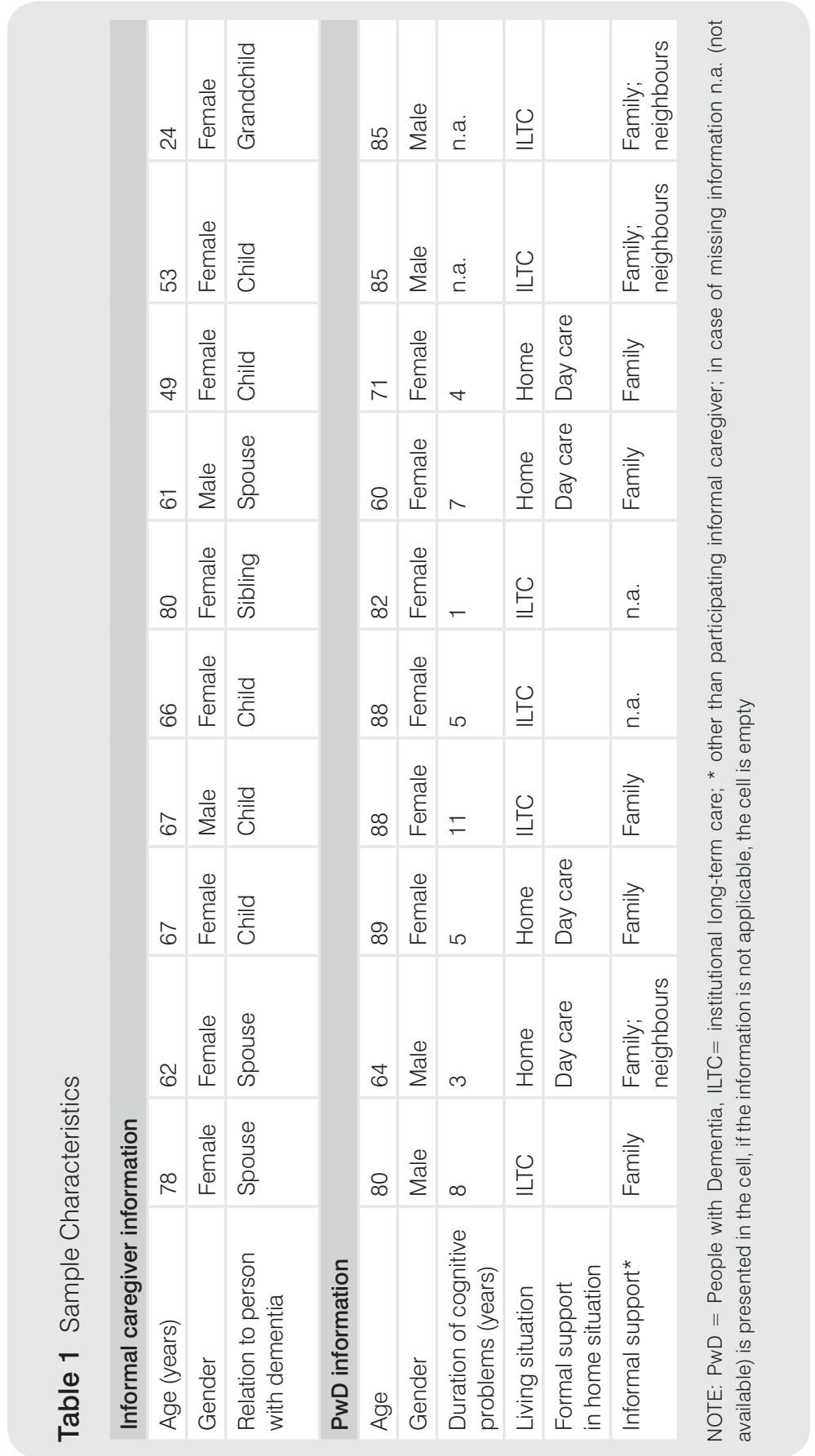




\begin{tabular}{|c|c|c|c|c|c|c|c|c|c|c|}
\hline$\stackrel{\underline{\underline{\underline{\underline{D}}}}}{\underline{\underline{n}}}$ & 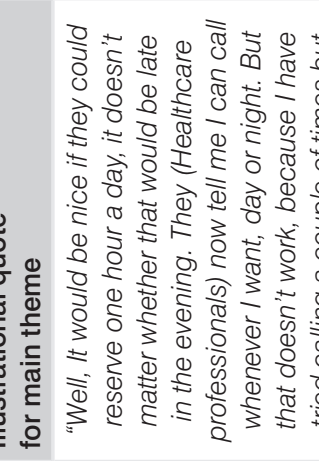 & 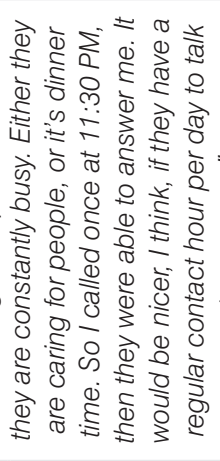 & & 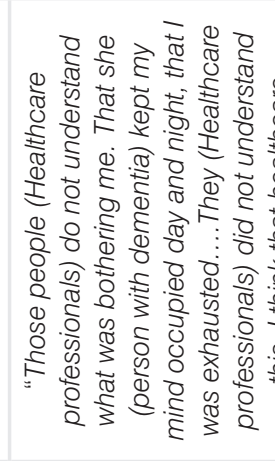 & 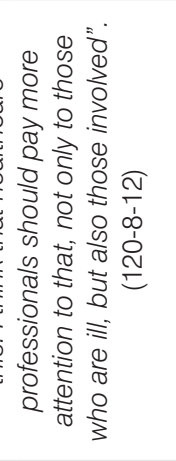 & & & \multicolumn{3}{|c|}{ 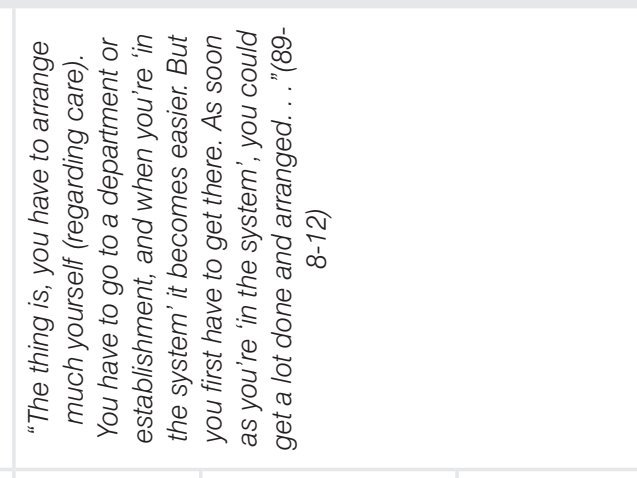 } \\
\hline 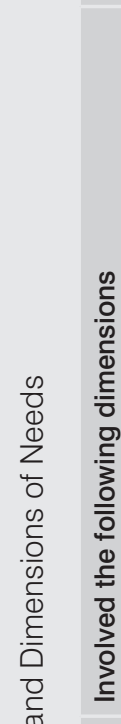 & 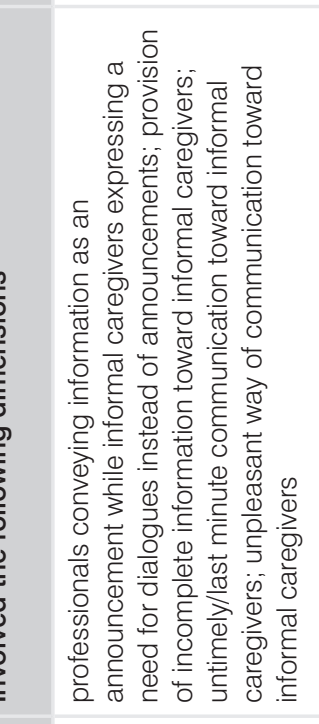 & 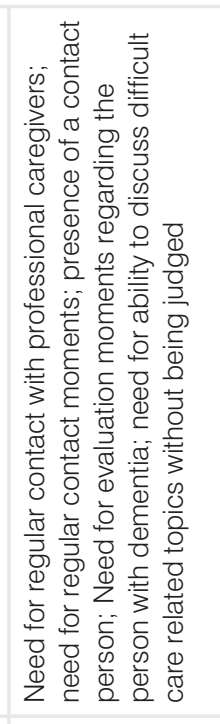 & 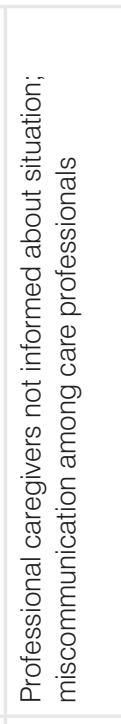 & 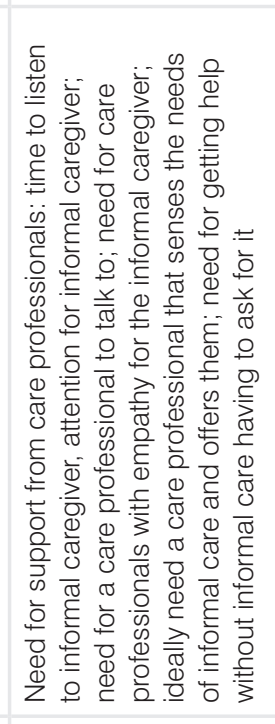 & 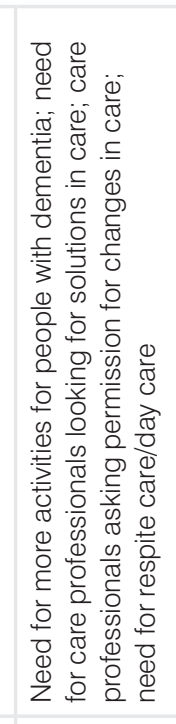 & 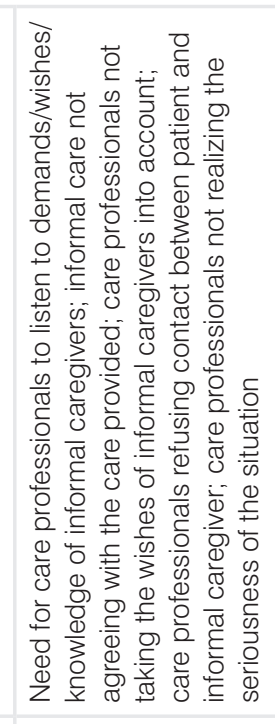 & 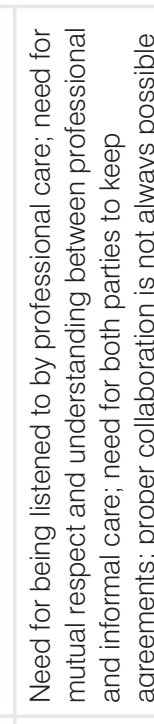 & 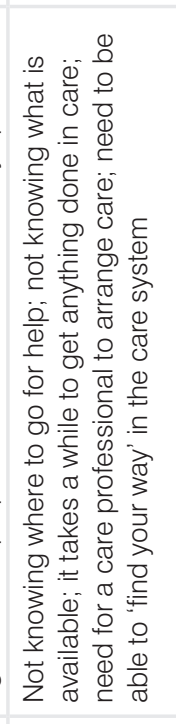 & 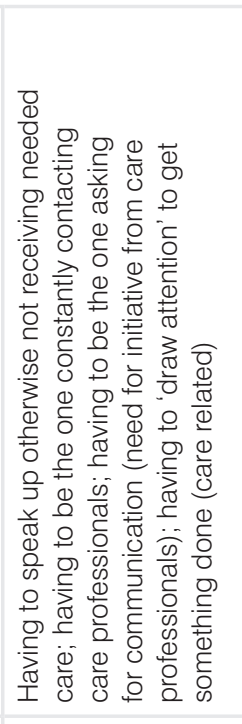 & 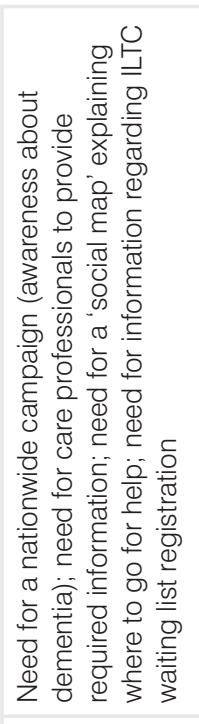 \\
\hline 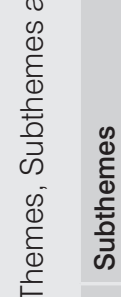 & 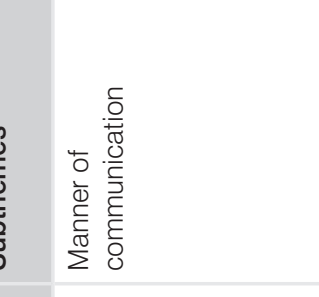 & 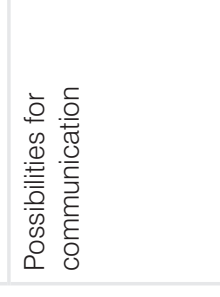 & 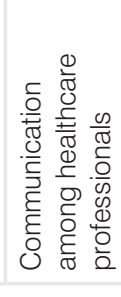 & 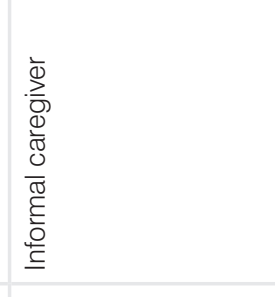 & 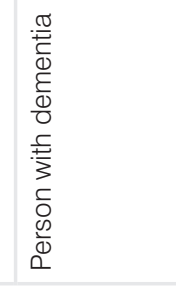 & 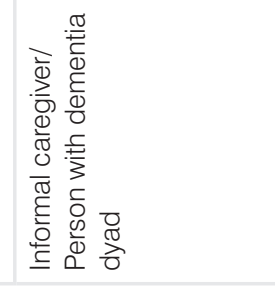 & 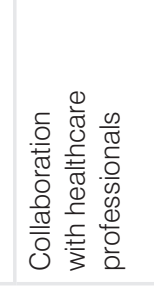 & 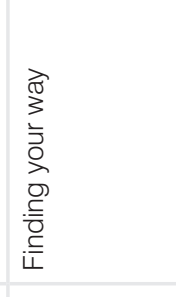 & 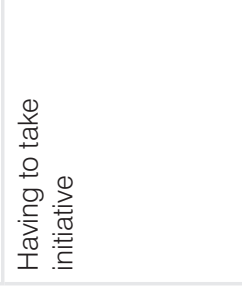 & 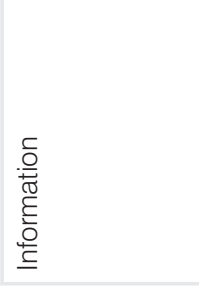 \\
\hline 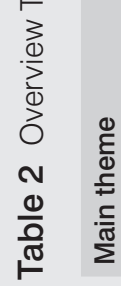 & & & & 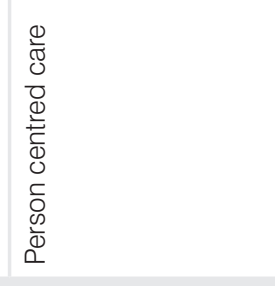 & & & & 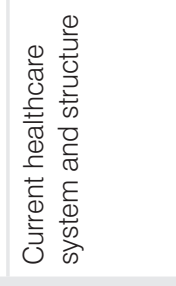 & & \\
\hline
\end{tabular}




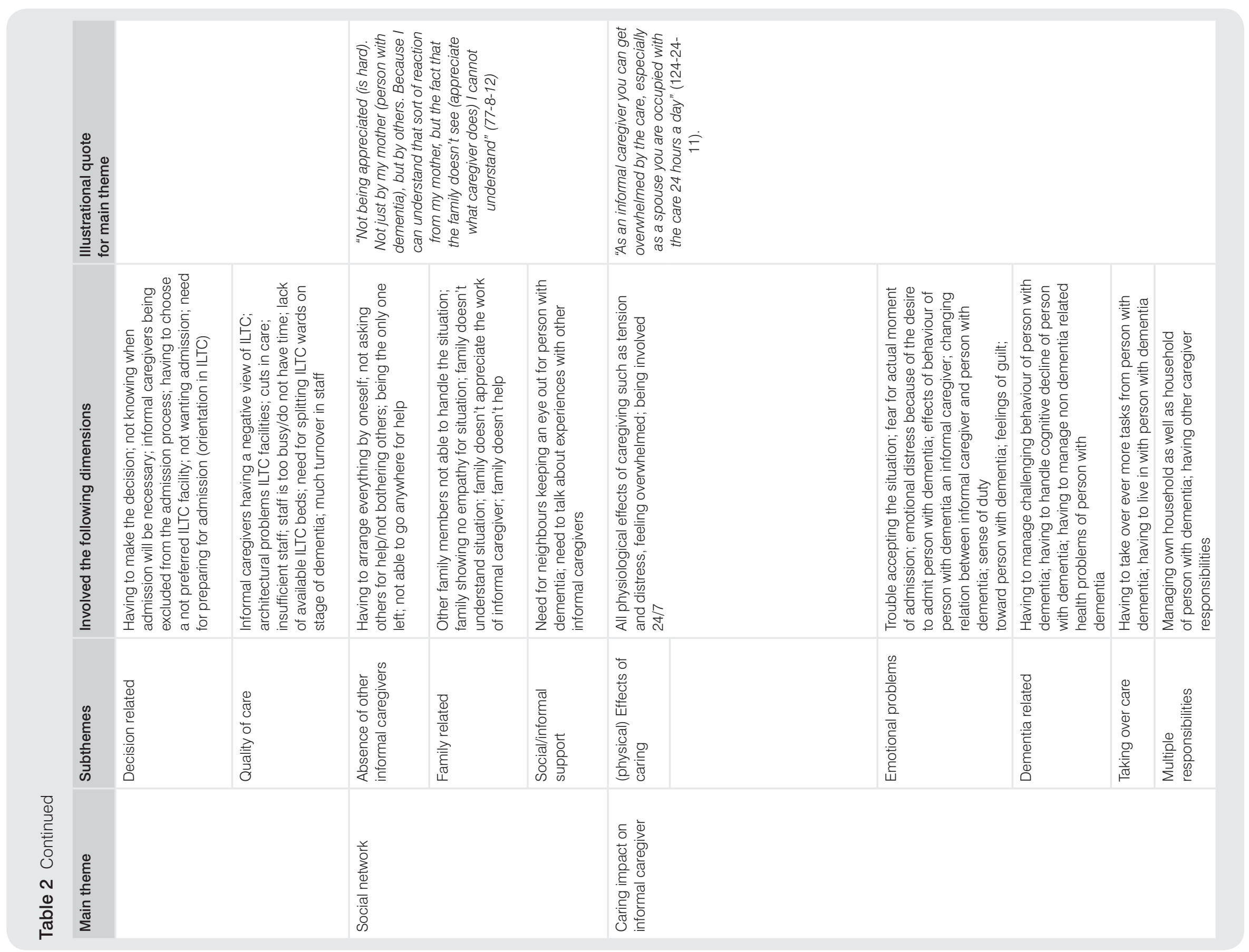


can also be linked to needs within the theme 'current healthcare system and structure'. For example, within the theme communication informal caregivers state they constantly have to initiate communication and explicitly state a need for healthcare professionals to take initiative, which is a need expressed under 'current healthcare system and structure' (see table 2).

Within the theme 'person centred care', needs were reported on care for the person with dementia, the informal caregiver, but also needs that affected the PwD-informal caregiver dyad. Concerning the theme 'person centred care', there is an influence on caring impact which informal caregivers experience. For example, if informal caregivers, do not receive the option to vent and talk about their experiences to an empathetic healthcare professional, which are needs within person centred care, the emotional impact of caring might become more prominent, which falls under caring impact. Person centred care also consisted of care tailored to the needs and wishes of the care receiver. Not being able to find the way in the current healthcare system decreases the chance of receiving all the care to fulfil the needs, therewith showing a link between person centred care and the theme 'current healthcare system and structure'.

Issues related to the current healthcare system and structure can influence needs in other themes. The need of knowing what care and support is available and knowing where to get it was frequently mentioned as a need within the current healthcare system and structure. Not having this information can lead to non-use of services, which in turn influences the caring impact on the informal caregiver with caregivers taking over care or developing physical or emotional problems. Finally, cuts in care and therewith fewer healthcare professionals were discussed which could result in an increase in responsibilities for informal caregivers. This could, in turn, also result in physical or emotional problems. Furthermore the subthemes within the theme 'current healthcare system and structure' have interrelated needs, for example information is needed to be able to find your way in the system (see table 2).

The needs expressed in the theme 'social network' had one main underlying topic throughout, which is sharing responsibilities for the care of the person with dementia. Being the only caregiver or not being able to share responsibilities has clear links to the caring impact on the informal caregiver, not only physical o emotional, but also taking over care and having multiple responsibilities. Socia network also related to person centred care and the current healthcare system. For example, the need to talk with other informal caregivers, as expressed under the theme 'social network' can be a way to vent (as described under 'person centred care').To get this service, for instance in the form of support groups, caregivers need to know this service exists, which is a need expressed under the theme 'current healthcare system
Finally, multiple needs were mentioned that were the result of direct caregiving Many of these could be intercepted by applying services mentioned in the previous themes, as can be read by the links made previously.

\section{Discussion}

Our results show a wide variety of needs experienced by informal caregivers during the care transition period, with differences between the various caregivers. The diversity in needs between informal caregivers highlights the individuality of informa caregivers and the need for a multicomponent tailored approach to meet said needs. Though the individuality of informal caregivers should be heeded, certain overarching concepts should be noted. First, informal caregivers stated comparable needs prio and post admission. This similarity highlights that the care transition period from home towards ILTC should be defined as a continuum and not so much a single point in time (being the actual move from home-based care toward ILTC). Second, the diverse needs expressed could be subdivided into five overarching themes within this continuum: 1) communication, such as improving possibilities for communication between healthcare professionals and informal caregivers; 2) person centred care, with a need for care specified to the informal caregiver; 3) current healthcare system and structure, in particular the complexity of finding your way in the system as an informal caregiver; 4) social network, with informal caregivers experiencing isolation in the care for PwD; and 5) caring impact on the informal caregiver, especially physical and emotional consequences of caregiving. Previous studies on needs, not all specific to dementia and none specific to the care transition period, found comparable domains. ${ }^{10,26-31}$ Interventions aimed at informal caregivers of PwD target the increase of knowledge, address communication, and promote counselling, ${ }^{32-34}$ which are also similar domains as the needs in our results. These studies also show that it is the multicomponent interventions that have the best effects, though these effects are moderate. Considering the themes are connected to each other, and that multicomponent programs are most effective, ${ }^{1}$ a multicomponent approach should be offered during the care transition period as well.

Some questions arise based on our results, which are whether the current supply of services is appropriate and sufficient to meet the needs of informal caregivers, and why appropriate care and services, seemingly, not always reach the persons who need it, at the right moment. This all could point to a diminished tailored approach of meeting the needs of informal caregivers during the care transition period. The ollowing two aspects could be of importance in optimizing the care: 1) defragmentation of the current healthcare system; 2) more focus on the triad of care, consisting of the care receiver, informal caregivers and all healthcare professionals involved in the care. 
Despite studies identifying the importance of continuity of care, especially in chronic and elderly care. ${ }^{35-39}$ At present, the healthcare system is often fragmented with the care transition period being considered two separate conditions and the care is provided by multiple and individual care organizations, As an example of the fragmentation, in the Netherlands the care in both settings is financed through different systems with intramural care regulated on a national level, while home care is regulated on municipal level. ${ }^{40,}{ }^{41}$ The separation of both settings could result in a lack of transparency of what is already offered in terms of services and whose responsibility (home care providers or ILTC) certain services are, which could lead to voids in service provision. Based on our results, defragmentation of care provision prior and post admission could be a way of optimizing and tailoring care during the care transition period to the needs of informal caregivers. A solution for the fragmentation in care provision might be to bridge the two systems by a healthcare professional who is knowledgeable of both systems and, in addition, is aware of the individual situation and needs of the informal caregiver.

Looking at the existing range of tasks, case management might fulfil this bridge function. Case management is currently offered in the home situation and is mostly terminated at care transition. It would be beneficial if case managers stay involved and continue their tasks even after a change in setting. Informal caregivers might profit if the case manager stays on and guides them, because this is a person they know and trust. ${ }^{42}$ Though the role of case manager is operationalized differently between different care organizations, between, but also within countries, ${ }^{43-45}$ certain tasks are universal to case management. Looking at dementia care plans, case managers ought to fulfil tasks such as respond to specific care needs, direct and guide people towards information, and facilitate access to appropriate care.43, 45, 46 With additional training regarding the care system, case managers could introduce and guide informal caregivers through the new environment of ILTC and the new rules and regulations in addition to the other tasks they were already offering in the home situation. In fulfilling such a function, case managers would meet multiple needs as described in this study among different themes (e.g. person centred care, current healthcare system and structure). Continuity of care and services in this way would not only require changes from the level of the healthcare organizations, but also from the healthcare system, because such changes might also involve adjustment in the financing of services.

Besides defragmentation of the care system, improving the care triad could also optimize the care during the care transition period. Currently it is commonly accepted that the unit of care consists not only of the person with dementia, but also the socia environment, which are the informal caregivers. ${ }^{47,} 48$ However, all healthcare professionals involved in the care should also be taken into account, because they influence the care dynamic as well. Several studies state the importance to explore what each part of the triad brings to the dynamic. ${ }^{49-51}$ In terms of our results, one of the issues was that informal caregivers seemed to have difficulties in stating what they need when they weren't guided in answering this question. Not being able to pronounce ones needs could result in non-use of services, which in turn could result in unmet needs. In a care system in which empowerment of care receivers is promoted, and in which it is expected that care receivers voice what they need, ${ }^{52}$ no being able to voice these needs is an important issue. As part of the care triad al healthcare professionals involved could play an important facilitating role by guiding informal caregivers in voicing their needs. In order to fulfil said role, there may be a necessity for training healthcare professionals in perceiving the needs of informa caregivers and anticipating on them. The competence of being attentive and perceiving and anticipating on the needs is consistent with a professional competence, as described in several studies, such as a competence in mindful care. ${ }^{53-56}$ Though one of the most used models using attentiveness is explained by Tronto (2001). This model states how care consists of four elements: Caring for, which involves assuming responsibility; Caregiving, which is the actual performing of care tasks; Care receiving, which involves the response of the care receiver to the care received; and Caring about, involving attentiveness which is the recognition of others' needs to respond to them. ${ }^{57}$ While the responsibility for caring does not seem to be an issue and enough attention is paid to competences for providing care, it is the attentiveness that might need improving. Our results actually state the need for formal caregivers to 'sense' what is needed and anticipating on this. Additionally, some evidence shows how informal caregivers were sometimes unaware of care possibilities that were in fact offered by healthcare professionals..$^{52}$ This could in part be due to a flaw in communication, or interaction with the informal caregivers, which points to the importance of the communication and person centred care themes in this study. Attentiveness to the individuality of each informal caregiver could help healthcare professionals to notice not only what informal caregivers need in terms of care services, but also how to interact with informal caregivers. Consequently, there should not only be attention to providing information on care options, but also how this is done and in making sure this information is actually reaching the informal caregivers.

\section{Limitations}

This study had a relatively small sample size of caregivers that were all from the southern region of the Netherlands. However, reaching saturation was not per sé the aim. In this study offering "thick descriptions" of the needs was of more importance than saturation. ${ }^{25}$ Furthermore, there were informal caregivers in our sample along the entire line of the care transition period, that is to say, informal caregivers who were or had contemplated admission as well as informal caregiver who had already placed 
the person with dementia in ILTC. This offered a wide range of needs despite the limited sample size, with informal caregivers adding to each other's' experiences (both reminiscing the situation prior to admission as well as thinking ahead and imagining what they might need in the future).

\section{Conclusion and implications}

This study showed the importance of communication, person centred care, current healthcare system and structure, social network, and caring impact on the informa caregiver during the care transition period. Considering the continuing existence of unmet needs in informal caregivers during the care transition period, improvement in care, and support provision for informal caregivers is required.

In addition to multiple components, tailored care provision should again be stressed here. Considering the diversity of needs, there cannot be a one-size-fits-al approach in fulfilling the needs of informal caregivers during the care transition period, which should be kept in mind when offering multicomponent programs. Healthcare professionals should mix and match the multiple components to exactly fit the individual's needs, at the appropriate moment when they need it. Certain additional competences for healthcare professionals are important to perceive the needs, without informal caregivers having to state them. Besides improving attentiveness, improving communication skills might be necessary in order adjust their manner of communication to the informal caregiver, to make sure information is actually reaching the informal caregiver. With the options stated previously, the possibilities of optimizing the care and meeting needs of informal caregivers during the care transition period more effectively seems feasible. As soon as the topic of care transition rises, be it when it's brought up by informal caregivers, or by the healthcare professional, the individual needs within these themes should be identified. A template with examples of explicit needs within each theme could be used by healthcare professional to discuss the situation with the informal caregiver in a guided fashion.

\section{References}

Alzheimer's Disease International. World Alzheimer Report 2013 Journey of Caring An analysis of Iong-term care for dementia. London: Alzheimer's Disease International; 2013

2. Caron CD, Bowers BJ. Deciding whether to continue, share, or relinguish caregiving caregiver views. Qualitative Health Research. 2003:13:1252-71.

3. Caron CD, Ducharme F Griffith J. Deciding on institutionalization for a relative with dementia: The mos difficult decision for car, givers. Canadian Journal on Aging Revue Canadienne Du Vieillissement 2006; 25:193-205.

4. Lundh U, Sandberg J, Nolan M. 'I don't have any other choice': spouses' experiences of placing partner in a care home for older people in Sweden. Journal of Advanced Nursing 2000:32:1178-86.

5. Graneheim UH, Johansson A, Lindgren BM. Family caregivers' experiences of relinquishing the care of . Journal of Caring Sciences. 2014;28:215-24.

6. Livingston G, Leavey G, Manela M, Livingston D, Rait G, Sampson E, et al. Making decisions for people with dementia who lack capacity: qualitative study of family carers in UK. British Medical Journal. 2010;341.

7. Gaugler JE, Pearlin LI, Leitsch SA, Davey A. Relinquishing in-home dementia care: difficulties and perceived helpfulness during the nursing home transition. American Journal of Alzheimers' Disease and Other Dementias. 2001;16:32-42.

8. Wendler D, Rid A. Systematic Review: The Effect on Surrogates of Making Treatment Decisions for Others. Annals of Internal Medicine. 2011;154:336-U208.

9. Tilse C. Meaning as outcome: Understanding the complexity of decision-making around residentia placement in aged care. Australian Social Work. 2000;53:15-9.

10. Dellasega C, Nolan M. Admission to care: facilitating role transition amongst family carers. Journal of Clinical Nursing. 1997;6:443-51

11. Nolan M, Dellasega C. 'I really feel I've let him down': supporting family carers during long-term care placement for elders. Journal of Advanced Nursing. 2000;31:759-67.

2. Bramble M, Moyle W, McAllister M. Seeking connection: family care experiences following long-term dementia care placement. Journal of Clinical Nursing. 2009;18:3118-25

13. Butcher HK, Holkup PA, Park M, Maas M. Thematic analysis of the experience of making a decision to place a family member with Alzheimer's disease in a special care unit. Research in Nursing and Health 2001;24:470-80.

14. Kelsey SG, Laditka SB, Laditka JN. Caregiver Perspectives on Transitions to Assisted Living and Memory Care. American Journal of Alzheimers Disease and Other Dementias. 2010;25:255-64.

15. Hileman JW, Lackey NR, Hassanein RS. Identifying the needs of home caregivers of patients with cancer. Oncology Nursing Forum. 1992;19:771-7.

6. Ventura AD, Burney S, Brooker J, Fletcher J, Ricciardelli L. Home-based palliative care: A systematic literature review of the self-reported unmet needs of patients and carers. Palliative Medicine. 2014;28:391-402.

7. Shankar J, Muthuswamy SS. Support needs of family caregivers of people who experience mental illness and the role of mental health services. Familes in Society. 2007;88:302-10.

18. Henriksson A, Benzein E, Ternestedt BM, Andershed B. Meeting needs of family members of persons with life-threatening illness: A support group program during ongoing palliative care. Palliative and Supportive Care. 2011;9:263-71

19. Verhaeghe S, Defloor T, Van Zuuren F, Duijnstee M, Grypdonck M. The needs and experiences of family members of adult patients in an intensive care unit: a review of the literature. Journal of Clinical Nursing. 2005;14:501-9.

20. Verbeek H, Meyer G, Leino-Kilpi H, Zabalegui A, Hallberg IR, Saks K, et al. A European study investigating patterns of transition from home care towards institutional dementia care: the protocol of a RightTimePlaceCare study. BMC Public Health. 2012;12:68.

21. Kitzinger J. Qualitative Research - Introducing Focus Groups. British Medical Journal. 1995;311:299-302. 22. McLafferty I. Focus group interviews as a data collecting strategy. Journal of Advanced Nursing. 2004 48:187-94. 
23. Graneheim UH, Lundman B. Qualitative content analysis in nursing research: concepts, procedures and measures to achieve trustworthiness. Nurse Education Today. 2004;24:105-12.

24. Hsieh HF, Shannon SE. Three approaches to qualitative content analysis. Qualitative Health Research. 2005; $15: 1277-88$.

25. Ponterotto JG. Brief note on the origins, evolution, and meaning of the qualitative research concept "thick description". The Qualitative Report. 2006:11:538-49.

26. Peeters $J$ Werkman W, Francke 2014.

27. Peeters $J$, Werkman W, Francke AL. Mantelzorgers over ondersteuning bij dementie door het sociale netwerk en de gemeente.NIVEL; 2014

28. Peeters JM, Van Beek APA, Meerveld JHC, Spreeuwenberg PMM. Francke AL. Informal caregivers of persons ,

Zwaanswijk M, van Beek APA, Peeters J, Meerveld J, Francke AL. Problemen en wensen van Znergers van mensen met dementie: Een vergelijking tussen de beginfase en latere fasen in het . 2010;41:162-71

30. Ventura AD, Burney S, Brooker J, Fletcher J, Ricciardelli L. Home-based palliative care: A systematic Weralure

31. van der Roest HG, Meiland FJM, Comijs HC, Derksen E, Jansen APD, van Hout HPJ, et al. What do community-dwelling people with dementia need? A survey of those who are known to care and welfare Psychogeriatrics. 2009;21:949-65.

32. Selwood A, Johnston K, Katona C, Lyketsos C, Livingston G. Systematic review of the effect of psychological interventions on family caregivers of people with dementia. Journal of Affective Disorders. 2007:101:75-89.

33. Elvish R, Lever S-J, Johnstone J, Cawley R, Keady J. Psychological interventions for carers of people with dementia: A systematic review of quantitative and qualitative evidence. Counselling and Sychotherapy Research. 2013:13:106-25.

34. Pinquart M, Sörensen S. Helping caregivers of persons with dementia: Which interventions work and how large are their effects? International Psychogeriatrics. 2006;18:577-95.

35. Stange K, Burge F, Haggerty J. RCP Continuity of Care Toolkit: promoting relational continuity. British Journal of General Practice. 2014;64:274-5.

36. Guthrie B, Saultz JW, Freeman GK, Haggerty JL Continuity of care matters Bmi-British Medical Journa 2008;337.

37. Haggerty JL, Reid RJ, Freeman GK, Starfield BH, Adair CE, McKendry R. Continuity of care: a multidisciplinary review. British Medical Journal. 2003;327:1219-21.

38. Coleman EA. Falling through the cracks: Challenges and opportunities for improving transitional care for persons with continuous complex care needs. Journal Of The American Geriatrics Society. 2003;51:549-55.

9. Uijen AA, Schers HJ, Schellevis FG, van den Bosch WJHM. How unique is continuity of care? A review of continuity and related concepts. Family Practice. 2012;29:264-71.

40. http://www.rijksoverheid.n//onderwerpen/algemene-wet-bijzondere-ziektekosten-awbz. Accessed on july 15, 2014.

41. http://www.rijksoverheid.n//onderwerpen/wet-maatschappelijke-ondersteuning-wmo. Accessed on July 15, 2014

42. Mahler M, Meerveld J. Zorgstandaard Zementie: Steun en Zorg.Vilans and Alzheimer Nederland; 2013 4. MacAdam M. Frameworks of integrated care for the elderly: a systematic review: Canadian Policy Research Networks= Réseaux canadiens de recherche en politiques publiques, 2008 .

44. Khanassov V, Vedel I, Pluye P. Case management for dementia in primary health care: a systematic mixed studies review based on the diffusion of innovation model. Clinical Interventions in Aging 2014;9:915.

45. Somme D, Trouve H, Dramé M, Gagnon D, Couturier Y, Saint-Jean O. Analysis of case management programs for patients with dementia: a systematic review. Alzheimer's and Dementia. 2012;8:426-36.
46. Pot AM, Petreal. Improving dementia care worldwide: Ideas and advice on developing and implementing a National Dementia Plan. London: Bupa/ADl; 2013

47. Northouse L, Williams A-I, Given B, McCorkle R. Psychosocial care for family caregivers of patients with cancer. Journal of Clinical Oncology. 2012;30:1227-34.

48. Retrum JH Nowels CT Bekelman DB Patient and caregiver congruence The mportance of dyads in heart failure care. Journal of Cardiovascular Nursing. 2013;28:129-36.

49. Adams T, Gardiner P. Communication and interaction within dementia care triads: Developing a theory for relationship-centred care. Dementia. 2005;: :185-205.

50. Fortinsky RH. Health care triads and dementia care: integrative framework and future directions. Aging and Mental Health. 2001;5:S35-S48.

51. Quinn C, Clare L, McGuinness T, Woods RT. Negotiating the balance: The triadic relationship between spousal caregivers, people with dementia and Admiral Nurses. Dementia. 2013;12:588-605.

52. Wolfs CAG, de Vugt ME, Verkaaik M, Verkade P-J, Verhey FRJ. Empowered or overpowered? Service use, needs, wants and demands in elderly patients with cognitive impairments. International Journal of Geriatric Psychiatry. 2010;25:1006-12.

53. Browning DM, Meyer EC, Truog RD, Solomon MZ. Difficult Conversations in Health Care: Cultivating Relational Learning to Address the Hidden Curriculum. Academic Medicine. 2007;82:905-13 10.1097/ ACM. 0 b013e31812f77b9.

54. Epstein RM. Mindful practice in action (II): Cultivating habits of mind. Families, Systems, and Health 2003:21:11

55. Epstein RM, Hundert EM. Defining and assessing professional competence. Journal of the American Medical Association. 2002;287:226-35

56. Epstein RM. Mindful practice in action (I): Technical competence, evidence-based medicine, and relationship-centered care. Families, Systems, and Health. 2003;21:

57. Tronto JC. An ethic of Care. In: Holstein M. Mitzen P editors. Ethics in community-based elder care Springer Publishing Company, 2001. 


\section{7}

General Discussion

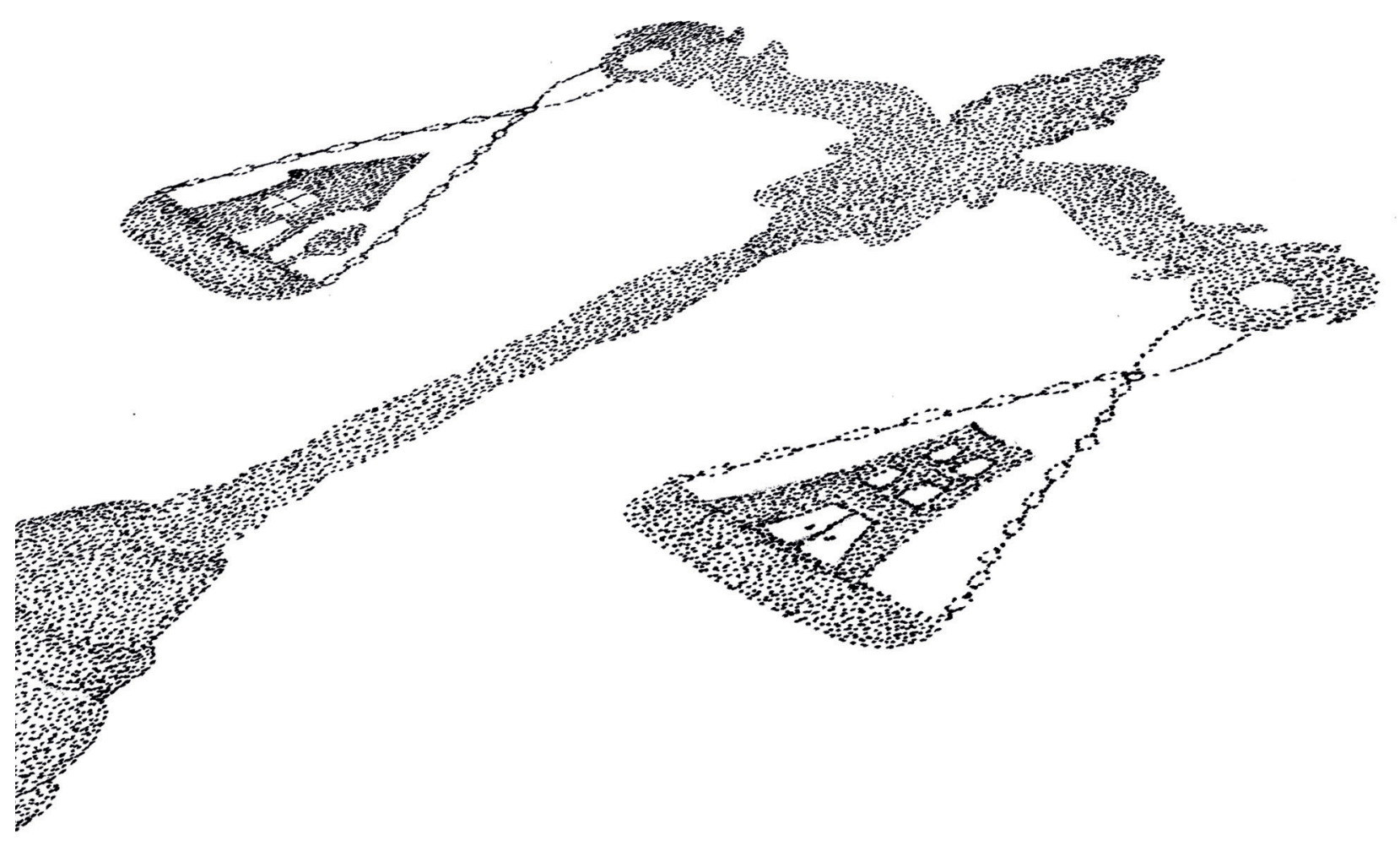


The aim of the research described in this dissertation was to provide information and insight about the perspective of informal caregivers regarding the care transition of people with dementia from home-based care towards institutional long-term care. This information adds to the existing evidence on care transition and strengthens it by providing knowledge on the perspective of informal caregivers regarding care transition, a view that had not yet been explored this rigorously. The two questions leading this dissertation were:

What are the reasons for institutional long-term care (ILTC) admission according to informal caregivers?

2) What needs do informal caregivers experience during the entire care transition period from home-based care towards ILTC?

In this final chapter the main findings of the previous chapters are summarised. Furthermore, methodological and theoretical considerations are explored. This chapter will be concluded with recommendations and implications based on the findings of the previously described studies.

\section{Main findings}

\section{Reasons for care transition according to informal caregivers} (chapters 2-4)

When asking informal caregivers of people with dementia (PwD) about the reasons for care transition from home-based care towards ILTC, they mostly stated reasons related to the person with dementia. Neuropsychiatric symptoms (e.g. aggression or wandering behaviour), care dependency (e.g. personal care or domestic chores), cognitive symptoms (e.g. forgetfulness), and overall deterioration (such as worsening of dementia) of the person with dementia were among the most frequently stated reasons for care transition. In addition to these reasons, two 'caregiver related' reasons, being caregiver burden and inability to care, were also stated frequently. Inability to care mainly refers to reasons such as deterioration of the health of the informal caregiver When looking individually at the eight countries that were part of RightTimePlaceCare (England, Estonia, Finland, France, Germany, the Netherlands, Spain and Sweden) differences were apparent between them regarding which reasons were among the most often stated. For example, 'fall incidents' was the third most mentioned reason in England and France, whereas this reason was not stated once in Estonia and Spain. Despite all differences, neuropsychiatric symptoms and care dependency were the two reasons that seemed to be consistently stated and overarched country boundaries (in the top five reasons of most countries) 
When comparing the views of informal caregivers and healthcare professionals (HCPs), the agreement in reasons for care transition was low to moderate. On an individual case level (i.e. the dyad of person with dementia and informal caregiver) discrepancies were evident. Differences were particularly evident in the category 'caregiver burden'. The HCP involved was more prone to state caregiver burden compared to the informal caregiver. When comparing the level of agreement across the participating countries, certain countries showed better conformity between informal caregivers and HCPs (Estonia, Finland, Sweden and Germany) than others (England and Spain). Though the sequence and frequency differed, overall the most stated reasons of HCPs were similar to the most stated reasons of the informal caregivers (i.e. neuropsychiatric symptoms, care dependency, overall deterioration of the person with dementia, caregiver burden and inability to care for the person with dementia)

Finally, two-thirds of the caregivers could indicate beforehand at least one expected reason (asked prior to care transition) that was also stated as an actual reason (asked after care transition) after admission had occurred. When comparing informal caregivers' statements of actual reasons for care transition with the scores on corresponding measurement instruments (as measured prior to admission), agreement was also found on several measurement instruments.

\section{Needs of informal caregivers during the care transition period}

\section{(chapters 5 and 6)}

Both the literature review and the focus group study show that informal caregivers expressed similar needs prior and post care transition. Reported needs concerned: good communication (for example with HCPs), sufficient information (such as understanding the healthcare system), person centred care or support (such as HCPs paying attention to, and showing empathy for the informal caregiver), and the negative effects of caring (such as emotional concerns and family related problems linked to the caring situation)

The similarity in needs at home and ILTC in both studies shows that the care transition period is not an isolated moment in time but is a continuum. For example, both prior as after admission, informal caregivers reported emotional concerns regarding the decision for care transition. Prior to admission informal caregivers report, for example, grief and stress regarding the pending decision for care transition. After admission emotional concerns regarding the decision for care transition did not vanish, and caregivers reported self-doubt, regret and self-blame due to the decision.

\section{Methodological considerations}

In all scientific research methodological considerations can be made. Each chapter describes in detail the limitations particular to that study. In this section some overarching methodological considerations are made that apply to the entire project. The origina studies in this dissertation are part of a large European collective. Being part of an international project yields several benefits, such as large datasets and the opportunity to compare between countries and settings. However, certain considerations have to be made.

\section{Sample and selection}

A consideration that should be made regards the sample throughout all participating countries. Selection bias may be a consideration that has to be kept in mind. Ideally, the study population is clearly defined, accessible and has an increased risk to develop the outcome of interest, ${ }^{1}$ which in this study was the transition towards ILTC. One of the inclusion criteria for the homecare setting was whether the person with dementia was considered 'at risk for care transition' by an involved HCP. The definition of being 'at risk' was not strictly defined in the protocols and guidelines of the project The only description was that an involved HCP assesses that there is a chance of permanent care transition within the next six months. Whether the care transition actually occurs or not was not relevant. This open way of interpretation of the 'at risk' criterion could result in a selection bias due to the interpretation of the concept of being 'at risk'. Bias in concepts comes from a lack of clarity about the concepts used in the research and gives the opportunity to use subjective interpretations as to what meets the definition of this concept. ${ }^{2}$ This subjectivity in interpretations could have led to diversity in the sample and as a consequence influences the analyses.

However, several reasons can be argued as to why no stricter guidelines were set for the 'at risk' criterion. The first is that, dependent on the healthcare system and culture within a country, being at risk for care transition does probably differ between countries. This makes it impossible to set strict criteria that would be applicable for all eight countries. If criteria would have been defined, for example, based on the criteria of one country the included participants would have been considered at risk in that particular country, and not per sé in the country of residence. This statement is corroborated by a recent study showing how PwD who were recently institutionalised differ between countries in, for example, cognitive status, care dependency, and neuropsychiatric symptoms. ${ }^{3}$ Another possibility would be to find consensus between all eight countries regarding a set of criteria. However, this would probably lead to a very long and complicated list of criteria with many disclosures and exceptions for severa countries. Al in all, keeping the at risk assessment up to an involved HCP was, therefore perhaps the most fair way to include the intended target population in each country. 


\section{Trustworthiness and validity}

The main source of data throughout the dissertation consisted of qualitative data in the form of open-ended questions within a structured interview. These open ended questions were part of a large, structured, face-to-face interview. Trustworthiness is an overarching term in qualitative research consisting of the concepts credibility dependability and transferability which can be translated to the terms validity reliability and generalizability in quantitative research. ${ }^{4}$

A first consideration that has to be made regards the data collection. No audio files of the original answers as stated by the informal caregivers were available of that data. RightTimePlaceCare was a mainly quantitative oriented project, which means that the qualitative data collection was not as optimal as it could have been if the project were qualitatively oriented. During the interview the interviewers wrote down the answer of the informal caregiver, which means that the data file used for analyses consists of the written answers of the interviewers. The fact that the answers had to be written down quickly during an elaborate interview may mean a loss of data richness in that the original answers as stated by the informal caregivers were far more elaborate and detailed than the data that has been analysed.

Second, having a large variation in the number of interviewers between the countries may have caused some form of interviewer bias ${ }^{2}$ which could have affected the data in the sense that not all interviewers were experienced enough to elicit answers the same way. Interviewers who have performed many or most of the interviews in each country might have become more comfortable with, and experienced in doing, the interviews. This could result in them being able to handle specific situations more successfully and elicit better or more truthful responses from the respondents, while other interviewers with less experience, may not have been. Aware of the length and intensity of the interviews, elaborate instructions were provided both in writing as we as in (international) meetings. All new interviewers were to receive both the written manual as well as an instruction meeting, in order to prevent interviewer bias where possible. These manuals, protocols and instruction meetings were to ensure uniformity in the project and trustworthiness of the research performed. Interviewers were, for example, instructed to write the answer down as completely as possible and ask follow-up questions in order to prompt informal caregivers for (more detailed) answers. That is to say, when informal caregivers replied with a short and general answer, let's say, "forgetfulness of the person with dementia", interviewers tried to ge a more specific answer, for example, "when my husband not only keeps forgetting his keys when he goes out, but starts forgetting how to get home". Despite the instructions given, not all answers were as elaborate and specific as others.

A third point to make regarding the data is the fact that the original answers had o be translated to English for the analyses. This additional step could have caused some loss of data richness. However, multiple measures were taken and reliability and validity tests were performed to assure correctness of the data file. A random $10 \%$ of the data of each country was re-translated and compared to the data file. Another random 10\% of the English (translated) data file that was already coded was checked against the original answers in the native language. Both strategies showed high reliability of the translated data. An elaborate and exact overview of how this process was performed is to be found in the relevant chapters (chapters 2-4). This detailed description offers insight into the process and therewith addresses the issue of dependability of the data. ${ }^{5} 6$

A final point on the issue of the data is the analysis. This dissertation is exploratory in nature using mainly qualitative designs and data to answer the individual study aims of each chapter. In qualitative research the concern of objectivity, also called conformability, is at play. ${ }^{5}$ Confirmability aims to ensure as best as possible that the findings come from the experiences and ideas of the participants, and do not reflect the assumptions and the ideas of the researcher. Especially since it concerned international data, there may have been a risk of interpreting certain answers differently than intended due to either language use or cultural differences. Confirmability was handled in multiple ways. To assure correct interpretations of the data, researchers from each country checked part of the coded data to assure there were no wrong interpretations due to language use or translational errors. Also, to assure that the results indeed came from the data and reflect the experiences of the informa caregivers, the raw data was continuously kept at hand and, in an iterative process the raw data was structurally consulted during analyses. Furthermore, to avoid strong interpretations and assumptions, during data analyses multiple researchers were involved and findings were discussed at the hand of the raw data. Another way to assure confirmability was to involve multiple researchers throughout the entire process of collection and analyses. Throughout the analysis process, at least two researchers were involved and during multiple points meetings were planned to check the interpretations of the involved researchers. In case of discrepancy in the views of the involved researchers, another researcher was introduced into the process to come to a consensus.

\section{Theoretical Considerations}

As early as the 1980's researchers started looking at the effects of caring and the accompanying adverse effects, such as burden of informal caregivers. It is widely acknowledged that supporting and unburdening informal caregivers should be the standard. Though this has been the aim for over 30 years, relatively little scientific attention has been paid particularly to the perspective of these same informa caregivers during one of the most difficult periods of the caregiving process, the care transition of the person with dementia towards ILTC. 
Linking the reasons for care transition to needs of informal caregivers This dissertation consists of two research lines, being: the reasons for care transition and the needs of informal caregivers during care transition, both from the perspective of the informal caregivers regarding their own situation. Existing research on predictors and risk factors for admission ${ }^{7-10}$ state that by studying these risk factors it is possible to predict and ideally postpone ILTC admission. It is suggested that predictors of care transition may be the aspects to target in interventions aiming to improve care. However, we have to be careful in assuming that the risk factors or predictors for care transition are the areas of needs. Our studies show discrepancies between the reported reasons and the expressed needs. While the reasons for care transition were mostly related to the PwD, such as behavioural aspects and cognitive decline, the needs expressed were generally not PwD related. Many of the needs expressed by informal caregivers were more on care related aspects, from how the care is organised, to the communication with $\mathrm{HCPs}$. Multiple reasons are possible for this discrepancy. The discrepancies could mean that the reasons are the underlying causes of the needs (or vice versa), but it may also mean that the two are not immediately related to each other

It might be the case that, by expressing dementia related aspects as the reason for admission, informal caregivers actually give insight into the underlying reasons for their need of support. For example, while burden is considered one of the stronges predictors for care transition, studies on predictors do not state what causes the burden for each particular respondent in their sample. Caregiver burden is a very broad term which is known to be caused by different reasons. ${ }^{11-13}$ It just may be the case that, by stating the PwD related reasons, informal caregivers in our study gave insight into the reasons for their individual burden without expressing burden explicitly The lack of correspondence between the reasons for admission and the explicitly stated needs may, therefore, not be as severe as it may initially seem.

\section{Informal caregivers as resources and as care receivers}

Multiple models on care use and needs depict informal care as a resource, $9,14,15$ without explicitly integrating either the effects of caring on the informal caregiver or the informal caregiver as a care receiver as well. This might be important since it is widely accepted that the informal caregiver forms a dyad with the person with dementia in which both affect each other and should be considered the unit of care. $^{16-20}$ This being the case could mean that these models are not complete and might benefit from an additional cluster showing the influence of formal support for the informal caregiver on the needs and use of services of the person with dementia. Because of the dynamic of the care dyad, it is important to include the support for the informal caregivers in the care plan of the person with dementia. This implies that, as in the models, HCPs should include the needs of both PwD as well as informa caregivers to form a more holistic view of the situation.

\section{The care dyad vs. the care triad}

As stated in the previous section, care provision and care plans should not only take the person with dementia into account, due to the dynamic of the care dyad, consisting of the person with dementia and the informal caregiver. Though another consideration should be made to include the entire care system into a care triad consisting of the person with dementia, the social network, and all HCPs involved, because all influence the care dynamic. Several studies state the importance of exploring the role of each part of the triad on the care dynamic. ${ }^{21-23}$ Several reasons within this dissertation point to the benefit of considering a triad. One of the most prominent ones is evident in chapter 2, in which the views of informal caregivers clearly differed from those of HCPs involved. Considering how, in most countries, HCPs have a decisive role in care transition and an assessment of a HCP is required for admission, ${ }^{24-27}$ a discrepancy in the view of the situation between informa caregivers and HCPs could mean that timely admission may be impeded. Moreover, it could mean that, on a larger level, proper and appropriate care is not offered to either the person with dementia or the informal caregiver. This discrepancy in views may be the result of multiple reasons. First of all, it might be the case that HCPs are too remotely involved. For example, they may only focus on the task at hand and no take interest in the situation. There may also be a lack of communication between involved HCPs resulting in an incomplete view of the situation. Especially if multiple care organisations are involved in the care it becomes harder to stay updated and keep an overview of the entire situation.

Additionally, it might be the case that HCPs are unaware of the views and even the needs and desires of informal caregivers. One has to bear in mind that informa caregivers might not give complete or honest information. Here again multiple reasons can be given, one of which is that informal caregivers do not want to admit to their struggles with the situation and accompanying needs. This may be especially true if the informal caregiver does not feel a personal connection with the HCP. Another possibility could be a communicative problem between the HCP and the informal caregiver. For example, if HCPs communicate about a concept such as burden and informal caregivers do not recognise themselves as burdened or the situation as burdensome. Caregivers with a strong (cultural) belief that families have to care for a relative with dementia ${ }^{28}$ may disregard their own burden. It is therefore important that HCPs are aware of the beliefs and way of thinking of informal caregivers, so HCPs can adjust their communication to the informal caregiver.

In all, each possible reason and underlying problem stated requires a stronger involvement of HCPs, which could be achieved if the care is revolved around a care triad, with all involved HCPs being part of the dynamic. This will strengthen the overview HCPs have of the situation, develop a bond with the informal caregiver (and person with dementia) and consequently create better insight into the beliefs of each 
person in the triad and learn how to approach subjects to result in a better service delivery. From the informal caregivers' perspective a stronger involvement of HCPs in the care provision might result in a bond that makes them have greater trust in the HCPs involved. This might lower the barrier to ask for help, express their needs and discuss difficult topics such as the care transition.

\section{Recommendations}

The general aim of this dissertation was to explore the perspective of informa caregivers regarding the reasons for care transition of PwD towards ILTC, and the perceived needs of informal caregivers during the care transition period in order to contribute to the existing knowledge regarding the care transition of PwD. Based on the results of this dissertation, the following recommendations can be made.

\section{Recommendations for practice}

Guiding and supporting informal caregivers during the care transition period requires a custom and tailored approach. This tailored approach calls for HCPs to know what informal caregivers need. The results in this dissertation show that informal caregivers are capable of providing valuable and detailed information specific to the care transition period, but that they need guidance in expressing their specific reasons for admission or vocalizing their needs. What is required for a tailored approach is explained below.

Within this dissertation various reasons for care transition were reported by informal caregivers. Important to note was the discrepancy between the views of the informal caregiver and the involved HCP, with both often stating different expected reasons for admission. Since informal caregivers as well as HCPs are involved in the process of care transition, it is important for both to be aware of the views of the other. This highlights how HCPs should collaborate closely with informal caregivers regarding their particular situation and what may cause admission in their particular circumstance. This requires HCPs to be attuned to informal caregivers or take them seriously. In practice it is often the case that HCPs reason from their expertise and do not always seem to value informal caregivers' opinions. ${ }^{29-31}$

The results in this dissertation also show that there are multiple (unmet) needs experienced by informal caregivers during the care transition period, showing how informal caregivers should be offered support and considered care receivers in the process. Support and guidance is currently not structurally offered to informa caregivers during the care transition period, despite it being known that informa caregivers would appreciate this. ${ }^{32-38}$ Though there are services available aimed at informal caregivers, ${ }^{39-43}$ these existing services are not designed specifically for the care transition period and,therefore, may not meet the needs informal caregivers experience during this specific period.

Finally, this dissertation highlights how informal caregivers are often unaware of the possibilities of formal services. HCPs should, therefore, take time to informe informal caregivers regarding all possibilities according to their situation and needs. What has to be kept in mind herein is the way that HCPs communicate this information Research suggests that HCPs feel like they communicate, but that informal caregivers do not pick up on this information. ${ }^{44} \mathrm{HCPs}$ should communicate with each particular informal caregiver in a way he or she can relate to. This requires much responsiveness and empathy on the part of HCPs.

\section{Recommendations for future research}

Based on the results in this dissertation, further research is required into a number of areas regarding the care transition period of PwD towards ILTC and in particular the informal caregivers within this process.

First, research is needed to investigate why and how changes in reasons for admission according to informal caregivers occur and what the determining factors are for these changes. The results of this dissertation show how informal caregivers stated various reasons for care transition. It was also studied whether informa caregivers state similar reasons prior and post admission, which showed that there was no $100 \%$ match for all informal caregivers in these statements. This means that, even in the short period of time of this study, the reasons for admission can change though what determines these changes remains unclear.

Second, results in this dissertation highlight the difference in the views of informa caregivers and the involved HCPs regarding the reasons for admission. Future research should be considered to identify what causes the discrepancy in views between informal caregivers and HCPs regarding the reasons for admission Identifying the reasons for the discrepancy in views may improve collaboration between HCPs and informal caregivers during the care transition process.

Third, further research is required in order to properly target the individual needs of informal caregivers. In order to do this it is important to know what causes certain needs, whether and how the needs of a particular informal caregiver vary over time and what factors are important herein. Models like the one by van Bilsen et al. on the relation between needs, resources and demand for care,${ }^{14}$ depict informal caregivers as a resource, without integrating the effects of caring on the informal caregiver and the needs they themselves develop. Existing models on care use and needs9, 14, 1 may, therefore, be considered incomplete because they lack clusters regarding how the informal caregiver as a resource is influenced, for example, by their own need and the development and changes in these needs. It is important to know how informal caregivers as a resource are influenced in their caregiving by the needs they 
experience. This requires research into whether and how the needs of a particula informal caregiver vary over time, what causes certain needs and what factors are important herein.

A fourth point of interest for research regards matching formal services up with the individual needs. Innovations are needed to keep delivering high quality care which fits the demands. In order to do this it is important to inventory the scope of formal services and match these with the actual needs of informal caregivers and PwD to study whether the current supply of services can meet said needs and whether more efficient methods are possible.

Finally, future research should focus on the relationship between the reasons for care transition as reported by informal caregivers and the needs experienced along the transition period. Results in this dissertation show discrepancies between the reasons for admission and the needs experienced. Is it the case that reasons for care transition are the underlying causes of the needs experienced and can the needs be targeted by addressing the reasons for care transition? Or is there in fact no immediate relation between the two?

\section{References}

1. Pannucci CJ, Wilkins EG. Identifying and Avoiding Bias in Research. Plastic and Reconstructive Surgery 2010;126:619-25.

2. Indrayan A. Medical biostatistics: CRC Press, 2012

3. Beerens HC, Sutcliffe C, Renom-Guiteras A, Soto ME, Suhonen R, Zabalegui A, et al. Quality of Life and Quality of Care for People With Dementia Receiving Long Term Institutional Care or Professional Home Care: The European RightTimePlaceCare Study J urnal of the American Medical Directors Association. 2014; 15:54-61.

4. Graneheim UH, Lundman B. Qualitative content analysis in nursing research: concepts, procedures and measures to achieve trustworthiness. Nurse Education Today. 2004:24:105-12.

5. Guba EG, Lincoln YS. Guidelines and checklist for constructivist (aka fourth generation) evaluation Retrieved June. 2001;18:2008.

6. Shenton AK. Strategies for ensuring trustworthiness in qualitative research projects. Education for Information. 2004:22:63-75

Gaugler JE, Yu F, Krichbaum K, Wyman JF. Predictors of Nursing Home Admission for Persons with Dementia. Medical Care. 2009;47:191-8.

8. Yaffe K, Fox P, Newcomer R, Sands L, Lindquist K, Dane K, et al. Patient and Caregiver characteristics and nursing home placement in patients with dementia. Journal of the American Medical Association. 2002:287:2090-7.

9. Luppa M, Luck T, Braehler E, Koenig HH, Riedel-Heller SG. Prediction of institutionalisation in dementia A systematic review. Dementia and Geriatric Cognitive Disorders. 2008:26:65-78.

10. Drame M, Lang PO, Jolly D, Narbey D, Mahmoudi R, Laniece I, et al. Nursing home admission in elderly subjects with dementia: predictive factors and future challenges. Journal of the American Medica Directors Association. 2012:13:83 e17-20.

11. Etters $L$, Goodall D. Harrison BE. Caregiver burden among dementia patient caregivers: A review of the literature. Journal of the American Association of Nurse Practitioners. 2008;20:423-8.

12. Gallagher D, Ni Mhaolain A, Crosby L, Ryan D, Lacey L, Coen RF, et al. Dependence and caregiver burden in Alzheimer's disease and mild cognitive impairment. American Journal of Alzheimer's Disease and Other Dementias. 2011;26:110-4

13. Gaugler J, Mittelman M, Hepburn K, Newcomer R. Predictors of Change in Caregiver Burden and Depressive Symptoms Following Nursing Home Admission. Psychology and Aging. 2009;24:385-96.

14. Van Bilsen P, Hamers J, Groot W, Spreeuwenberg C. Demand of elderly people for residential care: an exploratory study. BMC Health Services Research. 2006;6:30.

15. Andersen R. Revisiting the behavioral model and access to medical care: does it matter? Journal of Health and Social Behavior. 1995;36:1-10.

6. Northouse L, Williams A-I, Given B, McCorkle R. Psychosocial care for family caregivers of patients with cancer. Journal of Clinical Oncology. 2012;30:1227-34

17. Northouse LL, Mood DW, Schafenacker A, Kalemkerian G, Zalupski M, LoRusso P, et al. Randomized clinical trial of a brief and extensive dyadic intervention for advanced cancer patients and their family caregivers. Psycho-Oncology. 2013;22:555-63.

18. Dow B, Meyer C, Moore KJ, Hill KD. The impact of care recipient falls on caregivers. Australian Health Review. 2013;37:152-7.

19. Ingersoll-Dayton B, Raschick M. The relationship between care-recipient behaviors and spousa caregiving stress. The Gerontologist. 2004;44:318-27.

20. Retrum JH, Nowels CT, Bekelman DB. Patient and caregiver congruence: The importance of dyads in heart failure care. Journal of Cardiovascular Nursing. 2013;28:129-36.

21. Adams $\mathrm{T}$, Gardiner P. Communication and interaction within dementia care triads: Developing a theory for relationship-centred care. Dementia. 2005;4:185-205.

22. Fortinsky RH. Health care triads and dementia care: integrative framework and future directions. Aging and Mental Health. 2001;5:S35-S48. 
23. Quinn C, Clare L, McGuinness T, Woods RT. Negotiating the balance: The triadic relationship between spousal caregivers, people with dementia and Admiral Nurses. Dementia. 2013;12:588-605.

24. Caron $\mathrm{CD}$, Ducharme F, Griffith J. Deciding on institutionalization for a relative with dementia: the most difficult decision for caregivers. Canadian Journal on Aging. 2006;25:193-205.

25. Couture M, Ducharme F, Lamontagne J. The role of health care professionals in the decision-making process of family caregivers regarding placement of a cognitively impaired elderly relative. Home Health Care Management and Practice. 2012;24:283-91.

26. Ducharme F. Couture M, Lamontagne J. Decision-making process of family caregivers regarding placement of a cognitively impaired elderly relative. Home Health Care Services Quarterly: The Journalof Community 0 (2012:31:107-218-

Lundh U, Sandberg J, Nolan M. 'I don't have any other choice': spouses' experiences of placing Veople in Sweden. Journal of Advanced Nursing. 2000;32:1178-86.

28. Vellas B, Hausner L, Frolich L, Cantet C, Gardette V, Reynish E, et al. Progression of Alzheimer disease Europe: data from the European ICTUS study. Current Alzheimer Research. 2012;9:902-12.

29. van der Roest HG, Meiland FJ, Comijs HC, Derksen E, Jansen AP, van Hout HP, et al. What do community-dwelling people with dementia need? A survey of those who are known to care and welfare services. International Psychogeriatrics. 2009;21:949-65.

30. van der Roest HG, Meiland FJ, Maroccini R, Comijs HC, Jonker C, Dröes R-M. Subjective needs of people with dementia: a review of the literature. International Psychogeriatrics. 2007;19:559-92.

31. de Klerk M, de Boer A, Kooiker S, Plaisier I, Schyns P. Hulp geboden: Een verkenning van de mogelijkheden en grenzen van (meer) informele hulp. Den Haag: Sociaal en Cultureel Planbureau; 2014

32. Paun O, Farran CJ. Hearing and healing the hurts of dementia, part 1: nursing home placement of

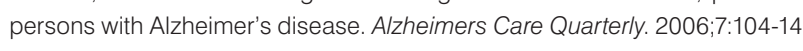

33. Kelsey SG, Laditka SB, Laditka JN. Caregiver Perspectives on Transitions to Assisted Living and Memory Care. American Journal of Alzheimers Disease. 2010;25:255-64

sis of the experience of making a decision to special care unit. Research in Nursing and Health.

35. Gaugler JE, Pearlin LI, Leitsch SA, Davey A. Relinquishing in-home dementia care: difficulties and perceived helpfulness during the nursing home transition. American Journal of Alzheimers Disease and Other Dementias. 2001;16:32-42.

36. Couture M, Ducharme F, Lamontagne J. The Role of Health care Professionals in the Decision-Making Process of Family Caregivers Regarding Placement of a Cognitively Impaired Elderly Relative. Hom Health Care Management and Practice. 2012;31:197-218.

37. Caron CD, Ducharme F, Griffith J. Deciding on institutionalization for a relative with dementia: The mos difficult decision for caregivers. Canadian Journal on Aging-Revue Canadienne Du Vieillissement 2006;25:193-205

38. Bramble M, Moyle W, McAllister M. Seeking connection: family care experiences following long-term dementia care placement. Journal of Clinical Nursing. 2009;18:3118-25.

39. Zwaanswijk M, Peeters JM, van Beek AP, Meerveld JH, Francke AL. Informal caregivers of people with dementia: problems, needs and support in the initial stage and in subsequent stages of dementia: questionnaire survey. The Open Nursing Journal. 2013;7:6-13.

40. Peeters JM, Van Beek AP, Meerveld JH, Spreeuwenberg PM, Francke AL. Informal caregivers of persons with dementia, their use of and needs for specific professional support: a survey of the National Dementia Programme. BMC Nursing. 2010;9:9,

41. Henriksson A, Benzein E, Ternestedt BM, Andershed B. Meeting needs of family members of persons with life-threatening illness: A support group program during ongoing palliative care. Palliative and Supportive Care. 2011;9:263-71.

42. Gaugler JE, Roth DL, Haley WE, Mittelman MS. Can counseling and support reduce burden and depressive symptoms in caregivers of people with Alzheimer's disease during the transition to institutionalization? Results from the New York University caregiver intervention study. Journal of the American Geriatrics Society. 2008;56:421-8.
43. Gaugler JE, Zarit SH, Townsend A, Stephens MAP, Greene R. Evaluating community-based programs for dementia caregivers: The cost implications of adult day services. Journal of Applied Gerontology. 2003;22:118-33.

44. Wolfs CAG, de Vugt ME, Verkaaik M, Verkade PJ, Verhey FRJ. Empowered or overpowered? Service use needs, wants and demands in elderly patients with cognitive impairments. International Journal of Geriatric Psychiatry 2010:25:1006-12 


\section{Summary}

Nederlandse samenvatting

Valorisation addendum

Dankwoord

About the author

Publications

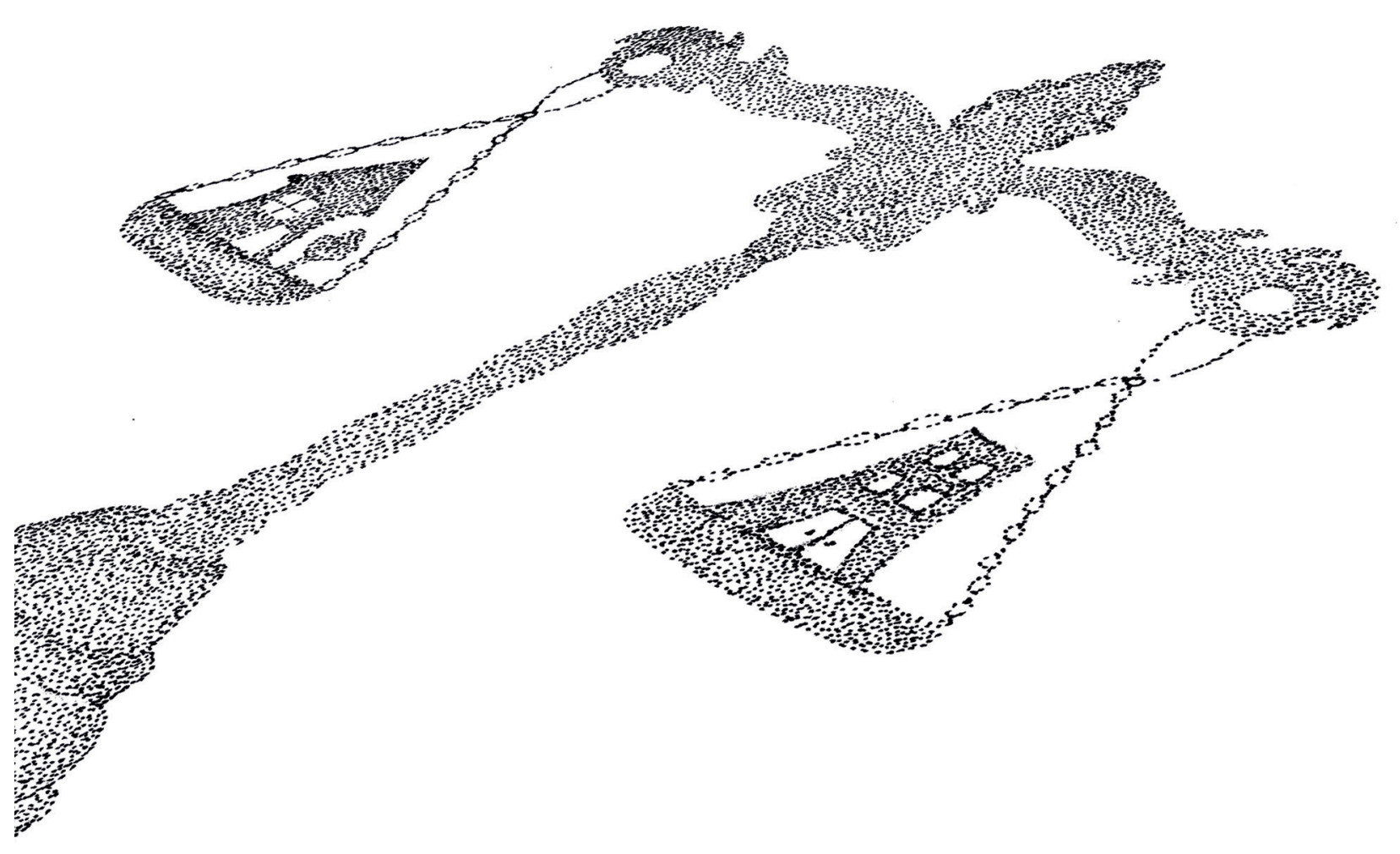




\section{Summary}

The care transition from home towards institutional long-term care (ILTC) of a relative with dementia can be considered one of the most difficult processes informal caregivers have to endure. Because informal caregivers have an important voice in the care transition process, their views of the process are valuable. The purpose of this dissertation was to examine the perspective of informal caregivers of people with dementia during the care transition period (i.e. the entire process of the permanent move from home-based care towards institutional long-term care). Two lines are studied within this dissertation: 1) reasons for care transition according to informal caregivers (chapters 2-4); 2) needs of informal caregivers during the entire care transition period (chapters 5 and 6). All data used within this dissertation was collected as part of the international RightTimePlaceCare project in which the following eight European countries were involved: England, Estonia, France, Germany, the Netherlands, Spain and Sweden In this section a summary is provided of all studies described in this dissertation.

Chapter 1 gives an introduction about dementia and the roles of informal caregivers in dementia caregiving. Furthermore, care transition is explained as well as the gaps of knowledge within the line of research on care transition. Additionally some background is provided regarding the underlying European project, RightTimePlaceCare. The chapter is concluded with a specification of the aims and outline of the dissertation.

Chapter 2 discusses an explorative cross-sectional study. This study aimed to explore reasons for institutionalisation of people with dementia according to informa caregivers as well as variation in reasons between countries. Informal caregivers stated mainly patient related reasons, such as neuropsychiatric symptoms (e.g aggression and wandering behaviour), care dependency (e.g. in personal care or domestic chores), and cognition (e.g. forgetfulness). Beside patient related reasons, caregiver burden (both physical as emotional) and the inability of the informa caregiver to care for the patient (e.g. diminished health of the informal caregiver) were among the top five most stated reasons. Further analyses showed countries diffe significantly in reasons according to informal caregivers, with certain reasons being among the most stated reasons in particular countries, whereas in other countries the same reasons may not have been stated at all. Despite the evident differences neuropsychiatric symptoms seemed to overarch country boundaries.

Chapter 3 describes a cross-sectional study about the expected reasons for admission to ILTC. Statements of both informal caregivers and healthcare professionals (HCPs) across eight European countries were analysed. The open ended questions revealed a multitude of expected reasons, covering 22 categories. 
Most of the categories were related to the person with dementia. The top five most stated reasons being: neuropsychiatric symptoms, care dependency and overall deterioration (all of the person with dementia), caregiver burden and inability of the informal caregiver to provide care. Furthermore the conformity of the expected reasons between the informal caregiver and an involved HCP was explored. These analyses showed low conformity when examined on individual case level (i.e. the dyad of person with dementia and informal caregiver). Discrepancy was especially high for reasons related to caregiver burden, with HCPs being more prone to state caregiver burden than the involved informal caregiver.

Chapter 4 consists of a mixed methods study exploring two aims: 1) the agreement between expected reasons and actual reasons for care transition according to informal caregivers; 2) the agreement between scores on measurement instruments prior to admission and the actual reasons for care transition according to informa caregivers. The results show that about two-thirds of informal caregivers were able to indicate beforehand what will cause care transition, in other words, there was agreement between their statements on the expected reason and the actual reason. Bivariate associations between the actual reasons for admission and scores on corresponding measurement instruments also showed a level of agreement, though agreement was not unambiguous for all measurement instruments.

Chapter 5 describes a systematic literature review aiming to give insight into problems and needs of informal caregivers caring for people with dementia during the care transition from home-based care to institutional long-term care. Thirteen qualitative studies describing the decision making experiences of informal caregivers were included. Fourteen themes comprising needs and problems of informal caregivers during the care transition period were found. The themes reported in most of the included publications were: 'emotional concerns' (e.g., grief and shame about the decision), 'knowledge/information' ( e.g., understanding the care system) and 'support' (e.g., need for counselling). Similar topics were found prior and after admission, with examples specific to the either the home or nursing home situation.

Chapter 6 explores a Dutch focus group study on the needs of informal caregivers during the entire care transition period from home-based care towards institutiona long-term care. Similar needs were identified prior and post care transition. In tota five main themes were found with several subthemes. The five main themes showed needs regarding: 1) communication (e.g. better communication with healthcare professionals), 2) person centered care (e.g. attention for the informal caregiver), 3) the complexity of the current healthcare system and structure (e.g. finding your way in the care system), 4) social network (e.g. family members not showing empathy fo the informal caregiver), and 5) caring impact on the informal caregiver (e.g. physical effects of caring).
Chapter 7 discusses the main findings of the studies within this dissertation (chapters 2-6). Furthermore, methodological and theoretical considerations are contemplated. The chapter is concluded with recommendations based on the included studies. 


\section{Nederlandse Samenvatting}

De zorgtransitie van thuiszorg naar verpleeghuiszorg van een naaste met dementie is voor mantelzorgers een van de meest ingrijpende gebeurtenissen. Omda mantelzorgers een centrale rol in de zorg voor hun naaste met dementie hebben, is hun visie op dit transitietraject waardevol. Dit proefschrift heeft als doel kennis te vergaren over het transitietraject van thuiszorg naar verpleeghuiszorg van mensen met dementie vanuit het perspectief van mantelzorgers. De twee hoofdvragen in dit proefschrift zijn: 1) Wat zijn, volgens mantelzorgers, de redenen dat mensen met dementie opgenomen worden in een verpleeghuis? (hoofdstukken 2-4); 2) Wat zijn de behoeften van mantelzorgers gedurende het volledige transitietraject van thuiszorg naar verpleeghuiszorg? (hoofdstukken 5-6). De gegevens die gebruikt worden in dit proefschrift zijn verzameld als onderdeel van het internationale RightTimePlaceCare project, waarin de volgende acht Europese landen deelnamen: Duitsland, Engeland, Estland, Finland, Frankrijk, Nederland, Spanje en Zweden. Dit project had als doe om best practice strategieën te ontwikkelen waarbij specifiek aandacht werd gegeven aan de transitie van thuiszorg naar verpleeghuiszorg. Vanwege de focus op deze zorgtransitie, is het onderzoek afgenomen bij mantelzorgers van mensen me dementie die nog thuis woonden en bij mantelzorgers van mensen met dementie die recentelijk waren opgenomen.

Hoofdstuk 1 geeft een introductie over dementie en de rol van mantelzorgers in dementiezorg. Vervolgens wordt er uitleg gegeven over zorgtransitie van thuiszorg naar verpleeghuiszorg. Hierbij wordt tevens aangegeven welke kennis nog ontbreek in het onderzoeksveld betreffende de zorgtransitie rondom dementie. Aanvullend wordt in dit eerste hoofdstuk uitleg gegeven over RightTimePlaceCare, het internationale project waarbinnen de studies in dit proefschrift zijn uitgevoerd. Hoofdstuk 1 word afgesloten met de doelstellingen van het proefschrift.

Hoofdstuk 2 beschrijft een exploratieve cross-sectionele studie met als uitgangspunt het verkennen wat, volgens mantelzorgers, de redenen zijn voor de opname van mensen met dementie. Tevens is gekeken of deze gerapporteerde redenen verschillen tussen de deelnemende landen. De resultaten tonen aan dat mantelzorgers vooral patiën gerelateerde redenen benoemen, zoals neuropsychiatrische symptomen (e.g. agressie en dwaalgedrag), zorgafhankelijkheid (e.g. persoonlijke verzorging of huishoudelijke taken) en cognitieve problemen (e.g. vergeetachtigheid). Naast patiënt gerelateerde redenen worden (over)belasting van mantelzorg (zowel fysiek als emotioneel) en het onvermogen om voor de persoon met dementie te zorgen (bijvoorbeeld door slechte gezondheid van de mantelzorger) vaak genoemd als redenen voor opname. Verdere analyses laten zien dat de gerapporteerde redenen voor opname significant verschilden tussen de landen, waarbij een veel voorkomende redenen in het ene land, doo 
mantelzorgers in een ander land helemaal niet werd genoemd. Ondanks de duidelijke verschillen lijken neuropsychiatrische symptomen consistent genoemd te worden in alle landen.

Hoofdstuk 3 bestaat uit een cross-sectionele studie naar de verwachte redenen voor opname van mensen met dementie, zoals gerapporteerd door mantelzorgers en professionele zorgverleners uit acht Europese landen. De open vragen van he onderzoek leverden een breed scala aan redenen op, die 22 categorieën vormden. Het merendeel van de gevonden categorieën heeft betrekking op (de persoon met) dementie. De meest genoemde redenen zijn: neuropsychioatrische symptomen, zorgafhankelijkheid, algehele achteruitgang van de persoon met dementie, (over)belasting van de mantelzorger en het onvermogen om voor de persoon met dementie te zorgen. Aanvullend zijn er analyses gedaan naar de overeenstemming tussen mantelzorgers en professionele zorgverleners op individueel niveau (i.e. gekeken naar de persoon me dementie). Deze resultaten tonen een lage tot gemiddelde overeenstemming tussen mantelzorgers en professionele zorgverleners, waarbij de afwijking vooral duidelijk aanwezig was in redenen gerelateerd aan (over)belasting van de mantelzorger(s). Zorgprofessionals waren meer geneigd overbelasting te noemen dan mantelzorgers zelf.

Hoofdstuk 4 beschrijft een studie met als doelstelling het verkennen van de overeenstemming tussen 1) verwachte en daadwerkelijke redenen voor opname zoals gerapporteerd door mantelzorgers; 2) daadwerkelijke redenen voor opname gerapporteerd door mantelzorgers en scores op meetinstrumenten gemeten vóó opname. De resultaten tonen aan dat twee-derde van de mantelzorgers in staat was om vooraf aan te geven wat opname zou veroorzaken, oftewel dat er overeenstemming was in de verwachte redenen zoals gerapporteerd vóór opname en de daadwerkelijke redenen zoals gerapporteerd na opname. Bivariate associaties tussen de daadwerkelijke opnamereden (bijvoorbeeld ervaren zorgbelasting), en gerelateerde meetinstrumenten (bijv. De Zarit Burden Interview) tonen enige overeenstemming. Deze overeenstemming was echter niet eenduidig voor alle meetinstrumenten.

Hoofdstuk 5 beschrijft op basis van bestaande literatuur wat de problemen en behoeften zijn van mantelzorgers tijdens het zorgtransitietraject van thuiszorg naa verpleeghuiszorg. Dertien kwalitatieve studies zijn geanalyseerd die de ervaringen beschrijven van mantelzorgers tijdens het keuzeproces voor opname. In totaal zijn veertien thema's gevonden waarin de problemen en behoeften van mantelzorgers zijn onderverdeeld. De thema's die in de meeste geïncludeerde studies werden gerapporteerd waren: 'emotionele zorgen' (e.g., verdriet en schaamte over de keuze tot opname), 'kennis/informatie' (e.g., informatie om het zorgsysteem te begrijpen) en 'ondersteuning' (e.g., behoefte aan begeleiding). Zowel voor als na opname werden gelijksoortige thema's genoemd, waarbij de beschreven problemen en behoeften wel specifiek waren aan de thuis-, of verpleeghuissituatie.
Hoofdstuk 6 beschrijft een Nederlandse focusgroep studie naar de behoeften van mantelzorgers gedurende het zorgtransitietraject van thuiszorg naar verpleeghuiszorg. De resultaten van dit onderzoek tonen gelijksoortige behoeften bij mantelzorgers van mensen met dementie die nog thuis wonen en mantelzorgers van mensen met dementie die zorg ontvangen in een verpleeghuis. In totaal zijn vijf hoofdthema's gevonden waarin de gerapporteerde behoeften zijn geclassificeerd. De vijf hoofdthema's waren: 1) communicatie (e.g. betere communicatie met zorgprofessionals);

2) persoonsgerichte zorg (e.g. aandacht van professionele zorg voor de mantelzorger); 3) de complexiteit van de huidige zorgstructuur (e.g. je weg kunnen vinden in he zorgsysteem); 4) het sociale netwerk (e.g. ervaren steun uit de omgeving ondergaat); en 5) de impact van zorgverlening (e.g. fysieke effecten van het verlenen van zorg).

Hoofdstuk 7 vormt de algemene discussie van het proefschrift. Hierin worden de belangrijkste resultaten beschreven van de studies in dit proefschrift. Verder worden methodologische en theoretische overwegingen toegelicht. Afsluitend worden aanbevelingen gedaan op basis van de resultaten van dit proefschrift voor de praktijk alsook voor vervolgonderzoek. 


\section{Valorisation addendum}

Research on care services and care systems may have a limited "lifespan", due to the fact that care systems are dynamic and care policies are frequently changed However, despite the many changes in healthcare systems, certain topics remain an issue for decades. One of these topics is informal caregiving in dementia care.

The persistence of certain societal issues related to health and healthcare, such as informal care in dementia, are not the result of a lack of attention from researchers per se, considering the amount of research in existence. Looking at all the attention given by researchers to unburden and support informal caregivers of people with dementia and the many studies on predictors for care transition, one should contemplate why the issues are still in existence after decades of research. The question that should be asked is: Why are informal caregivers of people with dementia still experiencing similar issues, despite all the scientific evidence and the recommendations by the researchers based on this evidence? The answer lies more in the "translation" of scientific research to these healthcare issues, in this case informal care in dementia.

No one will argue the importance of informal care either in general or specifically in dementia care. Throughout this entire dissertation it is stressed how informa caregivers of people with dementia have a crucial role in the care in general, and in the transition from home-based care to care in the nursing home. It is also explained that the decision to move a beloved one to a nursing home is very difficult with many adverse effects, both prior to, and after the actual move. Informal caregivers experience, for example, feelings of guilt and betrayal towards the person with dementia. Often the decision regarding the move to a nursing home is not well prepared, with informal caregivers not thinking or not wanting to think about the care transition. This may result in the informal caregiver being "caught off guard" by the care transition process, adding to the stress and adverse effects of the decision.

This chapter aims to translate the results of this dissertation into more explicit "added value" to society and dementia care, that is to say, to valorise the results. The act of valorisation is to create value from knowledge. Valorisation can be done in many ways and depends on the type of research as well as the outcomes thereof. One form of valorisation, for example, is to make knowledge available and suitable for social exploitation. In this particular case, the research was explorative, giving a possible starting point for practice and future research. The aim is to imbed the results within the current and most recent shift in healthcare as organised within the Netherlands.

A major shift has been initiated in the Netherlands, by which municipalities are now responsible for the care of their citizens instead of the national government. The (social) care now has to be organised by and within the community. Social community teams, consisting of multiple professionals such as social workers, physical therapists and community nurses, act as a safety net to provide and stimulate care from and by 
the community in order to decrease the use of more expensive specialist care. An additional aim is to offer the tools for people to be able to manage their own situation as well as possible and to empower them. These teams should also aim to provide more holistic care and prevent the fragmentation of care. The preferred approach is: "One household; one plan; one care professional". One of the target groups of these community teams are the informal caregivers. Certain aims of these community teams, such as empowerment, and the provision of holistic and defragmented care, preferably by the same main health professional (as a sort of case manager), are ideal for informal caregivers of people with dementia, as will be explained further.

Bearing in mind how hard the process of care transition from home to the nursing home is, informal caregivers deserve to be guided and coached through the care transition process, preferably by healthcare professionals. To make this guidance effective, some points of advice are provided here, by which the results of this dissertation may be used as a starting point within the new decentralisation of care in the Netherlands.

In the spirit of the holistic care aimed for in the new social community teams, care and services may be offered as a "care carrousel". In a "care carrousel" informa caregivers are introduced to multiple healthcare professionals and services, and then decide whether that service is required. Care professionals of the multi-disciplinary community team may visit informal caregivers at home at various stages during the dementia process, instead of informal caregivers having to seek and visit different healthcare professionals at their office. During these visits, healthcare professionals inventory, along with the informal caregiver, whether their service is required at that particular stage by that particular informal caregiver. These stages should be at moments of change within the situation of the person with dementia and his or her social environment. The results of this dissertation can be used to define or identify these stages. As seen in this dissertation, patient-related aspects are often the tipping points, initiating the move to a nursing home, according to informa caregivers. So if, for example, the person with dementia develops certain dementia related behaviour, such as wandering behaviour, or when the behaviour intensifies, the "care carrousel" should be initiated again. These changes are the "red flags" for the care professionals to look out for and to use as a guideline when determining whether it is necessary to inventory the need for their services again. In this process both healthcare professionals as well as the informal caregivers inventory whethe the services of a certain healthcare field are required. It is not suggested that all services should be offered "casually" to everyone but rather that they should really suit the situation. In order to make this work, the proximity and close involvement of the social community team is essential (coordinated by a single professional in the role of a case manager); otherwise these signals will not be detected in time. This approach, with healthcare professionals closely involved in the process within the community, means that informal caregivers do not have to figure out what is possible care-wise and be the ones taking the initiative to cumulate information. Within this dissertation, evidence is provided that obtaining information regarding care and services is an obstacle for informal caregivers. They claim that they are unaware about what is available care-wise, that they have to be the ones taking the initiative in gathering information, which is often difficult, and that they prefer being offered the information by healthcare professionals.

As a care carrousel, these community teams can offer a gradual, continued and long-term guidance approach. This should be a "start-to-finish" process. Considering that the progress of dementia is still irreversible and incurable, care transition towards a nursing home is a realistic prospect in dementia. Therefore, it would be worth considering "introducing" informal caregivers to the idea of care transition from an early stage, despite the difficulty of the topic. In this dissertation it is stated that the care transition period starts prior to the decision and ends after the actual move. However, how long this period is and how early it starts is not set. The care transition period probably varies per situation, that is to say, per person with dementia and his or her (social) environment. Due to this variation, a gradual and structural exposure to the idea and possibilities of care transition carefully guided, coached and empowered by healthcare professionals is wise and may have multiple benefits.

First, this exposure may decrease or even eliminate informal caregivers being caught off guard regarding the impeding necessity of care transition. This in turn may reduce crisis transition. That is transition due to acute reasons such as the demise of the informal caregiver or a sudden physical ailment of the person with dementia. As stated in this dissertation, informal caregivers seem quite able to realistically evaluate their own situation and express probable reasons for the care transition, and needs they experience. These evaluations then can be used by health professionals to offer appropriate care and services. For this to happen, it is important for healthcare professionals to truly listen to informal caregivers and take them seriously. An often recurring issue is that care professionals "work from experience" and fill in the needs of the informal caregiver. As shown in this dissertation, there is a big discrepancy between the views of informal caregivers and healthcare professionals. This stresses the importance of truly listening to the informal caregivers and not "assuming" the needs.

Second, the involvement of healthcare professionals will ease the process for informal caregivers. Research shows us that decisions regarding care transition in which both informal caregivers and healthcare professionals were involved facilitated the decision for informal caregivers, resulting in fewer negative effects from the decision. Due to structural, continued and holistic guidance and coaching by the social community team, the needs in this area can be met, resulting in fewer negative effects from the decision. 
Finally, as stated at the beginning of this chapter, informal caregivers are one of the target groups for the social community teams. This means that, when they would like to, informal caregivers may still request some form of support from the community, even after the actual transition of the person with dementia to a nursing home. This continuation of attention for the informal caregiver after the actual care transition has not been part of regular care. This resulted in informal caregivers claiming they "fel off the radar" of the healthcare professionals, despite being in need of some sort of service. Certainly continuation of social services will not be required by all informa caregivers. However, it should be possible for those who are in need to be able to acquire certain services. These services may be simple things, such as being introduced to other informal caregivers who have been through the process or even being offered options to enhance the own social environment by (re-)introducing them to activities. These services will probably be performed by other community members and not by the healthcare professionals.

Besides all the previously mentioned options through which a translation can be made of the findings in this dissertation to be used in practice, one of the clearest ways of valorisation is to actually offer a product which is required and requested by the target group. Within this dissertation the needs of informal caregivers regarding the care transition period were inventoried. Some concrete examples of what they consider helpful were provided by the informal caregivers themselves. One such product was a "land map" or a decision tree which explains in a clear way what care services are available and where one should request these services (that is, what organisations offer particular services) 


\section{Dankwoord}

Zoals voor elke stap in mijn leven, wil ik beginnen met dank betuigen aan dat wat mij kracht geeft. Alle dingen zijn mij mogelijk door Christus, Die mij kracht geeft

-Filippenzen 4:13-

De afronding van mijn proefschrift is zeker de uitkomst van een collectieve inspanning waarbij ik bij dezen ook hen wil bedanken die mij hebben bijgestaan en soms zelfs hebben 'gedragen' de afgelopen paar jaar.

Mam, pap, ik begin uiteraard met jullie. Alles wat ik bereik, kan ik bereiken vanwege jullie liefde, steun en vertrouwen. Jullie hebben mij de vrijheid gegeven om mezelf te ontwikkelen. Dank voor jullie geduld, wijsheid, inzichten en motivatie. De fysieke afstand tussen ons was soms zwaar voor me, voornamelijk op die momenten dat het tegenzat en niets leek te gaan zoals het zou moeten. Maar dan hoefde ik enkel jullie stemmen te horen, en dan voelde ik me weer "thuis". Ono ko rehmanxu!

Daantje, mijn engeltje. Aloho torelax.

Frederik, dank je voor alle momenten waarop je me vooral in de afrondende fase van dit traject de ruimte gaf om mijn hart te luchten, en precies dát zei wat ik nodig had om nuchter de situatie te bekijken waarna ik weer door kon gaan. Nu kijken we samen een nieuwe situatie tegemoet met veel geregel, georganiseer, gestress maar vooral vreugde en blijdschap. Ik waardeer alle momenten waarop ik iets te neurotisch word en jij mij kalmeert met uitspraken zoals: "Maar daar maak ik me niet druk over". Laten we ons vooral richten op de vreugde en blijdschap. Ik kan niet wachten dit jaar aan ons nieuwe avontuur te beginnen. Ik houd van je.

Ook wil ik mijn familie danken, die op welke manier dan ook (soms bewust, soms onbewust), mij heeft bijgestaan tijdens mijn promotie. Atra, je weet dat je een speciaal plekje in mijn hart hebt, daarom wil ik jou expliciet bij naam noemen. Nu ik wat dichterbi ben gaan wonen, zullen we wat vaker onze afspraken/beloftes nakomen om bij elkaa langs te gaan. We zullen elkaar sowieso vaker zien, omdat ik je ga lastigvallen met heel veel dingetjes die jij als qarito mag gaan regelen ;)

Jannet, Sara, jullie weten dat ik jullie als mijn 'zussen' beschouw. Dank jullie we voor alle gekkigheid, maar ook serieuze momenten die ik met jullie heb gedeeld, en zal blijven delen. Hopelijk worden deze momenten ook meer met de kortere afstand

Prisje! My fellow hobbit, same minds think alike, and like alike. Thank you so much for sharing my many quirks. Now that l've moved closer let us cash in those IOU's for sleepovers 
Ola, we zijn nu buren...soort van. Nu hebben we geen excuses meer om steeds een half jaar ertussen te laten zitten om af te spreken. Heel veel succes met jouw promotie!

Alexandra, we've had some crazy conversations in which, for a bystander, it might have seemed like a "how crazy was your day?" contest. Truthfully, I think I have to give you that award, when considering all stories. All kidding aside, thank you for being there for me! Understandably you won't be able to stand behind me on this important day, nevertheless, thank you that you were willing to! I wish you all the best in finishing your $\mathrm{PhD}$ and I pray you'll have the bright future you deserve!

WuShu-crew, thanks for all the crazy trainings and fun times I had with (some combination of) you. Ladies, you in particular.

Dat allemaal gezegd hebbende moet erkend worden dat onderzoek niet kan worden uitgevoerd zonder gegevens. Daarom wil ik iedereen bedanken die op welke manie dan ook heeft bijgedragen aan het verkrijgen van deze gegevens. De zorgorganisatie die bereid waren deel te nemen aan het onderzoek; de contactpersonen vanuit de organisaties die zich allen heel erg hebben ingezet om de moeilijk te werven doelgroep te werven. Zonder jullie inzet was het zeker nooit gelukt. De verpleegkundigen op de vloer, die soms zelfs in hun eigen pauzes mijn vele vragen geduldig hebben beantwoord. Maar zeker wil ik ook alle deelnemers bedanken. Ondanks de turbulente periode waarin zij zich bevonden hebben ze de tijd en moeite genomen om deel te nemen.

Dit dankwoord zal niet compleet zijn zonder Jan, Michel en Hilde (mijn promoti team) te bedanken. Aangezien de samenstelling van mijn promotieteam is veranderd gedurende het proces, wil ik hierbij ook Sandra noemen. Dank voor jullie expertise adviezen en feedback tijdens mijn promotietraject.

I would also like to express my gratitude towards the entire RTPC consortium. Thank you for being part of this interesting project and the wonderful journey I had as an as a PhD candidate. Gabriele, thank you in for your coordination of this project, in which I know you've had tremendous help from Astrid and Anna. Thank you for all the work you've put in and I want to thank you all for the pleasant collaboration!

Hanneke, ook jou wil ik nog expliciet danken voor de gezelligheid op kantoor, die volgens mij duidelijk door de muurties van de Dub te horen was. Ook wil ik je danken voor onze brainstorm sessies over en weer en de fijne samenwerking overall. Misschien moet ik je ook danken voor het tolereren van mijn "kunst" tot de laatste dag dat ik op de Dub zat.

Elles, jij bent in dit onderzoek werkelijk 'above and beyond' gegaan om mij te helpen en te ondersteunen. In de avonden samen informatiepakketjes in elkaar vouwen; belachelijke afstanden afleggen om interviews af te nemen (soms op de vreemdste plekken!); en het werkelijk zorg dragen voor me toen ik te beroerd was om je überhaup te herkennen. Ik zou een pagina kunnen vullen met alle dingen waar ik je voor wil danken. Op deze manier wil ik jou de waardering geven die je hebt verdiend!

Bij dezen wil ik ook de leden van de beoordelingscommissie danken die, onder voorzitterschap van prof. Dr. Jos Schols, mijn proefschrift hebben gelezen en beoordeeld.

Wil, mijn gesprekken met jou zorgden voor relativering van de situatie, waardoo ik zaken in een juist perspectief kon zien. Dankjewel hiervoor.

Marla, dank je wel dat je een klankboord voor me wilde zijn! Ik heb heel veel gehad aan mijn gesprekken met jou en ik wens jou, Joe en kleine Zoë al het beste toe!

Ook wil ik mijn collega's van HSR, die teveel zijn om individueel te noemen, danken voor de fijne tijd samen. Ongeacht of dit de pauzes, lunchwandelingen, congressen of gewonde werkmomenten waren.

Tawd 


\section{About the Author}

Basema Afram was born on February 6th in El-Qamishli, Syria. She completed he bachelor and master degree at Twente University, majoring in Psychology. During her studies she also followed two minors: one in International Management [while on exchange in Krakow] during her bachelor, and one in Marketing-communication and Consumer Behaviour during her master. She received her master's degree in Psychology in 2009 after defending her thesis entitled: The Health Belief Model and Maternal Acceptation of the HPV-vaccine.

In 2010, Basema started as a PhD candidate at Maastricht University. She was involved with the RightTimePlaceCare study, a large project exploring dementia care across Europe. Within this large project, Basema sought a topic close to her heart: informal care. Her research within RightTimePlaceCare explored the perspectives of informal caregivers regarding the care transition period from home-based care towards institutional long-term care.

Since November 2014, Basema has been employed at the HAN University of Applied Sciences. She is involved in teaching and developing the psycho-social education at the Physical Therapy department of the Institute of Health Studies, and the coordination and further development of the multidisciplinary Minor Pain for Health Professionals. 


\section{Publications}

\section{International refereed journals}

Afram B, Stephan A, Verbeek H, Bleiilevens MHC, Suhonen R, Sutcliffe C, Raamat K Cabrera E, Soto ME, Hallberg IR, Meyer G, Hamers JPH on behalf of the RightTimePlaceCare consortium. Reasons for Institutionalization of People with Dementia: Informal Caregiver Reports from Eight European Countries. Journal of American Medical Directors Association, 2014;15

Afram B, Verbeek H, Bleijlevens MHC, Challis D, Leino-Kilpi H, Karlsson S, Soto ME, Meyer G, Saks K, Zabalegui A, Hamers JPH on behalf of the RightTimePlaceCare consortium. Predicting institutional long-term care admission in dementia a mixed methods study of informal caregivers' reports. Journal of Advanced Nursing, doi: 10.1111/jan.12479

Stephan A, Afram B, Bleijlevens MHC, Verbeek H, Viitanen M, Sutcliffe C, Lethin C, Risco E, Soto ME, Saks K, Hamers JPH, Meyer G on behalf of the RightTimePlaceCare consortium. Older persons with dementia at risk for institutionalisation in eight European countries: A cross- sectional study on the perceptions of informal caregivers and healthcare professionals. Journal of Advanced Nursing doi:10.1111/jan.12493.

Afram B, Verbeek H, Bleijlevens MHC, Hamers JPH. Needs of Informal Caregivers During Transition from Home towards Institutional Care in Dementia: Systematic Review of Qualitative Studies. International Psychogeriatrics, doi:10.1017/ S1041610214002154

Afram B, Bleijlevens MHC, Verbeek H, Hamers JPH. Preliminaire titel: Caring for a person with dementia at the care transition period: informal caregivers' needs and experiences (submitted)

\section{National refereed journals}

Stephan A, Afram B, Renom Guiteras A, Gerlach A, Meyer G. [People with dementia in nursing homes: caregivers' information on reasons for admission and how they experience the post-admission situation Offering guidance and support in the phase of transition]. Pflegezeitschrift, 2013; 66(4): 208-212 
